\title{
Mehran Misaghi
}

\section{Um Ambiente Criptográfico Baseado na Identidade}

Tese apresentada à Escola Politécnica da Universidade de São Paulo para obtenção do Título de Doutor em Engenharia Elétrica. 


\section{Mehran Misaghi}

\section{Um Ambiente Criptográfico Baseado na Identidade}

Tese apresentada à Escola Politécnica da Universidade de São Paulo para obtenção do Título de Doutor em Engenharia Elétrica.

Área de concentração:

Sistemas Eletrônicos

Orientador:

Prof. Dr. Marcelo Knörich Zuffo 


\section{FICHA CATALOGRÁFICA}

Misaghi, Mehran

Um Ambiente Criptográfico Baseado na Identidade. São Paulo, 2008. $146 \mathrm{p}$.

Tese (Doutorado) — Escola Politécnica da Universidade de São Paulo. Departamento de Engenharia de Sistemas Eletrônicos.

1- Criptografia Baseada na Identidade 2- Esquemas de Cifração 3- Esquemas de Assinatura 4- Esquemas de Acordo de Chaves 5- Busca Cifrada 6-Aplicabilidades I. Universidade de São Paulo. Escola Politécnica. Departamento de Engenharia de Sistemas Eletrônicos. II. t. 


\section{DEDICATÓRIA}

À meus pais, Masnuulah(in memoriam) e Nahid(in memoriam), e meu estimado sogro Silvestre(in memoriam), que sempre me apoiaram e se preocuparam com a minha educação. Tenho certeza de que estou os deixando muito felizes. À minha querida esposa Patrícia que durante todo este tempo foi muito mais que companheira, me incentivou a terminar esta tese, e de forma incessante e incansável, cuidou das nossas jóias raras sozinha, para que eu pudesse me dedicar à minha pesquisa. À minha filha Mirela Parissa, que em muitas ocasiões teve seus momentos de convívio comigo substituídos pela minha ausência. À minha outra filha, Sofia Anissa, que repetidas vezes teve que brincar sozinha e se privar da minha presença em prol do desenvolvimento da presente tese. 


\section{AGRADECIMENTOS}

A Deus, pela bênção da minha existência. A minha família pelo apoio e incentivo constante, para elaboração da tese. Ao meu orientador, prof. Marcelo Knörich Zuffo, pela confiança depositada no presente trabalho, pelas recomendações e orientações na elaboração da tese. Ao Eduardo Takeo Ueda, pelo verdadeiro apoio e prontidão para ajudar em todos os momentos de que mais necessitei.

Ao professor Routo Terada, que me auxiliou e apoiou desde o primeiro momento que comecei as minhas atividades discentes na USP.

À agência CAPES, pela conecessão de uma bolsa no primeiro ano de doutorado.

Ao Eduardo da Silva, pelo valioso auxílio na formatação do documento. A Nádia de Oliveira, pelas dicas e correções de ortografia e formatação do documento.

À Sociedade Educacional de Santa Catarina, pela oportunidade concedida e confiança depositada. Aos professores Sandro Murilo Santos, Roque Antônio Mattei, Wesley Masterson Belo de Abreu, Paulo Santana e Eliane Ramos Miranda Mattei pelo incentivo e apoio no cotidiano profissional.

Ao Benoit Libert, pelo esclarecimento sobre formalismos de segurança a respeito de esquemas de criptografia baseados na identidade. Ao Michel Abdalla, pelo esclarecimento a respeito de esquemas de acordo de chave baseados na identidade. Ao amigo Mads Rasmussen pelos comentários a respeito da minha tese.

Aos professores Paulo Barreto e Routo Terada, pelos valiosos comentários bem colocados no meu documento de qualificação.

Aos meus ex-professores Edson Espinola, Marco Gubitoso e Siang, pelo convívio e troca de experiências. Aos sábios administradores da rede VISION, pela paciência que tiveram comigo e sempre prontos para auxiliar.

As outras pessoas que não foram mencionadas e de alguma forma me auxiliaram no decorrer do meu doutorado. 


\section{RESUMO}

O crescimento acelerado de negócios voltado para Internet aumenta significativamente a necessidade por mecanismos que possam garantir a confidencialidade dos dados, fornecendo ferramentas para autenticidade e irretratabilidade dos usuários em qualquer meio de comunicação, mesmo em equipamentos que possuem recursos computacionais limitados, como um telefone celular, por exemplo. Este trabalho apresenta um esquema de criptografia que utiliza os dados pessoais para geração de chave e cifração, chamado Criptografia Baseada na Identidade, sem necessidade de um certificado digital. São apresentados diversos modelos de cifração, assinatura, acordo de chaves, bem como principais características, diferenças operacionais e respectivos aspectos relevantes de segurança. Algumas aplicabilidades como busca de dados cifrados, por exemplo, são implementadas, para melhor entendimento das operações e fases envolvidas. Os comparativos de custos computacionais das operações envolvidas destacam o esquema de assinatura de Barreto et al. (2005) e esquema de acordo de chave McCullagh e Barreto (2004b). São descritos também os pré-requisitos de um ambiente criptográfico baseado na identidade, o qual permite realizar as operações de cifração, assinatura e acordo de chaves com menor custo computacional possível. 


\section{ABSTRACT}

The accelerated growth of Internet-based business increase significantly the need for mechanisms that can guarantee the data confidentiality, providing tools for authenticity and non-repudiation users in any medium of communication, even with computer resources becoming increasingly scarce, eg into a cell phone. This paper describes an encryption scheme that uses personal data for key generation and encryption, called the Identity Based Encryption, without need for a digital certificate. Various encryption schemes, signature, key agreement are shown, and its main characteristics, operational differences and their respective relevant aspects of security. Some aplicabilities such as encrypted data search, for example, are implemented, for better understanding of the operations and stages involved. The comparative computataional costs of operations highlight the Barreto et al. (2005) signature scheme and McCullagh e Barreto (2004b) key agreement scheme. They are also described, the prerequisites of an Identity-based cryptography environment, which allows to perform the operations of encryption, signing and key agreement with lower computational cost possible. 


\section{SUMÁRIO}

1 Introdução 19

1.1 Relevância . . . . . . . . . . . . . . . 20

1.2 Motivação . . . . . . . . . . . . . . . . . . . . 21

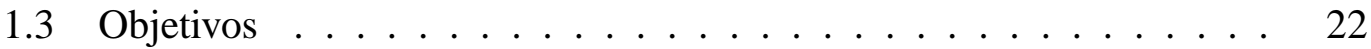

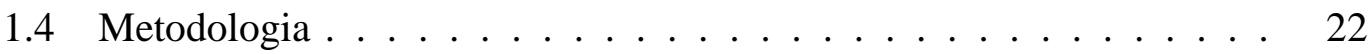

1.5 Estrutura da Tese . . . . . . . . . . . . . . . 23

2 Fundamentos de Sistemas Criptográficos Baseados na Identidade 25

2.1 Introdução . . . . . . . . . . . . . . . . . 25

2.1.1 Evolução da Criptografia . . . . . . . . . . . . 25

2.1.2 Surgimento de criptossistemas baseados em identidade . . . . 26

2.2 Noções de Segurança para Sistemas Criptográficos . . . . . . . . . . 27

2.2.1 Ataques Criptográficos . . . . . . . . . . . . . . 27

2.2.2 Definições de Segurança . . . . . . . . . . . . . . 28

2.3 Noções de Segurança para IBE . . . . . . . . . . . . . . . . 30

2.3.1 Relacionamento entre Noções de Segurança em IBE . . . . . 30

2.4 Esquemas de Cifração Baseados em Identidade . . . . . . . . . . . . 31

2.4.1 Um esquema genérico de IBE . . . . . . . . . . 31

2.4.2 Esquema de Boneh e Franklin . . . . . . . . . . . . 32

2.4.3 Esquema de Cocks ................ . . 34 
2.4.4 Esquema de Waters . . . . . . . . . . . . . . . . . 35

2.4.5 Esquema de Naccache . . . . . . . . . . . . . . . 36

2.4.6 Esquema Hierárquico - HIBE _. . . . . . . . . . . . 37

2.4.7 Esquema Autenticado - AIBE . . . . . . . . . . . . . . 39

2.4.8 Comparativo de esquemas de IBE $\ldots \ldots \ldots \ldots \ldots$

2.5 Esquemas de Assinatura Baseados em Identidade - IBS . . . . . . . 41

2.5.1 Um esquema genérico de IBS $\ldots \ldots \ldots \ldots$. . . . . . 41

2.5.2 Esquema de Shamir . . . . . . . . . . . . . . . . . 42

2.5.3 Esquema de Sakai-Ohgishi-Kasahara . . . . . . . . . . . 44

2.5.4 Esquema de Paterson . . . . . . . . . . . . . . . . 45

2.5.5 Esquema de Hess . . . . . . . . . . . . . . . . . . 46

2.5.6 Esquema de Cha-Cheon . . . . . . . . . . . . . . . 47

2.5.7 Esquema de Barreto et al. . . . . . . . . . . . . . 48

2.5.8 Comparativo dos esquemas de IBS . . . . . . . . . . . . . 49

2.6 Esquemas de Acordo de Chaves Baseados em IBE $\ldots \ldots \ldots$. . . . 50

$2.6 .1 \quad$ Esquema de Smart . . . . . . . . . . . . . . . 51

2.6 .2 Esquema de Scott . . . . . . . . . . . . . . . . . 52

2.6.3 Esquema de Shim . . . . . . . . . . . . . . . 55

2.6.4 Esquema de Chen e Kudla . . . . . . . . . . . . . . . . . 56

2.6.5 Esquema de McCullagh e Barreto . . . . . . . . . . . 58

2.6.6 Comparativo de esquemas de acordo da chave . . . . . . . 60

2.7 Aplicabilidade de IBE em diversas áreas . . . . . . . . . . . . . 62

2.7.1 Integração de PKI e IBE . . . . . . . . . . . . . . . . . 62

2.7.2 Serviços com Disponibilidade Temporal . . . . . . . . . . 62

2.7.3 Gerenciamento Responsável de Informações Pessoais . . . . . 63 
2.7.4 Pesquisa de Palavras-Chave em Dados Cifrados . . . . . . . . 64

2.7.5 Características de $\log$ de auditoria seguro . . . . . . . . . . . 67

2.7.6 Componentes do Sistema de Busca de Dados Cifrados . . . . 70

2.7.7 Redes Tolerantes a Atraso . . . . . . . . . . . . . . 72

2.8 Parâmetros de Desempenho . . . . . . . . . . . . . . 72

2.9 Comparativo entre RSA e Criptografia Baseada em Curvas Elípticas 74

2.10 Conclusões . . . . . . . . . . . . . . . . . . . 80

3 Ambiente Criptográfico Baseado na Identidade 82

3.1 Introdução . . . . . . . . . . . . . . . . 82

3.2 Modelos possíveis de ambiente criptográfico baseado em identidade . 83

3.3 Modelo Convencional . . . . . . . . . . . . . . . . . . 83

3.4 Modelos Não Convencionais . . . . . . . . . . . . . . . . . . 84

3.4.1 ACBI com criptoassinatura . . . . . . . . . . 84

3.4.2 ACBI sem criptoassinatura ............. 86

3.5 Análise de Segurança dos Ambientes Descritos . . . . . . . . . 87

3.5.1 Ambiente com criptoassinatura . . . . . . . . . . 88

3.5.2 Ambiente sem criptoassinatura . . . . . . . . . . 89

3.6 Otimização do Ambiente Criptográfico Baseado na Identidade . . . . 91

3.7 Conclusões . . . . . . . . . . . . . . . . . . . . . . 94

4 Experimentos Realizados em um Ambiente Criptográfico Baseado na Identidade $\quad 95$

4.1 Implementação do modelo de Boneh e Franklin com disponibilidade

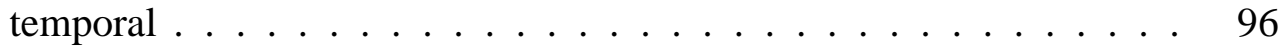

4.2 Implementação de Pesquisa em Banco de Dados Cifrados . . . . . . . 101 
4.2.1 Exemplificando o funcionamento da Busca Cifrada . . . . . . 105

4.3 Infra-estrutura de um modelo de acordo de chaves baseado na identidade 106

4.3.1 Ambiente de Acordo de Chaves . . . . . . . . . . . . 107

4.3.2 Chat Seguro ................... 108

4.3.3 Comparativo entre os modelos de Smart e Shim . . . . . . . . 114

4.3.4 Implementação de Segurança Adicional . . . . . . . . . . . . 117

4.4 Aplicabilidades . . . . . . . . . . . . . . . . . . 117

4.5 Conclusões . . . . . . . . . . . . . . . . . . . . . 118

5 Integração de Criptografia Baseada na Identidade e Criptografia de Chave $\begin{array}{lr}\text { Pública } & \mathbf{1 2 0}\end{array}$

5.1 Infra-estrutura de Chaves Pública . . . . . . . . . . . . . 120

5.2 Criptografia baseada na identidade . . . . . . . . . . . . . . . 122

5.3 Criptografia de Chave Pública Sem Certificado . . . . . . . . . . . . 123

5.4 Conclusões . . . . . . . . . . . . . . . . . . 124

6 Considerações Finais $\quad 125$

6.1 Resumo das Contribuições . . . . . . . . . . . . . . . . 125

6.2 Trabalhos Futuros . . . . . . . . . . . . . . . . 127

$\begin{array}{lr}\text { REFERENCIAS } & 129\end{array}$

Apêndice A - Aplicações e Produtos de IBE 138

A.1 Produtos IBE . . . . . . . . . . . . . . . . . . . 138

A.1.1 Plataforma Voltage . . . . . . . . . . . . 138

A.2 Aplicações IBE . . . . . . . . . . . . . . . . . . . . 139

A.2.1 Redes Sem Fio . . . . . . . . . . . . . . . 139 
A.2.2 Cartões Inteligentes . . . . . . . . . . . . . . . . . 140

A.2.3 Computação em Grade . . . . . . . . . . . . . . . . . . 140

A.2.4 Protocolos de Cifração na Camada de Rede . . . . . . . . . . 141

Apêndice B - Fundamentos Matemáticos de IBE 142

B.1 Grupo . . . . . . . . . . . . . . . . . . . 142

B.2 Corpo . . . . . . . . . . . . . . . . . . . 142

B.3 Curvas Elípticas . . . . . . . . . . . . . . . . . . . . . . . 143

B.4 Emparelhamentos Bilineares . . . . . . . . . . . . . . . . 143

B.4.1 Emparelhamento Tate . . . . . . . . . . . . . . . . . 144

B.4.2 Emparelhamento ate . . . . . . . . . . . . . . . . . 144

B.5 Problemas Computacionais utlizados em IBE . . . . . . . . . . 144

B.5.1 Problema de Fatoração de Inteiros . . . . . . . . . . . . . 144

B.5.2 Problema de Resíduos Quadráticos . . . . . . . . . . 145

B.5.3 Critério Euler . . . . . . . . . . . . . . . . . . . . . 145

B.5.4 Problema de Logarítmo Discreto . . . . . . . . . . . . . 145

B.5.5 Problema Diffie-Hellman . . . . . . . . . . . . . . . . 146 


\section{LISTA DE ILUSTRAÇÕES}

2.1 Relação entre noções de segurança em chave pública. . . . . . . . . . 30

2.2 Relação entre noções de segurança em IBE. . . . . . . . . . . . . . . 31

2.3 Um esquema genérico de IBE . . . . . . . . . . . . . . . 32

2.4 Um esquema genérico de IBS . . . . . . . . . . . . . . . . 43

2.5 Diagrama de atividades do esquema de Smart. . . . . . . . . . . . 53

2.6 Diagrama de atividades do esquema de Scott. . . . . . . . . . . 55

2.7 Diagrama de atividades do esquema de Shim. . . . . . . . . . . . 57

2.8 Diagrama de atividades do esquema de Chen e Kudla. . . . . . . . . 59

2.9 Diagrama de atividades do esquema de Barreto. . . . . . . . . . . 61

2.10 Esquema de busca de dados cifrados. Adaptado de Waters et al. (2004) 69

2.11 Pesquisa de palavras-chave em dados cifrados. . . . . . . . . . . . 71

2.12 Assinatura baseada em curvas elípticas 256 bits X RSA 1024 bits . . . 73

2.13 Taxa de criptografia do servidor sem autenticação . . . . . . . . . . 77

2.14 Latência criptográfica do Handshake sem autenticação . . . . . . . 78

2.15 Latência criptográfica do Handshake com autenticação . . . . . . . 78

2.16 Taxa de criptografia do servidor com autenticação . . . . . . . . . . 79

2.17 Latência criptográfica sem autenticação RSA2048 e ECC193 . . . . . 79

2.18 Criptografia servidor sem autenticação RSA2048 e ECC193 . . . . . 80

2.19 Latência criptográfica com autenticação RSA2048 e ECC193 . . . . . 80

2.20 Criptografia servidor com autenticação RSA2048 e ECC193 . . . . . 81 
3.1 IBCE com criptoassinatura $\ldots \ldots \ldots \ldots \ldots$

3.2 IBCE sem criptoassinatura $\ldots \ldots \ldots \ldots \ldots$

3.3 Análise de Segurança do Ambiente com Criptoassinatura . . . . . . . 89

3.4 Análise de Segurança do Ambiente sem Criptoassinatura . . . . . . 90

3.5 Variação do comprimento de loop . . . . . . . . . . . . . 93

4.1 Implementação Boneh e Franklin - Variáveis disponíveis . . . . . . 96

4.2 Implementação Boneh Franklin - Servidor PKG . . . . . . . . . . . 97

4.3 Implementação Boneh Franklin - Tela Principal . . . . . . . . . . 97

4.4 Implementação Boneh Franklin - Configuração servidor PKG e configuração da Identidade . . . . . . . . . . . . . . . . . . . . . . . . . 98

4.5 Implementação Boneh Franklin - Mensagem recebida . . . . . . . . . 99

4.6 Implementação Boneh Franklin - Mensagem recebida cifrada e decifrada 99

4.7 Implementação Boneh Franklin - Tela de Log . . . . . . . . . . 101

4.8 Implementação Boneh Franklin - Mensagem com disponibilidade temporal vencida . . . . . . . . . . . . . . . . . . 102

4.9 Implementação de busca de palavra em banco de dados cifrados - Modelo de entidades e relacionamento . . . . . . . . . . . . . . . 102

4.10 Implementação de busca de palavra em banco de dados cifrado - Diagrama de sequiência - Operação inserir . . . . . . . . . . . . . . . 104

4.11 Implementação de busca de palavra em banco de dados cifrado - Diagrama de seqüência - Operação buscar . . . . . . . . . . . . . . 105

4.12 Configuração do Ambiente. . . . . . . . . . . . . . . . . . . . . . . 109

4.13 Geração de parâmetros iniciais do PKG . . . . . . . . . . . . . 109

4.14 Solicitação da Chave Privada. . . . . . . . . . . . . . . . . . 110

4.15 Revogação de Acordo de Chave. . . . . . . . . . . . . . . . . . 111

4.16 Validade de Acordo de Chave. . . . . . . . . . . . . . . . . . . 112 
4.17 Novo Acordo de Chave. . . . . . . . . . . . . . . . . . . . . . . . 112

4.18 Revogação da Condição do Acordo. . . . . . . . . . . . . . . . . . . 112

4.19 Mudança do Acordo. . . . . . . . . . . . . . . . . . . 113

4.20 Conversação cifrada. . . . . . . . . . . . . . . . . . . 113

4.21 Novo Acordo. . . . . . . . . . . . . . . . . . . . . . 114

4.22 Identificação dos campos: Tempo 1, Tempo 2, Tempo 3 . . . . . . . . 115

4.23 Diagrama da disposição dos tempos . . . . . . . . . . . . . . 116

5.1 Arquitetura de ICP . . . . . . . . . . . . . . 121

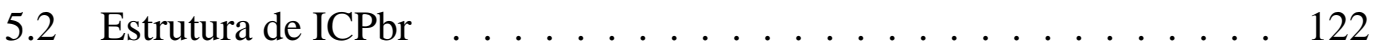

A.1 Ambiente de SecureMail do Voltage . . . . . . . . . . . . . 139 


\section{LISTA DE TABELAS}

2.1 Operações em ordem de custo computacional . . . . . . . . . . . . 41

2.2 Comparativo de cifração dos esquemas de IBE . . . . . . . . . . . . . 41

2.3 Comparativo de decifração dos esquemas de IBE . . . . . . . . . . . 42

2.4 Comparativo de assinatura dos esquemas de IBS . . . . . . . . . . . 49

2.5 Comparativo de verificação de assinatura dos esquemas de IBS . . . . 50

2.6 Comparativo de esquemas de acordo da chave . . . . . . . . . . 61

2.7 Tamanho da Chave RSA X ECC . . . . . . . . . . . . 75

2.8 Teste de Desempenho RSA x ECC . . . . . . . . . . . 75

2.9 Teste de Desempenho entre RSA x ECDSA x ECDH . . . . . . . 76

3.1 Técnicas de otimização para IBE . . . . . . . . . . . . . . . . 93

4.1 Tempo de Inserção de palavras chaves . . . . . . . . . . . . . . . 106

4.2 Tempo de Busca de palavras chaves . . . . . . . . . . . . . 107

4.3 Comparativo SMART x SHIM no números de emparelhamentos . . . 114

4.4 Comparativo SMART x SHIM de acordo com os temporizadores . . . 116

5.1 Comparativo de propriedades em diversos modelos . . . . . . . . . 123

A.1 Funcionalidade de SecureMail IBE Server . . . . . . . . . . . . . 138 


\section{LISTA DE ABREVIATURAS}

AACE Ataque Adaptativo por texto Cifrado Escolhido

ACBI Ambiente Criptográfico Baseado em Identidade

AIBE Authenticated Identity-Based Encryption

ANCE Ataque Não adaptativo por texto Cifrado Escolhido

APE Ataque por texto Plano Escolhido

CL-PKC Certificateless Public Key Cryptography

CMA Chosen-Message Attack

DES Data Encryption Standard

DTN Disruption-and Delay-Tolerant Networks

EUF-CMA Existencial Unforgeability against Chosen-Message Attacks

FSO/FUO Flexible Signcryption Oracle/Flexible Unsigncryption Oracle

HIBE Hierarchical Identity-Based Encryption

IBC Identity-Based Cryptography

IBCE Identity-Based Cryptography Environment

IBE Identity-Based Encryption

IBEKS Identity-Based Encryption with Keyword Search

IBKA Identity-Based Key Agreement

IBUDVS Identity-Based Universal Designated Verifier Signatures

IBS Identity-Based Signature 
IBSC Identity-Based Signcryption

ICP Infra-estrutura de Chaves Públicas

IND Incapacidade de Distinção

NM Não Maleabilidade

PEKS Public Key Encryption with Keyword Search

PETKS Public Key Encryption Temporary Keyword Searchable

PKC Public Key Cryptography

PKG Private Key Generator

PKI Public Key Infrastructure

SS Segurança Semântica 


\section{Introdução}

Os avanços tecnológicos têm proporcionado, cada vez mais, a possibilidade de troca de informações via Internet. O mundo dos negócios vem agilizando tais processos. Esse cenário aumenta significativamente a probabilidade de ocorrência de roubo de informações das mais variadas e avançadas técnicas existentes.

A técnica mais antiga de proteção de informação que ainda existe é a criptografia. A criptografia de chave pública envolve normalmente a comunicação entre dois usuários denominadas Alice e Beto, na literatura. Dessa forma, para enviar uma mensagem segura a Beto, Alice utiliza a chave pública do Beto para cifrar a mensagem, que somente o Beto, através da sua chave privada pode decifrá-la.

A criptografia de chave pública necessita de uma Infra-estrutura de Chaves Públicas (ICP) para gerenciamento e repositório de tais chaves. A ICP dispõe de mecanismos para oferecer confidencialidade, irretratabilidade e autenticidade para seus usuários em uma estrutura confiável. À medida que cresce o número de pessoas que utilizam os serviços de uma ICP, torna-se mais complexa a ICP.

O conceito de criptossistemas baseados em identidade foi introduzido por Shamir, em 1984 (SHAMIR, 1984). A idéia era permitir que a chave pública do usuário fosse uma sequiência binária correspondente a alguma informação que o identificasse , como parâmetros biométricos, por exemplo, enquanto a chave privada fosse calculada por uma autoridade confiável, chamada Geradora de Chave Privada ou Private Key Generator (PKG).

Os criptossistemas baseados em identidade possibilitam que qualquer par de usuários possam se comunicar de forma segura, sem a necessidade de troca de certificados de chaves públicas, sem a necessidade de manter um repositório de chaves públicas e também sem utilização dos serviços de terceiros. 
Depois que o conceito foi proposto, diversos criptossistemas baseados em identidade e esquemas de assinatura foram propostos. Os criptossistemas baseados em identidades hierárquicos também surgiram, conforme detalhados em Gentry e Silverberg (2002), Boneh e Boyen (2004), Yao et al. (2004), Boneh, Boyen e Goh (2005).

Segundo (CHEN et al., 2002), por muitos anos, alguns pesquisadores tentaram propor algoritmos eficientes e seguros para criptossistemas baseados em identidade, mas com pouco sucesso. Em 2001, dois criptossistemas baseados em identidade, mudaram esse panorama. Um foi proposto por Cocks (COCKS, 2001) e outro por Boneh e Franklin (BONEH; FRANKLIN, 2001).

A partir daí, as implementações de criptossistemas baseados em identidade receberam mais atenção dos pesquisadores em termos de redução de tempo computacional para cálculo de emparelhamento (HÉIGEARTAIGH, 2005), bem como redução do tamanho da chave em (NACCACHE, 2005) e propostas de esquemas mais eficientes, como é o caso do esquema proposto por (WATERS, 2005). O esquema de Waters (2005) não necessita de oráculos randômicos.

\subsection{Relevância}

A Infra-estrutura de chaves públicas necessita de um repositório para armazenamento de chaves públicas, tornando-as disponíveis e acessíveis para diversas pessoas que queiram fazer algum tipo de troca de mensagem com proprietário de tais chaves. Quanto maior for o número das pessoas, mais complexo será a infra-estrutura necessária para implementar esse repositório.

Por outro lado, há o problema de prova da autenticidade do proprietário da chave pública. Caso haja necessidade de revogar um certificado digital emitido externamente, ocorre uma certa demora no processo de revogação que poderá comprometer a segurança de um sistema e aumentar significativamente as vulnerabilidades existentes em sistema.

Dessa forma, fica evidente que a utilização de um sistema com mecanismos mais rápidos para revogar uma chave privada e sem necessidade de infra-estrutura para armazenamento de chaves públicas, torna o processo de criptografia mais prático e me- 
nos vulnerável ${ }^{1}$.

Alguns modelos propostos, como o de Boneh e Franklin (2001), possuem implementação para envio de emails. Os modelos que implementam hierarquia, citado em Gentry e Silverberg (2002), Boneh e Boyen (2004), Yao et al. (2004), Boneh, Boyen e Goh (2005) não possuem implementação proposta e somente foram citados o esquema teórico de implementação.

As vantagens que um criptossistema baseado em identidade são:

- Não necessita de um repositório para armazenamento de chaves públicas;

- Permite a implementação de modelos hierárquicos;

- Permite implementar assinaturas curtas, em anel e em grupo;

- Possui uma estrutura de revogação mais flexível;

- Permite agregar níveis adicionais de segurança, tais como dupla autenticação.

\subsection{Motivação}

Os criptossistemas baseados em identidade, sem dúvida alguma, são bastante atraentes no que diz respeito às suas características apresentadas anteriormente. Desde o seu surgimento, diversos modelos foram propostos com as devidas demonstrações matemáticas e sem ter uma implementação em prática, exceto o modelo de Boneh e Franklin (2001) que deu origem aos produtos e aplicações comerciais existentes.

Certamente, implementar um sistema que ilustre o funcionamento de diversos modelos de criptossistemas baseados em identidade de forma didática auxilia na compreensão dos modelos propostos, suas respectivas diferenças e, a partir daí, possibilita elaborar protótipos e simuladores para verificar o desempenho de diversos modelos propostos, e dessa forma, aproveita melhor os benefícios de cada modelo proposto.

\footnotetext{
${ }^{1}$ Em alguns casos. No decorrer do documento, serão discutidos os aspectos de segurança.
} 


\subsection{Objetivos}

A presente tese tem como objetivo geral apresentar uma visão crítica do estado da arte e evolução dos criptossistemas baseados em identidade, destacando principais contribuições dos autores e apresentar os critérios necessários para um ambiente criptográfico baseado na identidade, no qual possam ser realizadas as operações de cifração, assinatura e acordo de chaves baseadas na identidade.

Como objetivos específicos:

- Fazer um comparativo em termos de custo computacional das operações envolvidas entre diversos esquemas de cifração, assinatura e acordo de chaves;

- Estudar e apresentar os esquemas de cifração, assinatura e de acordo de chaves baseado na identidade;

- Comparar tais esquemas em termos de custo computacional envolvido;

- Implementar algumas aplicabilidades de criptografia baseada na identidade, como busca cifrada, esquema de cifração e esquema de acordo de chaves com níveis adicionais de segurança e disponibilidade temporal, para melhor visualização didática dos modelos propostos e auxiliar na implementação dos próximos modelos;

- Apresentar critérios necessários para implementar um ambiente criptográfico baseado na identidade que seja viável;

- Apresentar critérios para implementar um esquema misto de criptografia com as vantagens de criptografia de chave pública e criptografia baseada na identidade.

\subsection{Metodologia}

Para atender os objetivos propostos, será necessário estudar os conceitos e componentes de criptografia baseado em identidade e fazer um comparativo em termos de desempenho, eficiência e aspectos de segurança. Serão definidos os parâmetros de desempenho para fazer o estudo comparativo em termos de implementações sugeridas. 
As implementações propostas serão feitas e avaliadas em linguagem C e Java e utilizando a biblioteca MIRACL do Michael $\mathrm{Scott}^{2}$. O sistema operacional que será utilizado para implementação dos programas é Linux ubuntu $7^{3}$ e Windows XP.

\subsection{Estrutura da Tese}

O presente documento está estruturado em seis capítulos:

- O capítulo 2 aborda uma visão do estado da arte dos criptossistemas baseados em identidade, bem como uma comparação entre diversos algoritmos já propostos, enfatizando as suas principais características. Os diversos esquemas de assinatura, bem como esquemas de acordo de chave, também fazem parte do capítulo, que também conta com a apresentação de aplicabilidades de criptografia baseada na identidade. Além disso, são apresentadas as noções de segurança em criptossistemas baseados em identidade. O capítulo finaliza com a apresentação de parâmetros de desempenho e uma comparação entre criptografia RSA e criptografia baseada em curvas elípticas, conforme Gupta et al. (2002).

- O capítulo 3 apresenta os critérios necessários para implementar um ambiente criptográfico baseado na identidade. Além disso, algumas melhorais propostas para otimização de emparelhamentos adequados também são apresentados.

- O capítulo 4 apresenta os experimentos realizados em termos de implementações propostas. Um esquema de cifração será implementado para servir como base para outras implementações. Além disso, são implementados esquemas de acordo de chave com níveis adicionais de segurança, e no final, são comparados os modelos implementados em termos de tempos de resposta. Este capítulo também conta com uma implementação de busca cifrada com características adicionais e no final são medidos os tempos de cifração e busca de dados cifrados que o esquema implementado leva.

- No capítulo 5 é apresentado um comparativo entre criptografia de chave pública e criptografia baseada na identidade em termos de características principais e

\footnotetext{
${ }^{2}$ Com permissão do autor para realização de trabalhos acadêmicos, segundo o que consta no site do autor.

${ }^{3}$ http: //www. ubuntu.com/
} 
sugere um modelo híbrido para poder aproveitar as vantagens de cada modelo em um único modelo.

- As considerações finais, contribuições da tese, bem como as publicações e trabalhos futuros são ilustrados no capítulo 6 .

- Apêndice A ilustra alguns produtos e aplicações comerciais existentes para criptossistemas baseados em identidade.

- Apêndice B apresenta alguns conceitos matemáticos fundamentais em criptossistemas baseados em identidade. 


\section{Fundamentos de Sistemas Criptográficos Baseados na Identidade}

\subsection{Introdução}

Este capítulo tem como objetivo inicial citar um pequeno histórico de sistemas criptográficos baseados na identidade e apresentar os conceitos de criptografia baseado em identidade, bem como seus principais componentes. Os diversos esquema de assinatura e esquemas de distribuição e acordo de chave também são abordados neste capítulo. Além disso, são apresentados neste capítulo as noções de segurança em criptografia de chave pública e em esquemas de criptografia baseada na identidade. Este capítulo finaliza com apresentação dos parâmetros de desempenho em tais sistemas.

\subsubsection{Evolução da Criptografia}

Muitas foram as tentativas para resolver o problema de se estabelecer comunicações seguras, desde a Criptografia Simétrica e Criptografia de Chave Pública até o próprio Identity-Based Encryption (IBE).

Na década de 70, as redes militares, sistemas acadêmicos, protocolos de bancos, eram os adeptos da criptografia moderna, utilizando sistemas baseados em criptografia simétrica. Entre os criptossistemas simétricos dessa época, o mais conhecido foi o DES, amplamente utilizado nos anos 80. As características de sistemas de criptografia simétrica são:

- A utilização da mesma chave para remetente e destinatário, para cifração e decifração; 
- Autenticação realizada através de um servidor centralizado.

A utilização dos criptossistemas simétricos tinha os seus problemas específicos, para resolver tais problemas, uma nova classe de algoritmos, chamada criptografia de chave pública foi desenvolvida. O mais conhecido desses algoritmos é o RSA ${ }^{1}$. Um sistema baseado nesses algoritmos é chamado geralmente de Criptografia de Chave Pública, e foi introduzido ao mercado nos últimos anos da década de 80 .

No modelo de Criptografia de Chave Pública, duas chaves, uma pública e uma privada são utilizadas para cifrar e decifrar as mensagens. As chaves públicas são distribuídas freqüentemente usando os certificados emitidos por uma terceira parte, chamada Autoridade Certificadora. Utilizando a identidade como a chave pública, um Criptossistema Baseado em Identidade elimina a necessidade de certificado e todas as complexidades de uma infra-estrutura de chaves públicas. Como características de IBE, podem ser destacadas as seguintes:

- A chave pública baseada em identificadores conhecidos, como um endereço de e-mail, por exemplo;

- A autenticação é realizada através de um servidor centralizado;

- Tem benefícios como escalabilidade, cifração offline, simplicidade de administração e simplicidade de uso.

\subsubsection{Surgimento de criptossistemas baseados em identidade}

O esquema proposto por Shamir (1984) foi pioneiro no que diz respeito a Criptossistemas Baseados em Identidade, conhecidos normalmente como IBE ${ }^{2}$. Esse esquema permite uma comunicação segura, sem necessidade de utilizar certificados digitais fornecidos por uma autoridade certificadora.

Depois do modelo de Shamir, foram propostos outros modelos para melhorar o desempenho ou reduzir as vulnerabilidades existentes no esquema de IBE. O esquema proposto por Boneh e Franklin (2001) foi o primeiro modelo que deu origem as atuais

\footnotetext{
${ }^{1}$ Algoritmo de cifração de dados que deve o seu nome aos seus criadores Ron Rivest, Adi Shamir e Len Adelman

${ }^{2} \mathrm{IBE}$ é a abreviatura de Identity-Based Encryption.
} 
implementações do IBE, e de uma forma mais prática, presentes em diversos produtos comerciais já disponíveis no mercado.

\subsection{Noções de Segurança para Sistemas Criptográficos}

Para uma explicação mais adequada e abrangente, nesta seção, inicialmente serão apresentadas algumas definições preliminares que auxiliam na melhor compreensão das noções de segurança para IBE abordadas.

\subsubsection{Ataques Criptográficos}

Segundo Terada (2000), os ataques criptográficos podem ser classificados da seguinte forma:

- Ataque por só texto cifrado: O criptoanalista Carlos tenta adquirir conhecimento útil à quebra, analisando apenas um ou mais cifrados $y$. Se esse tipo de ataque for computacionalmente viável, o algoritmo em questão é considerado totalmente inseguro e inútil.

- Ataque por texto claro conhecido: O criptoanalista Carlos possui e analisa pares $(x, y)$ de plano e cifrado correspondentes. Nesse e nos tipos de ataque a seguir, o criptoanalista tem acesso ao algoritmo (sem conhecer a chave $K$ ) e não é necessariamente um mal-intencionado ou intruso: pode ser um especialista que objetiva descobrir se o algoritmo é vulnerável a esse tipo de ataque, sendo que o algoritmo fora projetado por outra pessoa, eventualmente.

- Ataque por texto claro escolhido: Além do suposto no tipo anterior, o criptoanalista Carlos pode escolher os legíveis $x$ e obter os $y$ correspondentes. Ele vai escolher um $x$ que apresente alguma característica estrutural que aumente o seu conhecimento do algoritmo e da chave em uso. Com o conhecimento adquirido, ele pode deduzir o plano correspondente a um cifrado novo.

- Ataque adaptativo por texto claro escolhido: Além do suposto no tipo anterior, a escolha de um novo $x$ pelo criptoanalista Carlos pode depender dos cifrados $y^{\prime}$ analisados anteriormente. Dessa forma, a escolha de um novo $x$ é condicionada ao conhecimento já adquirido pela análise dos $y^{\prime}$ anteriores. 
- Ataque por texto cifrado escolhido: O criptoanalista Carlos escolhe inicialmente o cifrado $y$ e então obtém o plano $x$ correspondente. Supõe-se que Carlos tenha acesso apenas ao algoritmo de decifração (sem ter acesso à chave) e o seu objetivo é, mais tarde, sem ter mais acesso à decriptografia, ser capaz de deduzir $x$ correspondente a um $y$ novo.

- Ataque adaptativo por texto cifrado escolhido: Além do suposto no tipo anterior, a escolha de um novo $y$ pelo criptoanalista Carlos pode depender dos cifrados $y^{\prime}$ analisados anteriormente. Dessa forma, a escolha de um novo $y$ é condicionada ao conhecimento já adquirido pela análise dos $y^{\prime}$ anteriores.

\subsubsection{Definições de Segurança}

Uma forma interessante de descrever o modelo de segurança de um esquema criptográfico, segundo Galindo e Hasuo (2005), é através da combinação das propriedades desejadas com os modelos de adversários. Os conceitos de segurança freqüentemente utilizados, conforme Bellare et al. (1998), são:

- IND: Incapacidade de Distinção ${ }^{3}$ que formaliza a inabilidade de um adversário para aprender qualquer informação a respeito do texto claro $x$ correspondente a um desafio de um texto cifrado $y$, capturando uma forte noção de privacidade. Esse conceito foi apresentado por Goldwasser e Micali (1984).

- NM: Não-Maleabilidade ${ }^{4}$ formaliza a inabilidade do adversário, dado um desafio de um texto cifrado $y$, obter um texto cifrado $y^{\prime}$, diferente, tal que os textos planos $x, x^{\prime}$, correspondentes destes dois textos cifrados sejam significativamente relacionados.

Os modelos de ataque são (BELLARE et al., 1998):

- APE: Modelo de Ataque por texto Plano Escolhido (CPA em inglês), no qual o adversário poderá obter textos cifrados conforme a sua escolha, a partir de textos planos e dada uma chave pública.

\footnotetext{
${ }^{3}$ do original indistinguishability

${ }^{4}$ do original non-malleability
} 
- ANCE: Modelo de Ataque Não adaptativo por texto Cifrado Escolhido (CCA1 em inglês). Nesse modelo formalizado por Naor e Yung (1990), o adversário, além de possuir uma chave pública, poderá acessar um oráculo para função de decifração. O adversário poderá utilizar a função de decifração somente pelo período de tempo em que precede o seu desafio de texto cifrado $y$. Também é importante salientar que o termo não adaptativo se refere ao fato de que as consultas para o oráculo de decifração não podem depender do desafio de texto cifrado $y$.

- AACE: Modelo de Ataque Adaptativo por texto Cifrado Escolhido (CCA2 em inglês). Conforme Rackoff e Simon (1992), o adversário, além de ter a chave pública, novamente acessa um oráculo para a função de decifração, mas, desta vez talvez a função de decifração seja utilizada de forma uniforme nos textos cifrados escolhidos, após a obtenção do desafio de texto cifrado $y$. Esse ataque é chamado de adaptativo, pois as consultas para o oráculo de decifração podem ser dependentes do desafio de $y$.

Os conceitos de segurança e modelos de ataques poderão ser combinados, resultando em seis noções de segurança para criptografia de chave pública com a seguinte notação: IND-APE, IND-ANCE, IND-AACE, NM-APE, NM-ANCE, NM-AACE.

Dessa forma, IND-APE segundo Goldwasser e Micali é considerada como segurança polinomial e também é equivalente à noção de segurança semântica ${ }^{5}$. A INDAACE pode ser considerada como a noção de segurança mais forte, sendo a incapacidade de distinção em ataque adaptativo por texto cifrado escolhido, equivalente a NM-AACE que é a não-maleabilidade de ataque adaptativo por texto cifrado escolhido. A relação entre diversas noções de segurança que foram apresentadas em Bellare et al. (1998) podem ser visualizadas na figura 2.1. As setas apresentam as implicações. $A \rightarrow B$ (A implica em B) significa que qualquer esquema criptográfico que satisfazer a noção de segurança $A$ também satisfaz a noção de segurança $B$. Já $A \nrightarrow B$ (A não implica em B) indica a existência de pelo menos um esquema criptográfico baseado em noção de segurança $A$ que não satisfaz a noção de segurança $\mathrm{B}$.

\footnotetext{
${ }^{5}$ do original semantic security
} 


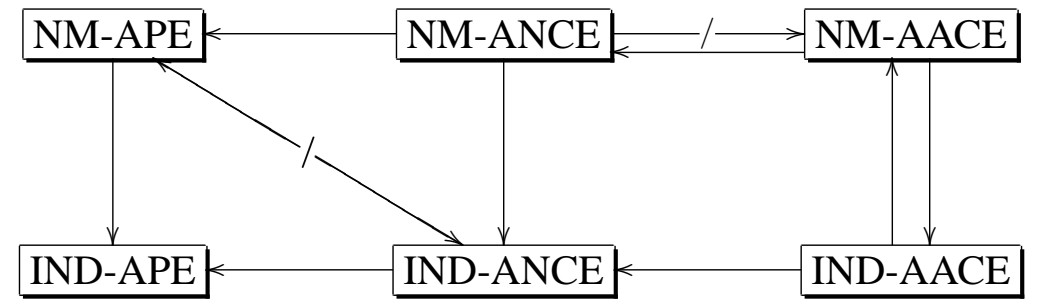

Figura 2.1: Relação entre noções de segurança em chave pública. As setas apresentam as implicações. $A \rightarrow B$ (A implica em B) significa que qualquer esquema criptográfico que satisfazer a noção de segurança $A$ também satisfaz a noção de segurança $B$. Já $A \nrightarrow B$ (A não implica em B) indica a existência de pelo menos um esquema criptográfico baseado em noção de segurança $A$ que não satisfaz a noção de segurança $B$.

\subsection{Noções de Segurança para IBE}

As primeiras noções de segurança para os criptossistemas baseados em identidade foram propostas por Boneh e Franklin (BONEH; FRANKLIN, 2003) e baseiam-se nas definições de noções de segurança de criptografia de chave pública. Para definição de noções de segurança em IBE, as propriedades desejáveis IND, SS e NM são consideradas, conforme Attrapadung et al. (2006). SS é a propriedade de Segurança Semântica que formaliza a inabilidade de um adversário para obter qualquer informação a respeito de texto claro de um dado texto cifrado (GOLDWASSER; MICALI, 1984). Dessa forma, as noções de segurança para IBE que poderão ser uma combinação entre as propriedades desejáveis e modelos de ataque, são as seguintes: NM-ID-APE, NM-IDANCE, NM-ID-AACE, IND-ID-APE, IND-ID-ANCE, IND-ID-AACE, SS-ID-APE, SS-ID-ANCE, SS-ID-AACE.

\subsubsection{Relacionamento entre Noções de Segurança em IBE}

A figura 2.2 apresenta as noções de segurança em IBE, segundo Attrapadung et al. (2006), da forma que as setas apresentam as implicações. $A \rightarrow B$ (A implica em B) significa que qualquer esquema criptográfico que satisfaça a noção de segurança $A$ também satisfaz a noção de segurança $B$.

Diversas literaturas abordam, e, em alguns casos, formalizam através de teoremas, as noções de segurança a respeito de criptossistemas baseados em identidade. (BOYEN; MEI; WATERS, 2005; GALINDO; HASUO, 2005; BARBOSA, 2005; ZHU; 


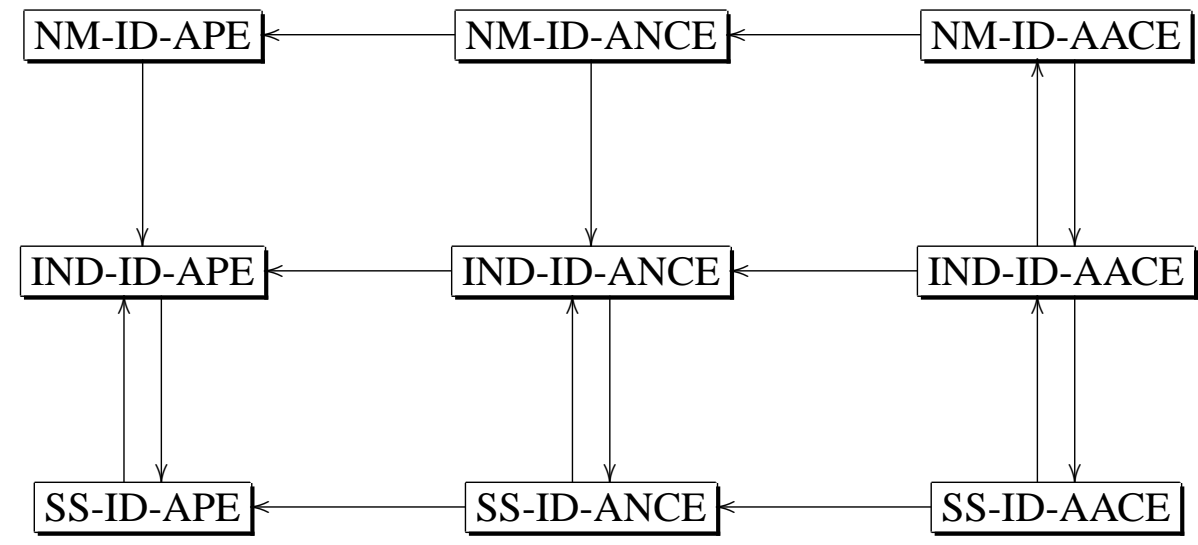

Figura 2.2: Relação entre noções de segurança em IBE. As setas apresentam as implicações. $A \rightarrow B$ (A implica em $B$ ) significa que qualquer esquema criptográfico que satisfaça a noção de segurança $A$ também satisfaz a noção de segurança $B$.

TIAN; WONG, 2005; HOLT, 2006; KILTZ, 2006; BONEH; FRANKLIN, 2003) são alguns exemplos de literaturas que abordam, com alguma variação, as noções de segurança.

\subsection{Esquemas de Cifração Baseados em Identidade}

Alguns esquemas de cifração baseados em identidades serão apresentados nesta seção. Para melhor entendimento dos esquemas, inicialmente, será apresentado um esquema genérico de IBE com seus principais componentes.

\subsubsection{Um esquema genérico de IBE}

Um esquema genérico de IBE consiste em quatro fases: inicializa, extrai, cifra e decifra. Normalmente qualquer usuário pode cifrar uma mensagem utilizando um $I D^{6}$ na fase de cifra. O destinatário proprietário do $I D$ na fase decifra, poderá decifrar a mensagem utilizando uma chave privada correspondente a $I D$, obtida de $P K G^{7}$.

As diversas fases de um esquema genérico podem ser detalhados conforme Baek et al. (2004) e estão ilustradas na figura $2.3^{8}$ :

\footnotetext{
${ }^{6} I D$ é qualquer informação pessoal do usuário que está sendo utilizado nesse caso para cifrar e decifrar a mensagem.

${ }^{7}$ PKG é Private Key Generator.

${ }^{8}$ Esta figura é uma adaptação da figura que consta em Baek et al. (2004).
} 
- INICIALIZA: O PKG cria o par de chaves privada $s k_{P K G}$ e pública $p k_{P K G}$.

- EXTRAI: O Beto se autentica com o PKG e obtém a chave privada $s k_{I D_{\text {Beto }}}$ que é associada à sua identidade $I D_{\text {Beto }}$.

- CIFRA: Utilizando a identidade do Beto, $I D_{\text {Beto }}$, e $p k_{P K G}$, Alice cifra a sua mensagem $M$ que é um texto claro e obtém o texto cifrado $C$.

- DECIFRA: Recebendo o texto cifrado $C$ de Alice, Beto decifra a mensagem $M$ através da sua chave privada $s k_{I D_{\text {Beto }}}$.

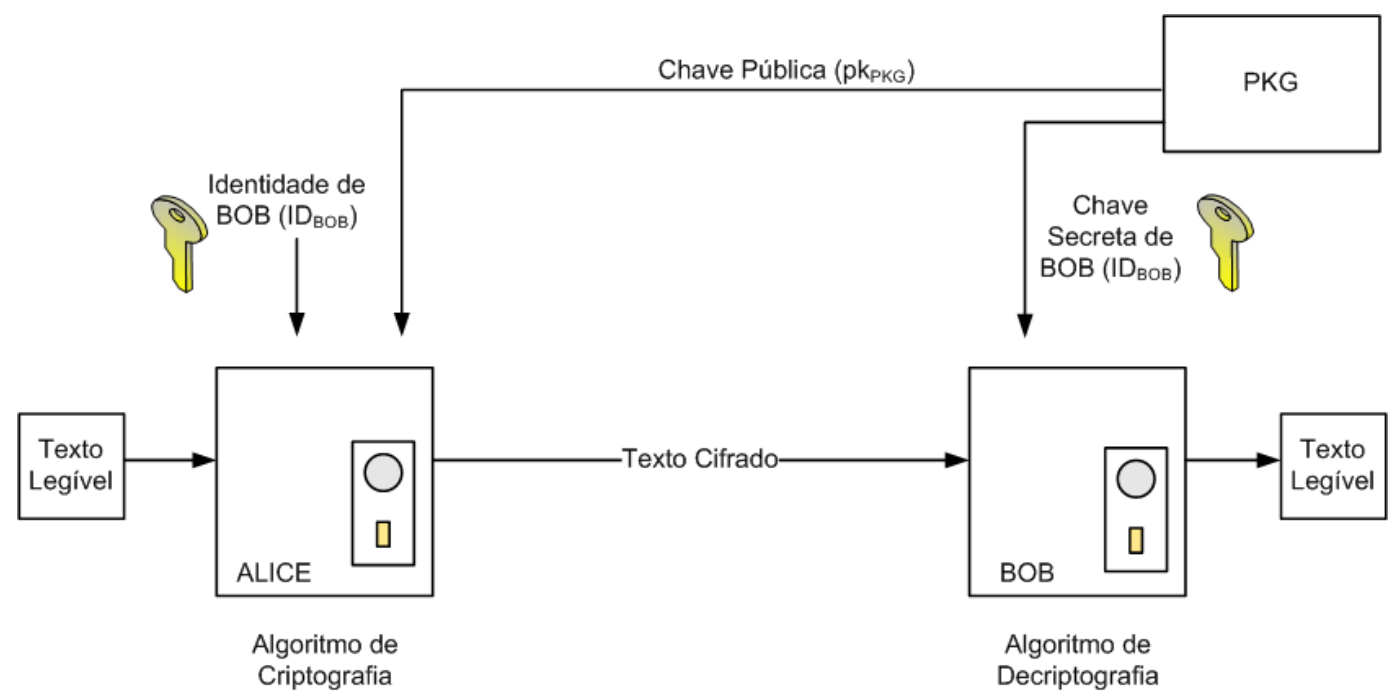

Figura 2.3: Um esquema genérico de IBE

\subsubsection{Esquema de Boneh e Franklin}

Boneh e Franklin (2001) propõem este modelo, como sendo o primeiro modelo de IBE implementado na prática e foi o ponto inicial de produtos comercializados, baseados em IBE. Antes de apresentar os componentes do modelo propriamente dito, será definida a função MapToPoint utilizada.

\section{MapToPoint:}

Sejam $\mathbb{G}_{1}, \mathbb{G}_{2}$ dois grupos gerados por $\mathscr{G}_{1}$ e $H_{1}:\{0,1\}^{*} \rightarrow A$ para algum conjunto $A$ e $L: A \rightarrow \mathbb{G}_{1}^{*}$ sendo uma função de codificação admissível ${ }^{9}$. Dessa forma,

\footnotetext{
${ }^{9}$ do original admissible encoding function.
} 
o conjunto $A$ será $\mathbb{F}_{p}$ e a função de codificação admissível será chamada de MapToPoint.

Os principais componentes do modelo Boneh e Franklin (2001) são:

- INICIALIZA: O PKG seleciona a chave-mestra privada $s \in Z_{q}^{*}$ e calcula a chave pública $P_{p u b}=s P$. Além disso, especifica duas funções hash da seguinte forma: $H_{1}:\{0,1\}^{*} \longrightarrow G_{1}^{*}$ e outra função hash da seguinte forma: $H_{2}: G_{2} \longrightarrow\{0,1\}^{n}$, com os seguintes parâmetros: $\left\langle G_{1}, G_{2}, e, P, P_{p u b}, H_{1}, H_{2}\right\rangle$ e a chave-mestra $\langle s\rangle$.

- EXTRAI: Dada uma string $I D \in\{0,1\}^{*}$, o $P K G$ verifica a identidade e faz:

1. Computar $Q_{I D}=H_{1}(I D) \in G_{1}^{*}$

2. Atualiza a chave privada $S_{I D}=s Q_{I D}$

O componente $Q_{I D}$ atua como uma chave pública correspondente à identidade ID.

- CIFRA: Para cifrar uma mensagem $m \in\{0,1\}^{n}$ a ser enviada à um usuário com identidade $I D$ deve ser feito:

1. Computar $Q_{I D}=H_{1}(I D) \in G_{1}^{*}$

2. Escolher um randômico $r \in Z_{q}^{*}$

3. Atualizar o texto cifrado para que seja:

$$
C=\left\langle r P, M \oplus H_{2}\left(g_{I D}^{r}\right)\right\rangle \text { onde } g_{I D}=e\left(Q_{I D}, P_{p u b}\right)
$$

Texto cifrado: $C=\left\langle U=r P, V=M \oplus H_{2}\left(g_{I D}^{r}\right)\right\rangle \in G_{1}^{*} \times\{0,1\}^{n}$

- DECIFRA: Para decifrar o texto cifrado $C=\langle U, V\rangle$ através de $I D$ computar

$$
V \oplus H_{2}\left(e\left(d_{I D}, U\right)\right)=M
$$

O modelo de Boneh e Franklin, na fase de cifração, necessita de uma operação de emparelhamento, uma operação hash $\mathrm{m} 2 \mathrm{p}^{10}, 1$ exponente de grupo em $G_{2}$, uma operação hash $\left(H_{2}\right)$, uma multiplicação escalar em $G_{1}$ e uma operação de XOR. Já na fase de decifração, necessita de uma operação de emparelhamento, uma operação de hash $\left(H_{2}\right)$ e uma operação de XOR.

\footnotetext{
${ }^{10}$ map-to-point
} 


\subsubsection{Esquema de Cocks}

O esquema proposto por Cocks (2001) utiliza o critério de Euler, que está descrito em apêndice B.5.3. O modelo de Cocks é, atualmente, o único esquema de IBE que não utiliza emparelhamento bilinear, e na prática não é muito utilizado devido ao alto grau de expansão de texto cifrado. Os componentes do esquema IBE proposto por Cocks, conforme (GORANTLA; GANGISHETTI; SAXENA, 2005) são:

- INICIALIZA: O PKG gera um módulo $M$ disponível universalmente, que é o produto de dois primos $P$ e $Q$. Os números primos $P$ e $Q$ são congruentes a 3 mod 4 e eles, são particularmente prendidos por PKG. O PKG também seleciona funções hash seguras disponíveis universalmente.

Os parâmetros utilizados são: $\langle M$, funções hash $\rangle$ e chave-mestra é a fatoração de $M$.

- EXTRAI: Quando alguém envia a string da sua identidade para PKG, PKG verifica a identidade e faz o seguinte:

1. Aplica uma função hash e produz um valor $a \bmod M$ tal que o símbolo de Jacobi $\left(\frac{a}{M}\right)$ é +1 . Isto envolve aplicações múltiplas de uma função hash de forma estruturada para produzir um conjunto de valores candidatos para $a$, parando quando $\left(\frac{a}{M}\right)$ for +1 . Desde que $\left(\frac{a}{M}\right)$ seja $+1,\left(\frac{a}{P}\right)=\left(\frac{a}{Q}\right)$ e também $a$ seja o módulo quadrático de $P$ e $Q$ e ainda o módulo quadrático de $M$.

2. O PKG apresenta uma raiz para pessoa como a chave privada correspondente à sua identidade, na qual só a PKG poderá calcular.

- CIFRA: A cifração de uma mensagem consiste em gerar uma chave de transporte e cifrar a mensagem com um algoritmo de cifração simétrica. Cada bit da chave de transporte será enviado da seguinte forma:

1. Seja $x$ um bit singular de uma chave de transporte codificado como +1 ou -1 .

2. Escolher um valor $t$ randômico de tal forma que $\left(\frac{t}{M}\right)$ seja igual a $x$.

3. Enviar $s=(t+a / t) \operatorname{Mod} M$. 
Se Beto não souber qual das raízes (a ou -a) Alice está guardando consigo, ele terá que replicar o processo acima, utilizando diferentes $t$ escolhidos randomicamente para enviar os mesmos $x$ bits como antes, e transmitindo $s=(t-a / t) \bmod$ $M$ cada vez.

- DECIFRA: Alice recupera o bit $x$ da seguinte maneira:

1. Alice calcula o símbolo de Jacobi, utilizando a sua chave privada $\mathrm{r}$, como $\left(\frac{s+2 r}{M}\right)$.

2. Alice recupera o bit $x$, calculando $\left(\frac{s+2 r}{M}\right)=\left(\frac{t}{M}\right)=x$, como: $s+2 r=t(1+r / t) *(1+r / t) \bmod M$.

3. Alice decifra a mensagem, recuperando todos os bits da chave de transporte.

\subsubsection{Esquema de Waters}

Modelo proposto por Waters (2005), é o primeiro modelo de IBE sem a utilização de oráculos randômicos. Este modelo utiliza o Problema de Decisão Diffie-Hellman. As fases do esquema são descritas a seguir:

- INICIALIZA: Nessa fase são criados os parâmetros do sistema. Um segredo $\alpha \in \mathbb{Z}_{p}$ e um gerador, $g \in \mathbb{G}$ são escolhidos de forma randômica. Logo, os seguintes valores são atribuídos:

1. $g_{1}=g^{\alpha}$.

2. Escolher $g_{2} \in \mathbb{G}$ de forma randômica.

3. Escolher $u^{\prime} \in \mathbb{G}$ de forma randômica.

4. Escolher um vetor de comprimento $n$, sendo $U=\left(u_{i}\right)$ de forma randômica com elementos randômicos em $\mathbb{G}$.

Dessa forma, os parâmetros públicos a serem publicados são $g, g_{1}, g_{2}, u^{\prime}$ e $U$. O segredo mestre é $g_{2}^{\alpha}$.

- GERA CHAVE: Seja $v$ uma string de $n$ bits que representa uma identidade, $v_{i}$ ilustrando o $i$-ésimo bit de $v$, e $\mathscr{V} \subseteq\{1, \ldots, n\}$ seja o conjunto de todos os $i$ que $v_{i}=1$. Uma chave privada para identidade $v$ é gerada como segue: 
1. Escolher $r \in \mathbb{Z}_{p}$ de forma randômica;

2. A chave privada é construída como:

$$
d_{v}=\left(g_{2}^{\alpha}\left(u^{\prime} \prod_{i \in \mathscr{V}} u_{i}\right)^{r}, g^{r}\right) .
$$

- CIFRA: Uma mensagem $M \in \mathbb{G}_{1}$ é cifrada para uma identidade $v$ como segue, um valor $t \in \mathbb{Z}_{p}$ é escolhido de forma randômica. Logo então o texto cifrado será:

$$
C=\left(e\left(g_{1}, g_{2}\right)^{t} M, g^{t},\left(u^{\prime} \prod_{i \in \mathscr{V}} u_{i}\right)^{t}\right)
$$

- DECIFRA: Sendo $C=\left(C_{1}, C_{2}, C_{3}\right)$ uma cifração válida de $M$ sob identidade $v, C$ poderá ser decifrado por $d_{v}=\left(d_{1}, d_{2}\right)$ como:

$$
C_{1} \frac{e\left(d_{2}, C_{3}\right)}{e\left(d_{1}, C_{2}\right)}
$$

\subsubsection{Esquema de Naccache}

O esquema proposto por Naccache (2005) é uma variante do modelo Waters com chaves mais curtas. Seja $\mathbb{G}$ um grupo primo de ordem $p$ e $g$ um gerador de $\mathbb{G}$, e $e$ um mapeamento bilinear admissível dentro do $\mathbb{G}_{1}$. As identidades poderão ser representadas como vetores $n$ dimensionais $v=\left(v_{1}, \ldots, v_{n}\right)$, onde cada $v_{i}$ é um inteiro de $l$ bits. Os inteiros $n$ e $l$ são parâmetros não relacionados para $p$ e $n^{\prime}=n$. $l$ é o comprimento de saída de uma função hash resistente à colisão. As etapas do sistema são muito semelhantes ao sistema de Waters e estão descritas a seguir.

- INICIAliZA: Nessa fase são criados os parâmetros do sistema. Um segredo $\alpha \in \mathbb{Z}_{p}$ e um gerador, $g \in \mathbb{G}$ são escolhidos de forma randômica. Logo, os seguintes valores são atribuídos:

1. $g_{1}=g^{\alpha}$. 
2. Escolher $g_{2} \in \mathbb{G}$ de forma randômica.

3. Escolher $u^{\prime} \in \mathbb{G}$ de forma randômica.

4. Escolher um vetor de comprimento $n$, sendo $U=\left(u_{i}\right)$ de forma randômica com elementos randômicos em $\mathbb{G}$.

Dessa forma, os parâmetros públicos são $g, g_{1}, g_{2}, u^{\prime}$ e $U$. O segredo mestre é $g_{2}^{\alpha}$.

- EXTRAI: Seja $v=\left(v_{1}, \ldots, v_{n}\right) \in\left(\{0,1\}^{a}\right)^{n}$ uma identidade, escolher $r$ randômico em $\mathbb{Z}_{p}$. A chave privada $d_{v}$ para a identidade $v$ é construída como:

$$
d_{v}=\left(g_{2}^{\alpha}\left(u^{\prime} \prod_{i=1}^{n} u_{i}^{v_{i}}\right)^{r}, g^{r}\right)
$$

- CIFRA: Uma mensagem $m$ é cifrada para uma identidade $v$ como segue, um valor $t \in \mathbb{Z}_{p}$ é escolhido de forma randômica. Logo, o texto cifrado será:

$$
C=\left(e\left(g_{1}, g_{2}\right)^{t} M, g^{t},\left(u^{\prime} \prod_{i=1}^{n} u_{i}^{v_{i}}\right)^{t}\right)
$$

- DECIFRA: Sendo $C=\left(C_{1}, C_{2}, C_{3}\right)$ uma cifração válida de $m$ sob identidade $v$, $C$ poderá ser decifrado por $d_{v}=\left(d_{1}, d_{2}\right)$ como:

$$
C_{1} \frac{e\left(d_{2}, C_{3}\right)}{e\left(d_{1}, C_{2}\right)}
$$

\subsubsection{Esquema Hierárquico - HIBE}

Gentry e Silverberg (2002) explicam o conceito de $\mathrm{HIBE}^{11}$ que reduz a sobrecarga de PKG's centrais. Dessa forma, delegam-se poderes de geração de chaves privadas e autenticação para níveis mais baixos de hierarquia, além de ter uma distribuição de chaves de uma maneira mais fácil e mais prática.

\footnotetext{
${ }^{11}$ Hierarchical Identity-Based Encryption, ou seja, Criptossistema Hierárquico Baseado em Identidade.
} 
O sistema HIBE proposto por Gentry e Silverberg (2002) tem os seguintes componentes:

- INICIALIZA RAIZ: A PKG raiz escolhe um gerador $P_{0} \in \mathbb{G}_{1}$, escolhe um randômico $s_{0} \in \mathbb{Z}_{q}^{*}$ e atribui $Q_{0}=s_{0} P_{0}$. Além disso, seleciona funções hash $H_{1}:\{0,1\}^{*}$ $\rightarrow \mathbb{G}_{1}, H_{2}:\{0,1\}^{n} \rightarrow \mathbb{G}_{2}$ e $H_{3}:\{0,1\}^{*} \rightarrow \mathbb{G}_{1}$. O segredo mestre da PKG raiz é $s_{0}$ e os parâmetros do sistema são: $\left\langle\mathbb{G}_{1}, \mathbb{G}_{2},, P_{0}, Q_{0}, H_{1}, H_{2}, H_{3}\right\rangle$.

- INICIALIZA NÍVEIS MAIS BAIXOS: Uma entidade de nível mais baixo (lowerlevel PKG ou usuário) no nível $t$ escolhe um randômico $s_{t} \in \mathbb{Z}_{q}^{*}$ que será armazenado de forma secreta.

- EXTRAi: Para uma entidade de nível $t$ com a seguinte tupla $\left\langle I D_{1}, \ldots, I D_{t}\right\rangle$, onde $\left\langle I D_{1}, \ldots, I D_{i}\right\rangle$ é uma tupla de ID de uma entidade anterior no nível $i$, sendo $(1 \leq i<t)$, a entidade parente computa $P_{t}=H_{1}\left(I D_{1}, \ldots, I D_{t}\right) \in \mathbb{G}_{1}$, atribui o ponto segredo $S_{t}$, dessa forma: $\sum_{i=1}^{t} S_{i-1} P_{i}=S_{t-1}+S_{t-1} P_{t}$ e define os valores $\mathrm{Q}$ atribuindo $Q_{i}=s_{i} P_{0}$ para $1 \leq i<t-1$. Para a entidade no nível $t$ são dados $S_{t}$ e valores Q pelo seu parente.

- CIFRA: Dada uma mensagem $m \in\{0,1\}^{n}$ como tuplas de $\left\langle I D_{1}, \ldots, I D_{t}\right\rangle$, a mensagem poderá ser cifrada inicialmente computando $P_{i}=H_{1}\left\langle I D_{1}, \ldots, I D_{i}\right\rangle \in$ $\mathbb{G}_{1}$ para $\left\langle I D_{1}, \ldots, I D_{t}\right\rangle$, escolhendo-se um valor randômico $r \in \mathbb{Z}_{q}^{*}$ e então o texto cifrado será:

$$
c=\left\langle r P_{0}, r P_{2}, \ldots, r P_{t}, m \oplus H_{2}\left(g^{r}\right)\right\rangle
$$

Onde $g=\hat{e}\left(Q_{0}, P_{1} \in \mathbb{G}_{2}\right)$, é um valor que poderá ser pré-computado.

- DECIFRA: Dado um texto cifrado $c=\left\langle U_{0}, U_{2}, \ldots, U_{t}, V\right\rangle$ cifrado por tupla de ID $\left\langle I D_{1}, \ldots, I D_{t}\right\rangle$, o texto cifrado poderá ser decifrado pelo cálculo de:

$$
m=V \oplus H_{2}\left(\frac{\left(U_{0}, S_{t}\right)}{\prod_{i=2}^{t}\left(Q_{i-1}, U_{i}\right)}\right)
$$

Outros esquema de HIBE foram propostos mais tarde, como o modelo de Boneh e Boyen (2004), por exemplo, que é semelhante ao modelo de Gentry e Silverberg, salvo a diferença da utilização de oráculos randômicos. O modelo de Yao et al. (2004) apresenta alguma forma de evitar a exposição das chaves secretas geradas através da atualização periódica da chave privada de cada usuário. Esse esquema é chamado de 
fs-HIBE ${ }^{12}$ e se baseia no fato do comprometimento de chaves grandes não comprometerem chaves de seções anteriores. Já o modelo Boneh, Boyen e Goh (2005) define um HIBE com texto cifrado de tamanho constante, além do processo de decifração ser independente da hierarquia do nível $\ell$.

O esquema de HIBE também poderá ser de forma anônima. Pesquisas realizadas recentemente por Boyen e Waters (2006) explicam como seria tal esquema sem a utilização de oráculos randômicos. Boyen e Waters alegam que a delegação de poderes em níveis mais baixos, como o modelo Gentry e Silverberg (2002) por exemplo, que utiliza oráculos randômicos, no momento em que haja necessidade de inclusão de componentes extras no sistema, implica cancelar a randomização, criando-se uma forma de endereçar as identidades no sistema. Uma vez que o modelo de Boyen e Waters (2006) não utiliza oráculos randômicos, tal problema não acontecerá e prevalece o anonimato do sistema.

\subsubsection{Esquema Autenticado - AIBE}

Lynn (2002) apresenta o conceito de $\mathrm{AIBE}^{13}$ como uma alternativa para providenciar integridade, confidencialidade e irretratabilidade. Este esquema é seguro contra ataque adaptativo de texto cifrado escolhido em um esquema de oráculo randômico assumindo a dificuldade de Problema Diffie Hellman. O sistema AIBE proposto em Lynn (2002) tem os seguintes componentes:

- INICIALIZA: PKG escolhe um gerador randômico $g \in G_{1}$ e define as seguintes funções hash:

1. $H_{1}: F_{q} \times G_{2} \rightarrow\{0,1\}^{n}$

2. $H_{2}:\{0,1\}^{*} \rightarrow G_{1}$

3. $H_{3}:\{0,1\}^{*} \times\{0,1\}^{*} \rightarrow F_{q}$

4. $H_{4}:\{0,1\}^{n} \rightarrow\{0,1\}^{n}$

Além disso, seleciona uma chave mestra $s \in F_{q}$. Nesse caso, os parâmetros são $\left\langle e, G_{1}, G_{2}, g, g^{s}, H_{1}, H_{2}, H_{3}, H_{4}, s\right\rangle$

\footnotetext{
${ }^{12}$ forward security for HIBE

${ }^{13}$ Authenticated Identity-Based Encryption, ou seja, esquema autenticado Baseado em Identidade.
} 
- EXTRAI: O PKG calcula uma chave privada para um usuário com a identidade $I D_{A}$ como $d_{A}=H_{2}\left(I D_{A}\right)^{s}$.

- Cifra AUTEnticada: um usuário $A$ com a identidade $I D_{A}$ cifra uma mensagem $M \in\{0,1\}^{*}$ para qualquer usuário $B$ com a identidade $I D_{B}$, utilizando a chave privada $d_{A}$ como segue:

1. Escolher um $\sigma$ randômico da seguinte forma: $\sigma \stackrel{R}{\leftarrow}\{0,1\}^{n}$.

2. Computar $c_{1}=H_{3}(\sigma, M)$ e $c_{2}=e\left(d_{A}, H_{2}\left(I D_{B}\right)\right)$.

3. A saída será o texto cifrado $C=\left\langle\sigma \oplus H_{1}\left(c_{1}, c_{2}\right), E_{H_{4}(\sigma)}(M)\right\rangle$.

- DECIFRA AUTEnTICAdA: Um usuário $B$ decifra uma mensagem $\langle U, V, W\rangle$ cifrada por um outro usuário $A$ com a identidade $I D_{A}$, utilizando a sua identidade $I D_{A}$, sua chave privada $d_{B}$ e os parâmetros apresentados, descritos da seguinte forma:

1. Computar $c_{2}=e\left(H_{2}\left(I D_{A}\right), d_{B}\right)$

2. $\sigma=V \oplus H_{1}\left(U, c_{2}\right)$

3. $M=D_{H_{4}(\sigma)}(W)$

4. Verificar quando $U=H_{3}(\sigma, M)$

5. Se a verificação resultou em positivo, a saída será o texto claro $M$, caso contrário, rejeitar o texto cifrado.

É importante salientar que AIBE necessita tanto na cifração como na decifração, de uma operação de emparelhamento, uma função hash map2p, 3 operações de hash e uma operação de XOR. Além disso, é necessário ter esquemas de cifração e decifração simétricas seguras. O fato relevante do AIBE é a sua rapidez em comparação com a cifração plana, pois tem uma operação de exponenciação a menos e nenhuma operação de multiplicação de ponto.

\subsubsection{Comparativo de esquemas de IBE}

A seção 2.4 apresentou diversos esquemas de IBE. É importante salientar que o custo computacional é relativo à complexidade de cada operação. A tabela 2.1 apresenta as operações realizadas nos modelos apresentados, em ordem de sua complexidade. Quanto mais complexa a operação, maior seu custo computacional. 
Tabela 2.1: Operações em ordem de custo computacional.

\begin{tabular}{clc}
\hline Operação & Descrição & Custo Computacional \\
\hline emp & Emparelhamento bilinear & Custo mais alto \\
$\exp$ & Exponenciação & Custo alto \\
$M s$ & Multiplicação escalar & Custo moderado \\
$h$ & função hash & Custo mais baixo \\
\hline
\end{tabular}

A tabela 2.2 ilustra um quadro comparativo do processo de cifração entre os diversos tipos de IBE em termos de operações existentes em cada modelo, permitindo ter uma idéia do custo computacional no processo de cifração dos diversos modelos apresentados, onde:

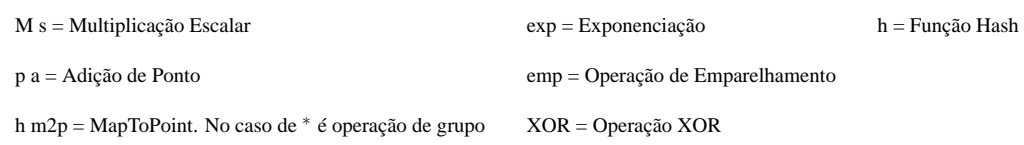

Tabela 2.2: Comparativo de cifração dos esquemas de IBE

\begin{tabular}{lccccccc}
\hline Esquema & M s & exp & h & p a & emp & h m2p & XOR \\
\hline Boneh e Franklin & 1 & 1 & - & - & 1 & 1 & 1 \\
Waters $^{*}$ & - & 3 & - & - & - & 1 & - \\
Naccache $^{*}$ & - & 4 & - & - & - & 1 & - \\
HIBE & $\mathrm{t}$ & 1 & 1 & - & 1 & 1 & 1 \\
AIBE & - & - & 3 & - & 1 & 1 & 1 \\
\hline
\end{tabular}

A tabela 2.3 ilustra um comparativo do processo de decifração entre os diversos tipos de IBE em termos de operações existentes em cada modelo.

\subsection{Esquemas de Assinatura Baseados em Identidade - IBS}

\subsubsection{Um esquema genérico de IBS}

Um esquema genérico de $\mathrm{IBS}^{14}$ consiste em quatro fases: inicializa, extrai, assina e verifica. Normalmente, nesse esquema, Alice pretende assinar um documento, obtém da PKG, a sua chave de assinatura que está associada à informação do seu

\footnotetext{
${ }^{14}$ Identity-Based Signature
} 
Tabela 2.3: Comparativo de decifração dos esquemas de IBE.

\begin{tabular}{lccccccc}
\hline Esquema & M s & exp & h & p a & emp & h m2p & XOR \\
\hline Boneh e Franklin & - & - & 1 & - & 1 & - & 1 \\
Waters & - & - & - & - & 2 & 1 & - \\
Naccache & - & - & - & - & 2 & 1 & - \\
HIBE & - & - & 1 & - & $\mathrm{t}$ & - & 1 \\
AIBE & - & - & 3 & - & 1 & 1 & 1 \\
\hline
\end{tabular}

identificador. Ela assina a mensagem com a chave obtida. Agora Beto utiliza o identificador de informação da Alice para verificar a assinatura e não necessita mais de um certificado. As diversas fases de um esquema genérico podem ser detalhados conforme Baek et al. (2004) e estão ilustradas na figura 2.4:

- INICIALIZA: O PKG cria o par de chaves privada $s k_{P K G}$ e pública $p k_{P K G}$.

- EXTRAI: Alice se autentica com o PKG e obtém a sua chave privada, $s k_{I D_{\text {Alice }}}$ associada a sua identidade $I D_{\text {Alice }}$.

- ASSINA: Utilizando a sua chave privada, $s k_{I D_{A l i c e}}$ Alice cria, a assinatura $\sigma$ na sua mensagem $M$.

- VERIFICA: Beto, recebendo a assinatura $\sigma$ e mensagem $M$ de Alice, verifica se $\sigma$ é a assinatura genuína sobre mensagem $M$ utilizando identidade de Alice e a chave pública do $\mathrm{PKG}, p k_{P K G}$. Se a assinatura for genuína, ele retorna "aceito", senão retorna "rejeito".

A seguir são apresentados alguns esquemas de assinatura baseada em identidade com base em (GORANTLA; GANGISHETTI; SAXENA, 2005; LIM, 2006).

\subsubsection{Esquema de Shamir}

- INICIALIZA: Nesta fase, o PKG escolhe os parâmetros de sistema da seguinte forma:

1. Calcula $n$ como um produto de dois números primos grandes.

2. Seleciona um número grande $e$ que é relativamente primo para $\Phi(n)$ onde $\Phi$ é função totiente de Euler. 


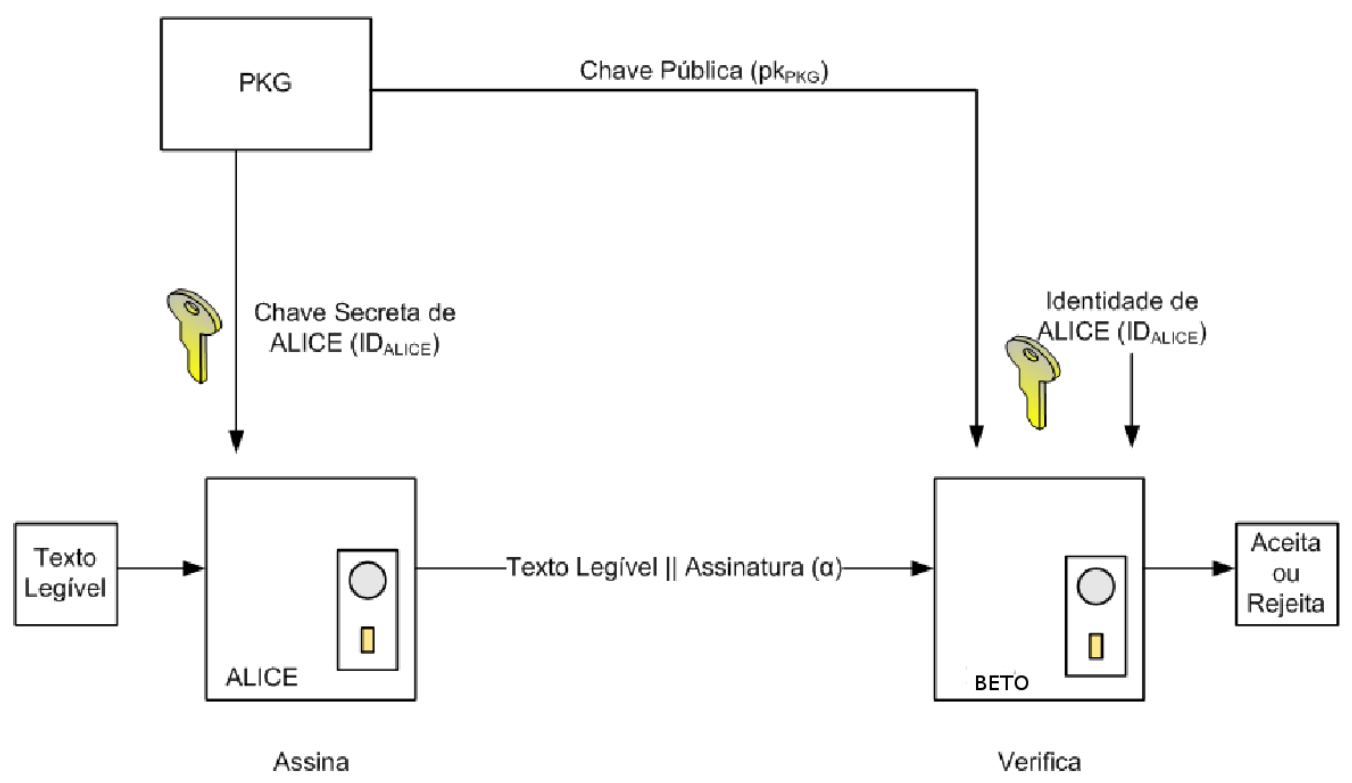

Figura 2.4: Um esquema genérico de IBS

3. Seleciona uma função $h$ que seja reversível, com parâmetros $\langle n, e, h\rangle \mathrm{e}$ chave-mestra como fatorização de $n$.

- EXTrai: Para um usuário com identidade $I D$, o PKG calcula a chave $g$ que é a chave privada correspondente, tal como $g^{e}=I D \bmod n$.

- ASSINA: Um usuário com a chave privada $g$ assina uma mensagem com as seguintes operações:

1. Escolher um número randômico $r$.

2. Calcular $t=r^{e} \bmod n$.

3. Computar $s=g \cdot r^{h(t, m)} \bmod n$. Dessa forma, a assinatura será $\sigma=\langle s, t\rangle \in$ $Z^{n} \times Z^{n}$.

- VERIFICA: A assinatura $\sigma=\langle s, t\rangle$ de um usuário com a identidade $I D$ é válida, se e somente se, acontecer a seguinte igualdade.

$$
s^{e}=I D \cdot t^{h(t, m)} \bmod n
$$

As etapas de assinatura e verificação de assinatura requerem 2 exponenciações de inteiros, 1 multiplicação de inteiro e uma operação de hash. 
A segurança nesse modelo de assinatura é baseada na dificuldade do Problema de Fatoração de Inteiros (IFP ${ }^{15}$ ). Os aspectos de segurança nesse modelo foram provados em Bellare, Namprempre e Neven (2004).

\subsubsection{Esquema de Sakai-Ohgishi-Kasahara}

SAKAI e KASAHARA (2003) apresentaram um modelo de IBS baseado em emparelhamentos com proposta de redução do número de computações necessárias para verificação da assinatura com as seguintes etapas, conforme Gorantla, Gangishetti e Saxena (2005):

- INICIALIZA: O PKG escolhe $s \in_{R}(Z / q)$ como a sua chave-mestra privada e computa a chave pública global $P_{p u b}$ como $s P$. Logo depois escolhe uma função randômica de hash da seguinte forma: $H_{1}:\{0,1\}^{n} \rightarrow G_{1}$. Os parâmetros são $\left\langle G_{1}, G_{2}, e, P, P_{p u b}, H_{1}\right\rangle$ e $\langle s\rangle$ como a chave-mestra.

- EXTRAI: O PKG verifica a identidade de $I D$ e computa a chave privada para essa identidade como $S_{I D}=s H_{1}(I D)$. O componente $Q_{I D}=H_{1}(I D)$, nesse caso, atua como a chave pública correspondente.

- ASSINA: Dada uma chave privada $S_{I D}$ e uma mensagem $M \in G_{1}$, escolher um $r \in R(Z / q)$ e calcular:

1. $S_{1}=S_{I D}+r M$

2. $S_{2}=r P$

Dessa forma, a assinatura será $\sigma=\left\langle s_{1}, s_{2}\right\rangle \in G_{1} \times G_{1}$

- VERIFICA: A assinatura $\sigma=\left\langle s_{1}, s_{2}\right\rangle$ de uma identidade $I D$ sobre uma mensagem $M$ será válida, se for conforme a seguinte equação:

$$
e\left(Q_{I D}, P_{\text {pub }}\right) e\left(M, S_{2}\right)=e\left(S_{1}, P\right)
$$

O processo de assinatura, nesse modelo, requer 2 multiplicações escalares em uma operação de adição de ponto em $G_{1}$. No processo de verificação da assinatura, são necessárias 3 operações de emparelhamento e uma operação de hash.

\footnotetext{
${ }^{15}$ Integer Facotrization Problem
} 
Bellare, Namprempre e Neven (2004) provam que uma versão modificada deste modelo é seguro contra ataque do tipo texto escolhido. É importante salientar que o modelo original do SAKAI e KASAHARA (2003) ainda não foi provado, segundo Gorantla, Gangishetti e Saxena (2005).

\subsubsection{Esquema de Paterson}

O esquema proposto por Paterson (2002) é semelhante ao esquema de assinatura de ElGamal e tem as seguintes etapas:

- INICIALIZA: O PKG escolhe $s \in_{R}\left(Z / q^{Z}\right)^{\times}$como a sua chave-mestra privada e computa a chave pública global $P_{p u b}$ como $s P$. Logo depois escolhe uma função randômica de hash da seguinte forma: $H_{1}:\{0,1\}^{*} \rightarrow G_{1}$ e duas funções hash: $H_{2}:\{0,1\}^{*} \rightarrow Z_{q}$ e $H_{3}: G_{1} \rightarrow Z_{q}$. Os parâmetros utilizados são $\left\langle G_{1}, G_{2}, e, P, P_{p u b}, H_{1}, H_{2}, H_{3}\right\rangle$ e $\langle s\rangle$ como a chave-mestra.

- EXTRAI: PKG verifica a identidade de $I D$ e computa a chave privada para essa identidade como $S_{I D}=s H_{1}(I D)$. O componente $Q_{I D}=H_{1}(I D)$, nesse caso, atua como a chave pública correspondente.

- ASSINA: Para assinar uma mensagem $M \in\{0,1\}^{*}$, um usuário, inicialmente, escolhe $k \in_{R} Z_{q}^{*}$ e computa:

1. $R=k P$

2. $S=K^{-1}\left(H_{2}(M) . P+H_{3}(R) . D_{I D}\right)$ onde $k^{-1}$ é o inverso de $k \in Z_{q}^{*}$

Dessa forma, a assinatura será $\sigma=\langle R, S\rangle \in G_{1} \times G_{1}$

- VERIFICA: Aceitar a assinatura $\sigma=\langle R, S\rangle$ de uma identidade $I D$ sobre uma mensagem $M$, se for conforme a seguinte equação:

$$
e(R, S)=e(P, P)^{H_{2}(M)} \cdot e\left(P_{p u b}, Q_{I D}\right)^{H_{3}(R)}
$$

Esse modelo, na fase de assinatura, necessita de 3 multiplicações escalares e 2 pontos de adição em $G_{1}, 2$ operações de hash. A fase de verificação requer 3 operações de emparelhamento, 2 exponenciações e 1 multiplicação em $G_{2}$ e uma operação de hash. Não há nenhuma prova formal de segurança para esse modelo. 


\subsubsection{Esquema de Hess}

Esse esquema de assinatura foi apresentado em (HESS, 2003) e permite a précomputação na fase de assinatura. A pré-computação é bastante útil no caso de um signatário ter muitos documentos para assinar. A pré-computação auxilia na eliminação de uma das operações de emparelhamento na fase de verificação de assinatura, contribuindo para desempenho do sistema. A seguir são descritas as diversas etapas do Esquema de Hess.

- INICIALIZA: O PKG escolhe $s \in_{R}(Z / q Z)^{\times}$como a sua chave-mestra privada e e computa a chave pública global $P_{p u b}$ como $s P$. Logo depois escolhe uma função randômica de hash da seguinte forma: $H_{1}:\{0,1\}^{*} \rightarrow G_{1}^{*}$ e outra função hash $h:\{0,1\}^{*} \times G_{2} \rightarrow(Z / q Z)^{\times}$. Os parâmetros utilizados são $\left\langle G_{1}, G_{2}, e, P, P_{p u b}, H_{1}, h\right\rangle$ e $\langle s\rangle$ como a chave-mestra.

- EXTRAI: Dada a identidade $I D$, calcular a chave privada para essa identidade como $S_{I D}=t H_{1}(I D)$. O componente $Q_{I D}=H_{1}(I D)$, nesse caso, atua como a chave pública correspondente.

- ASSINA: Para assinar uma mensagem $M \in\{0,1\}^{*}$, usando a chave privada $s_{I D}$, o signatário de forma arbitrária escolhe $P_{1} \in G_{1}^{*}$ e um número inteiro $k \in$ $(Z / q Z)^{\times}$e computa:

1. $r=e\left(P_{1}, P\right)^{k}$

2. $v=h(m, r)$.

3. $U=v S_{I D}+k P_{1}$.

Dessa forma, a assinatura será $\sigma=\langle U, v\rangle \in G_{1} \times(Z / q Z)^{\times}$

- VERIFICA: Para verificar a assinatura $\sigma=\langle U, v\rangle$ de uma identidade $I D$ sobre uma mensagem $M$, calcular:

1. $r=e(U, P) . e\left(Q_{I D},-P_{p u b}\right)^{v}$.

2. Aceitar a assinatura se e somente se $v=h(m, r)$.

A fase de assinatura requer uma operação de emparelhamento, 1 exponenciação em $G_{2}, 1$ ponto de adição, 2 multiplicações escalares em $G_{2}$ e 1 operação de hash. Na 
verificação, são necessárias 2 operações de emparelhamento, 1 hash e 1 exponenciação em $G_{2}$.

\subsubsection{Esquema de Cha-Cheon}

O modelo de assinatura de Cha-Cheon utiliza mapeamentos bilineares com os mesmos parâmetros utilizados pelo sistema Boneh e Franklin. Esse esquema de assinatura encontra-em em (CHA; CHEON, 2003). As etapas de assinatura são as seguintes:

- INICIALIZA: O PKG escolhe $s \in_{R}(Z / q)$ como a sua chave-mestra privada e computa a chave pública global $P_{p u b}$ como $s P$. Logo depois escolhe uma função randômica de hash da seguinte forma: $H_{1}:\{0,1\}^{*} \rightarrow G_{1}$ e outra função hash: $H_{2}:\left\{0,1 \times G_{1}\right\}^{*} \rightarrow Z / q$. Os parâmetros utilizados são $\left\langle G_{1}, G_{2}, e, P, P_{p u b}, H_{1}, H_{2},\right\rangle$ e $\langle s\rangle$ como a chave-mestra.

- EXTRAI: O PKG verifica a identidade de $I D$ e computa a chave privada para esta identidade calculando $S_{I D}=s H_{1}(I D)$. O componente $Q_{I D}=H_{1}(I D)$ nesse caso atua como a chave pública correspondente.

- ASSINA: Para assinar uma mensagem $M \in\{0,1\}^{*}$, utilizando a chave privada $S_{I D}$, o signatário utiliza um inteiro $r \in_{R} Z / q$ e calcula:

1. $U=r Q_{I D}$

2. $h=H_{2}(m, U)$

3. $V=(r+h) S_{I D}$

Dessa forma, a assinatura será $\sigma=\langle U, V\rangle \in G_{1} \times G_{1}$.

- VERIFICA: A assinatura $\sigma=(U, V)$ de uma identidade $I D$ sobre uma mensagem $m$ será válida se $\left(P, P_{p u b}, U+h Q_{I D}, V\right)$ é uma tupla válida de Diffie-Hellman. Isso poderá ser verificado através da seguinte equação:

$$
e(P, V)=e\left(P_{p u b}, U+h Q_{I D}\right)
$$

A fase de assinatura, nesse modelo, requer 1 hash, 2 multiplicações escalares em $G_{1}, 1$ hash criptográfica, e 1 adição em $Z_{q}$. Já na fase de verificação, são necessárias 
2 operações de emparelhamentos, 1 hash m2p, 1 multiplicação escalar e 1 ponto de adição em $G_{1}$. Pela eficiência da fase de assinatura, não há necessidade de operações de emparelhamento (GORANTLA; GANGISHETTI; SAXENA, 2005).

\subsubsection{Esquema de Barreto et al.}

Em 2005, Barreto et al. propõem um modelo eficiente de IBS baseado em mapeamentos bilineares descrito de forma detalhada em (BARRETO et al., 2005). O modelo se destaca por sua eficiência, pois na etapa de verificação necessita somente de um cálculo de emparelhamento singular. As etapas do modelo são:

- INICIALIZA: Dado um parâmetro de segurança $k$, o PKG escolhe grupos de mapeamentos bilineares $\left(\mathbb{G}_{1}, \mathbb{G}_{2}, \mathbb{G}_{T}\right)$ de ordem prima $p>2^{k}$ e geradores $P$ e $Q$ tal que $Q \in \mathbb{G}_{2}$ e $P=\psi(Q) \in \mathbb{G}_{1}$ e $g=e(P, Q)$. Depois disso, seleciona uma chave mestra $s \stackrel{R}{\leftarrow} \mathbb{Z}_{p}^{*}, H_{2}:\{0,1\}^{*} \times \mathbb{G}_{T} \rightarrow \mathbb{Z}_{p}^{*}$. Os parâmetros públicos são: $\left\{\mathbb{G}_{1}, \mathbb{G}_{2}, \mathbb{G}_{T}, P, Q, g, Q_{p u b}, e, \psi, H_{1}, H_{2}\right\}$

- EXTRAI: Para uma identidade $I D$, a chave privada é $S_{I D}=\frac{1}{H_{1}(I D)+s} P$.

- ASSINA: Para assinar uma mensagem $M \in\{0,1\}^{*}$ o signatário seleciona randomicamente $x \stackrel{R}{\leftarrow} \mathbb{Z}_{p}^{*}$ e calcula:

1. $r=g^{x}$

2. $h=H_{2}(M, r) \in \mathbb{Z}_{P}^{*}$

3. $S=(x+h) S_{I D}$

Dessa forma, a assinatura será $\sigma=(h, S) \in \mathbb{Z}_{P}^{*} \times \mathbb{G}_{1}$.

- VERIFICA: A assinatura $\sigma=(h, S)$ sobre uma mensagem $M$ será válida, se e somente se: $h=H_{2}\left(M, e\left(S, H_{1}(I D) Q+Q_{p u b}\right) g^{-h}\right)$

A fase de assinatura se destaca por ser composta apenas por 2 multiplicações, sem necessidade de exponenciação e operações de emparelhamento e leva 1,56 milisegundos. A fase de verificação necessita de 1 multiplicação e 1 operação de emparelhamento, levando um tempo de 3,60 milisegundos (BARRETO et al., 2005). 


\subsubsection{Comparativo dos esquemas de IBS}

A tabela 2.4 compara o processo de assinatura entre os diversos tipos de IBS em termos de operações existentes em cada modelo para melhor visualização de custo computacional envolvido nesse processo, onde:

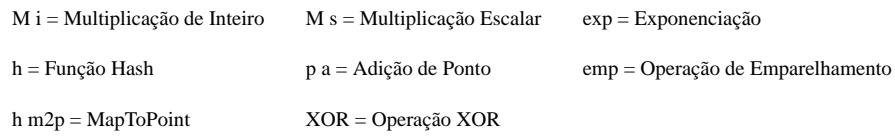

Tabela 2.4: Comparativo de assinatura dos esquemas de IBS.

\begin{tabular}{lccccccc}
\hline Esquema & M i & M s & exp & h & p a & emp & h m2p \\
\hline Shamir & 1 & - & 2 & 1 & - & - & - \\
S-O-Kasahara & - & 2 & - & - & 1 & - & - \\
Paterson & - & 3 & - & 2 & 2 & - & - \\
Hess & - & 2 & 1 & 1 & 1 & 1 & - \\
Cha-Cheon & - & 2 & 2 & 1 & - & - & 1 \\
Barreto & 1 & 1 & - & 1 & - & - & - \\
\hline
\end{tabular}

Analisando os dados da tabela, pode-se verificar que os esquemas de IBS apresentados nesse documento, exceto o esquema proposto por Shamir, utilizam as operações de multiplicação escalar. O modelo de assinatura de Barreto se destaca por ter apenas uma operação de multiplicação escalar, dessa forma pode ser considerada uma assinatura mais rápida e mais eficiente.

As operações de emparelhamento, conforme a tabela 2.4, são somente necessárias no modelo de Hess, bem como a operação de hash m2p. Dessa forma, pode-se concluir que o processo de assinatura é um processo relativamente rápido.

A tabela 2.5 compara o processo de verificação de assinatura entre os diversos tipos de IBS em termos de operações existentes em cada modelo.

A tabela 2.5 apresenta claramente o uso uniforme da operação de emparelhamento no processo de verificação de assinatura, exceto no esquema proposto por Shamir. Além disso, a operação hash $\mathrm{m} 2 \mathrm{p}$ também é utilizada por todos os modelos, exceto os modelos propostos por Shamir e Barreto.

Dessa forma, pode-se concluir que o processo de verificação de assinatura, em comparação com o processo de assinatura, necessita consideravelmente de mais tempo 
Tabela 2.5: Comparativo de verificação de assinatura dos esquemas de IBS.

\begin{tabular}{lccccccc}
\hline Esquema & M i & M s & exp & h & p a & emp & h m2p \\
\hline Shamir & 1 & - & 2 & 1 & - & - & - \\
S-O-Kasahara & - & - & - & - & - & 3 & 1 \\
Paterson & 1 & - & 2 & 2 & - & 3 & 1 \\
Hess & - & - & 1 & - & - & 2 & 1 \\
Cha-Cheon & - & 1 & - & - & 1 & 2 & 1 \\
Barreto & 1 & - & - & 1 & - & 1 & - \\
\hline
\end{tabular}

pela excessiva utilização de operações de emparelhamento e a operação de hash $\mathrm{m} 2 \mathrm{p}$. Mais uma vez o modelo de Barreto se destaca pela sua eficiência, com apenas uma operação de emparelhamento e nenhuma operação de hash $\mathrm{m} 2 \mathrm{p}$, em processo de verificação de assinatura.

Além dos esquemas de assinatura apresentados, Shahandshti e Safavi-Naini (2007) apresentam a construção genérica de um IBS a partir de uma assinatura padrão e discutem a sua segurança conforme o esquema proposto por Bellare, Namprempre e Neven (2004). O esquema proposto por Shahandshti e Safavi-Naini (2007) possui esquemas verificadores de assinatura baseado na identidade ${ }^{16}$.

\subsection{Esquemas de Acordo de Chaves Baseados em IBE}

O protocolo de acordo da chave é um dos primitivos fundamentais em criptografia, pois normalmente os esquemas de assinatura ou de cifração necessitam, no momento de estabelecimento de chaves, de uma forma de autenticar as partes envolvidas no processo de troca ou distribuição de chaves.

Dessa forma, um protocolo de acordo da chave pode ser definido como uma forma de providenciar autenticação implícita da chave de uma entidade para a outra entidade. Um protocolo de acordo da chave que providencie a autenticação implícita mútua da chave pode ser chamado de protocolo de acordo da chave autenticado, conforme Gorantla, Gangishetti e Saxena (2005). Isso pode ser feito através da combinação de esquemas de assinatura com esquemas de acordo da chaves (SMART, 2002). Alguns aspectos de segurança desejados nos esquemas de acordo de chaves são:

- Segurança da Chave de sessão: O comprometimento de uma chave de

\footnotetext{
${ }^{16}$ do original em inglês Identity-Based Universal Designated Verifier Signatures - IBUDVS
} 
sessão não deve resultar em comprometimento das outras chaves de sessão.

- Propagação de Segurança ${ }^{17}$ : Se uma chave privada de termo longo, de uma ou mais entidades foram comprometidas, a segurança das chaves de sessão previamente estabelecidas não deve ser afetada. Um sistema possui propagação de segurança parcial, se uma parcela das entidades com chaves de termos longos poderem ser corrompidas e comprometidas, sem o comprometimento das chaves de sessões estabelecidas anteriormente. Da mesma forma, um sistema possui propagação de segurança perfeita ou total, se, com o comprometimento de todas as entidades envolvidas que possuem chaves de termos longos, não houver comprometimento das chaves de sessões previamente estabelecidas.

- Personificação Unilateral ${ }^{18}$ : O comprometimento de uma chave privada da entidade $A$ poderá permitir a um adversário personificar $A$, mas não o habilita a personificar outras entidades para $A$.

- Controle de Chave: Nenhuma entidade deveria ser capaz de trocar uma chave de sessão com um valor pré-selecionado.

- Compartilhamento da Chave: Uma entidade $A$ não deveria ser coagida a compartilhar uma chave com qualquer entidade $C$, quando na verdade $A$ pensa que está compartilhando a chave com a entidade $B$.

Os esquemas de acordo de chaves autenticado são compostos de três algoritmos que, neste documento, são referenciados como INICIALIZA, EXTRAI e ACORDO DA CHAVE.

\subsubsection{Esquema de Smart}

O esquema foi proposto por Smart, está detalhado em Smart (2002) e se baseia no emparelhamento de Weil. Conforme Smart (2002), este protocolo possui autenticação implícita mútua da chave e possui também as características desejáveis. Os processos do esquema são:

\footnotetext{
${ }^{17}$ Tradução do autor, do original Forward Secrecy.

${ }^{18}$ Adequação do autor para português, do original Key-compromise Impersonation Resilience.
} 
- INICIALIZA: O PKG escolhe uma chave secreta $s \in 1, \ldots l$. Computa a chave pública calculando $P_{p u b}=s P$. Também é especificada uma função hash $\mathrm{m} 2 \mathrm{p}$ da seguinte forma: $H_{1}: Z_{q}^{*} \rightarrow G_{1}$ e os parâmetros de $\left\langle G_{1}, G_{2}, e, P, P_{p u b}, H_{1}\right\rangle$ e $s$ como a chave-mestra.

- EXTRAi: Para um usuário com a identidade $I D$, é dada a chave pública por $Q_{A}=H_{1}(I D)$ e o PKG gera a chave privada associada, calculando $S_{A}=s Q_{A}$.

- ACORDO DA CHAVE: O acordo chave será feito da seguinte forma:

1. A escolhe $a \in Z_{q}^{*}$ de forma randômica, computa $T_{A}=a P$ e envia $T_{A}$ para $B$.

2. $B$ escolhe $b \in Z_{q}^{*}$ de forma randômica, computa $T_{B}=b P$ e envia $T_{B}$ para $A$.

3. A computa o segredo compartilhado $K_{A B}=e\left(a \cdot Q_{B}, P_{p u b}\right) e\left(S_{A}, T_{B}\right)$

4. De forma semelhante, $B$ computa o segredo compartilhado:

$$
K_{B A}=e\left(b \cdot Q_{A}, P_{p u b}\right) e\left(S_{B}, T_{A}\right)
$$

5. Se ambos seguirem esse protocolo, calcularão o mesmo segredo compartilhado:

$$
K_{A} B=K_{B} A=e\left(a S_{B}+b S_{A}, P\right)
$$

Dessa forma, a chave compartilhada é $K=k d f\left(k_{A B}\right)=k d f\left(K_{B A}\right)$ onde $k d f$ pode ser definida como uma função hash $H_{2}: G_{2} \rightarrow\{0,1\}^{*}$

A figura 2.5 apresenta a seqüência de atividades realizadas no esquema de Smart. Dessa forma, $A$, recupera os parêmetros de PKG e recupera a sua chave privada e logo calcula $T_{a}$ e envia para $B$. Assim, o $B$, recupera os parâmetros de PKG e recupera a sua chave privada e calcula $T_{B}$. Logo, $B$ pode calcular $m 2 p$ de $A$ e calcula então $K_{B A}$ e em seguida hash de $K_{B A}$. Após armazenar o $K_{B A}$, envia $T_{B}$ para $A$.

A partir desse valor, $A$, calcula $m 2 p$ de $B$ e, em seguida, $K_{A B}$ e após calcular hash de $K_{A B}$, armazena $K_{A B}$.

\subsubsection{Esquema de Scott}

Scott, em 2002, apresentou seu esquema, baseado em emparelhamento de Tate. Esse esquema se destaca pelo fato de estar seguro contra personificação pela dificul- 
A
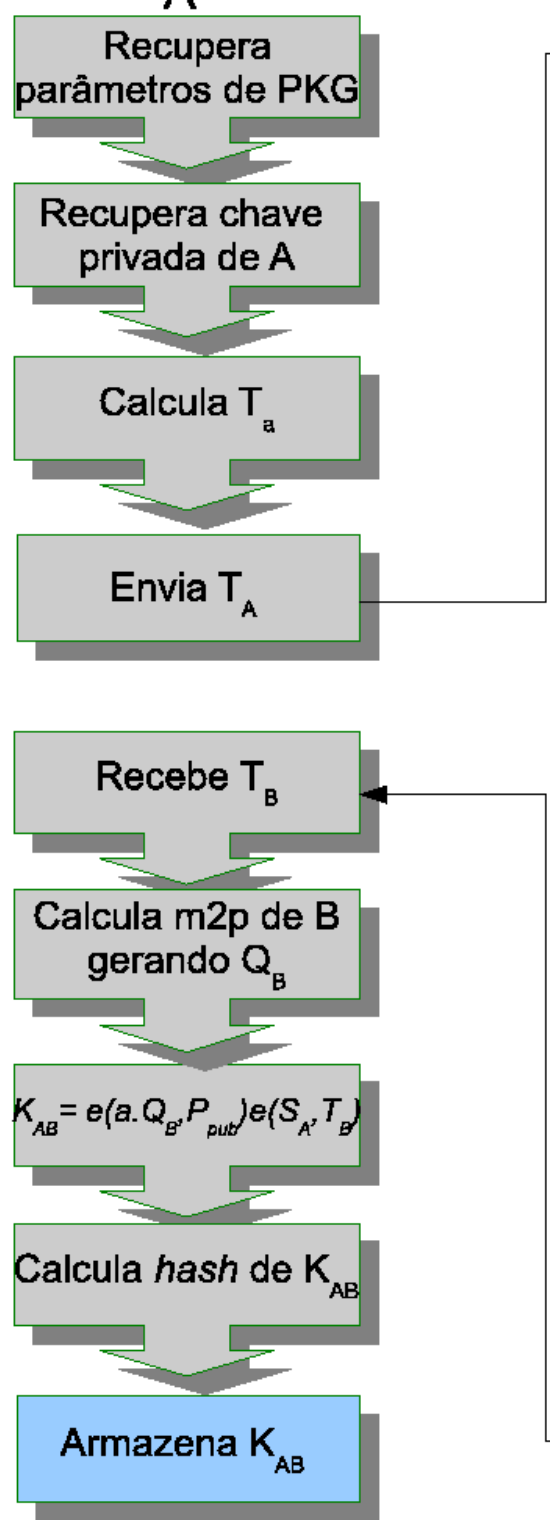

B

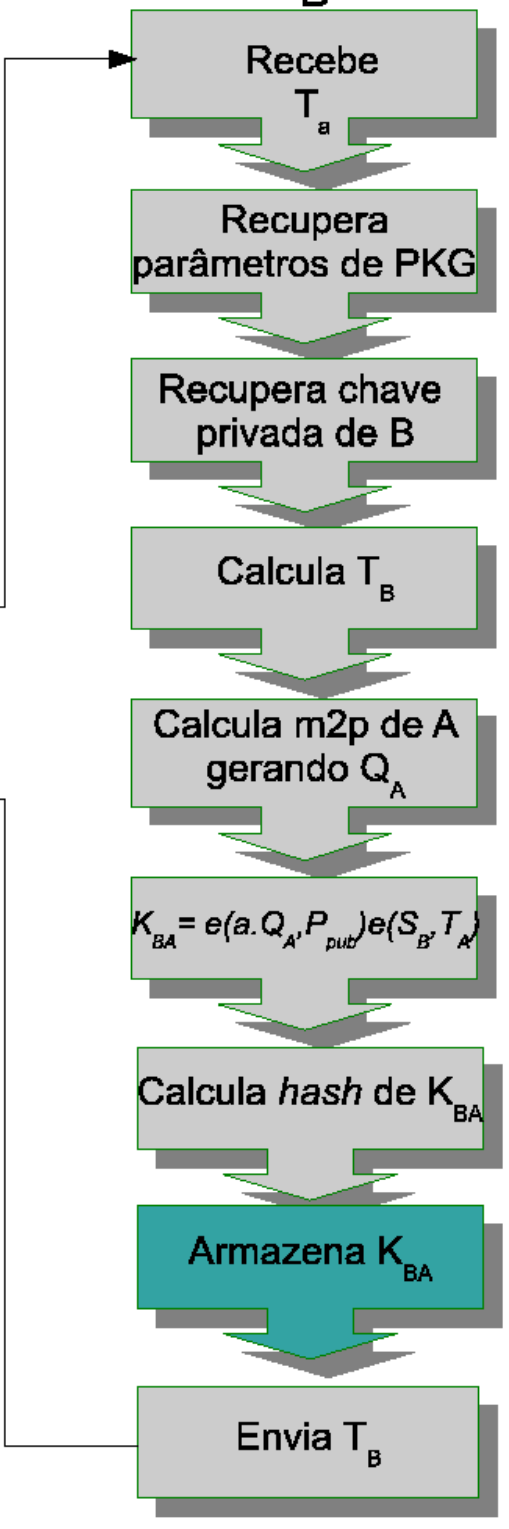

Figura 2.5: Diagrama de atividades do esquema de Smart. 
dade de Problema Bilinear Diffie Hellman.

- INICIALIZA: O PKG escolhe um número primo com $p=3 \bmod 4$ e $p+1$ é um produto de dois primos $c, r$. Além disso, escolhe uma função hash $\mathrm{m} 2 \mathrm{p}$ $H:\{0,1\}^{*} \rightarrow G_{1}$. Depois escolhe um randômico $s \in F_{q}$ como a sua chavemestra, com os seguintes parâmetros: $\left\langle G_{1}, G_{2}, e, P, q, H, s\right\rangle$.

- EXTRAi: Para um usuário com a identidade $I D_{A}$, PKG calcula a sua chave privada, calculando $S_{A}=s Q_{A}$, onde $Q_{A}$ é a chave pública do $A$ calculada como $Q_{A}=H\left(I D_{A}\right)$. O usuário escolhe um número PIN $\alpha_{A}$ e calcula $\alpha_{A} Q_{A}$ e $(s-$ $\left.\alpha_{A}\right) Q_{A}$, subtraindo $\alpha_{A} Q_{A}$ de $S_{A}$. O usuário armazena os valores $Q_{A},\left(s-\alpha_{A}\right) Q_{A}$ e pode reconstruir $S_{A}$ através dos valores armazenados e PIN $\alpha_{A}$ que foi memorizado.

- ACORDO DA CHAVE: O acordo da chave será feito da seguinte forma:

1. A escolhe $a<r$ de forma randômica, computa $T_{A}=e\left(\left(s-\alpha_{A}\right) Q_{A}+\alpha_{A} Q_{A}, Q_{B}\right)^{a}$ e envia então $T_{A}$ para $B$.

2. $B$ escolhe $b<r$ de forma randômica, computa $T_{B}=e\left(\left(s-\alpha_{B}\right) Q_{B}+\alpha_{B} Q_{B}, Q_{A}\right)^{a}$ e envia então $T_{B}$ para $A$.

3. $A$ calcula $K_{A B}=T_{B}^{a}$ e de forma semelhante, $B$ calcula $K_{B A}=T_{A}^{b}$. Se ambos seguirem o mesmo protocolo, calcularão a mesma chave secreta compartilhada $K_{A B}=e\left(a \cdot Q_{B}, P_{p u b}\right) e\left(S_{A}, T_{B}\right)$

4. De forma semelhante, $B$ computa o segredo compartilhado:

$$
K_{A} B=K_{B} A=e\left(Q_{A}, Q_{B}\right)^{s a b}
$$

Dessa forma, a chave compartilhada é $K=e\left(Q_{A}, Q_{B}\right)^{s a b}$

A figura 2.6 apresenta a sequiência de atividades realizadas no esquema de Scott. Dessa forma, $A$, recupera os parêmetros de $\mathrm{PKG}$ e recupera a sua chave privada dentro do pin armazenado e logo calcula $T_{A}$ e envia para $B$. Assim, o $B$, recupera os parâmetros de PKG e recupera a sua chave privada dentro do pin armazendo e calcula $T_{B}$. Logo, $B$ calcula $Q_{A}$ e pode calcular então $K_{B A}$. Após armazenar o $K_{B A}$, envia $T_{B}$ para A. 
A partir desse valor, $A$, calcula $Q_{B}$ e, em seguida, $K_{A B}$ e armazena $K_{A B}$.

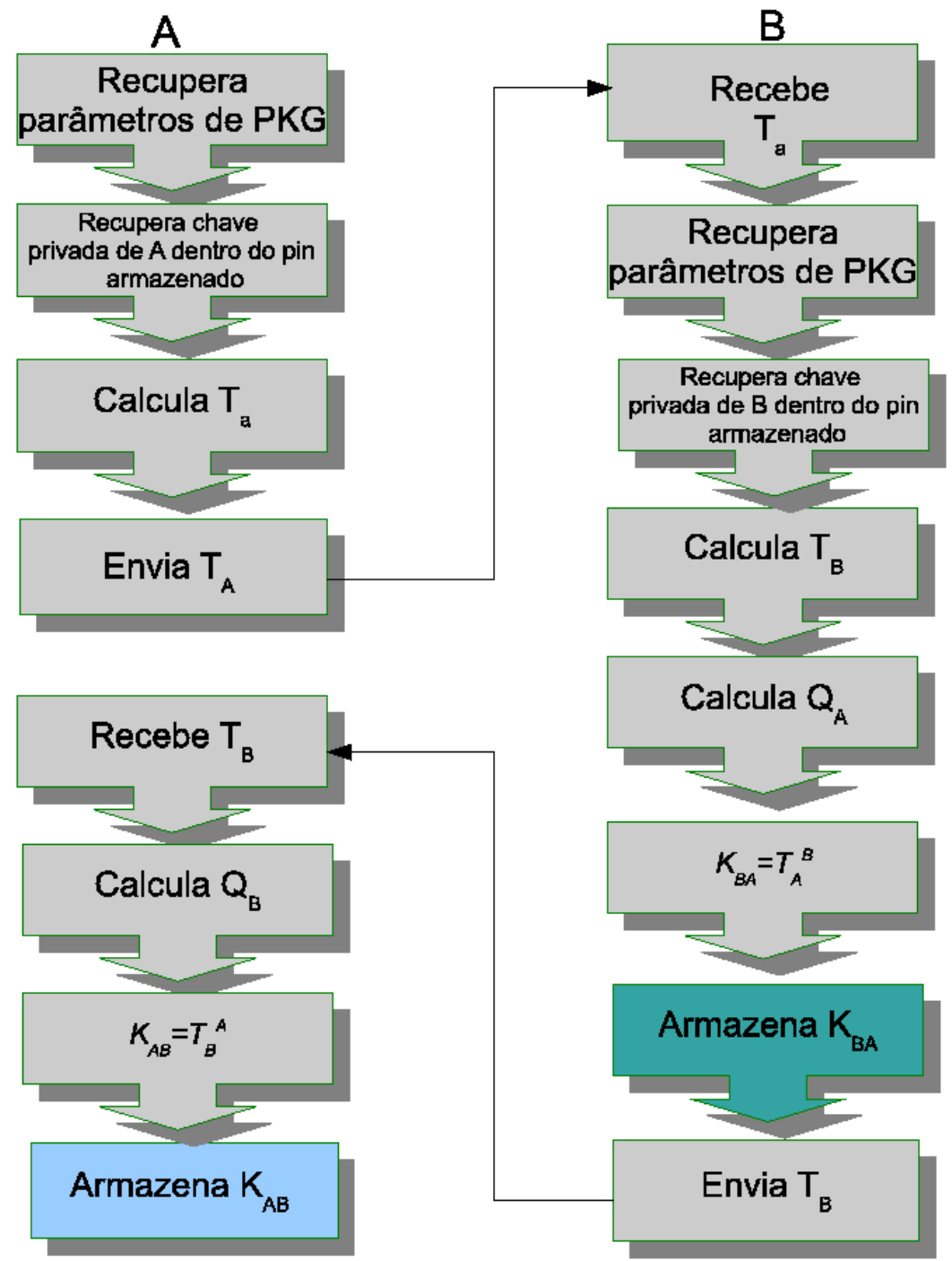

Figura 2.6: Diagrama de atividades do esquema de Scott.

\subsubsection{Esquema de Shim}

O esquema proposto por Shim (2003) apresenta um protocolo de acordo de chave eficiente através de modificações sugeridas no modelo de (SMART, 2002) com fases idênticas em INICIALIZA e EXTRAI.

- INICIALIZA: O PKG escolhe uma chave secreta $s \in 1, \ldots l$ que é na ordem do subgrupo de primo grande sobre uma curva elíptica. Computa a chave pública 
calculando $P_{p} u b=s P$. Isso também especifica uma função hash $\mathrm{m} 2 \mathrm{p}$ da seguinte forma: $H_{1}: Z_{q}^{*} \rightarrow G_{1}$ e os parâmetros de $\left\langle G_{1}, G_{2}, e, P, P_{p} u b, H_{1}\right\rangle$ e $s$ como a chave mestra.

- EXTrai: Para um usuário com a identidade $I D$, é dada a chave pública $Q_{A}=$ $H_{1}(I D)$ e o PKG gera a chave privada associada, calculando $S_{A}=s Q_{A}$.

- ACORDO DA CHAVE: O acordo da chave será feito da seguinte forma:

1. A escolhe $a \in Z_{q}^{*}$ de forma randômica, computa $T_{A}=a P$ e envia $T_{A}$ para $B$.

2. $B$ escolhe $b \in Z_{q}^{*}$ de forma randômica, computa $T_{B}=b P$ e envia $T_{B}$ para $A$.

3. A computa o segredo compartilhado $K_{A B}=e\left(a P_{p u b+S_{A}, T_{B}+Q_{B}}\right)$.

4. De forma semelhante, $B$ computa o segredo compartilhado:

$$
K_{B A}=e\left(b P_{p u b+S_{B}, T_{A}+Q_{A}}\right)
$$

5. Se ambos seguirem esse protocolo, calcularão o mesmo segredo compartilhado:

$$
K_{A} B=K_{B} A=e\left(P_{p u b}, a Q_{B}+b Q_{A}+a b P\right) e\left(Q_{A}, Q_{B}\right)^{s}
$$

A figura 2.7 apresenta a seqüência de atividades realizadas no esquema de Shim. Dessa forma, $A$, recupera os parêmetros de PKG e recupera a sua chave privada e logo calcula $T_{A}$ e envia para $B$. Assim, o $B$, recupera os parâmetros de PKG e recupera a sua chave privada e calcula $T_{B}$. Logo, $B$ pode calcular $m 2 p$ de $A$ e calcula então $K_{B A}$ e em seguida o armazena. Após armazenar o $K_{B A}$, envia $T_{B}$ para $A$.

A partir desse valor, $A$, calcula $m 2 p$ de $B$ e, em seguida, $K_{A B}$ e o armazena.

\subsubsection{Esquema de Chen e Kudla}

Chen e Kudla (2003) propuseram um esquema também baseado em Smart (2002), no qual, as fases INICIALIZA e EXTRAI são idênticas.

- INICIALIZA: O PKG escolhe uma chave secreta $s \in 1, \ldots l$. Computa a chave pública calculando $P_{p u b}=s P$. Isso também especifica uma função hash $\mathrm{m} 2 \mathrm{p}$ da 
A
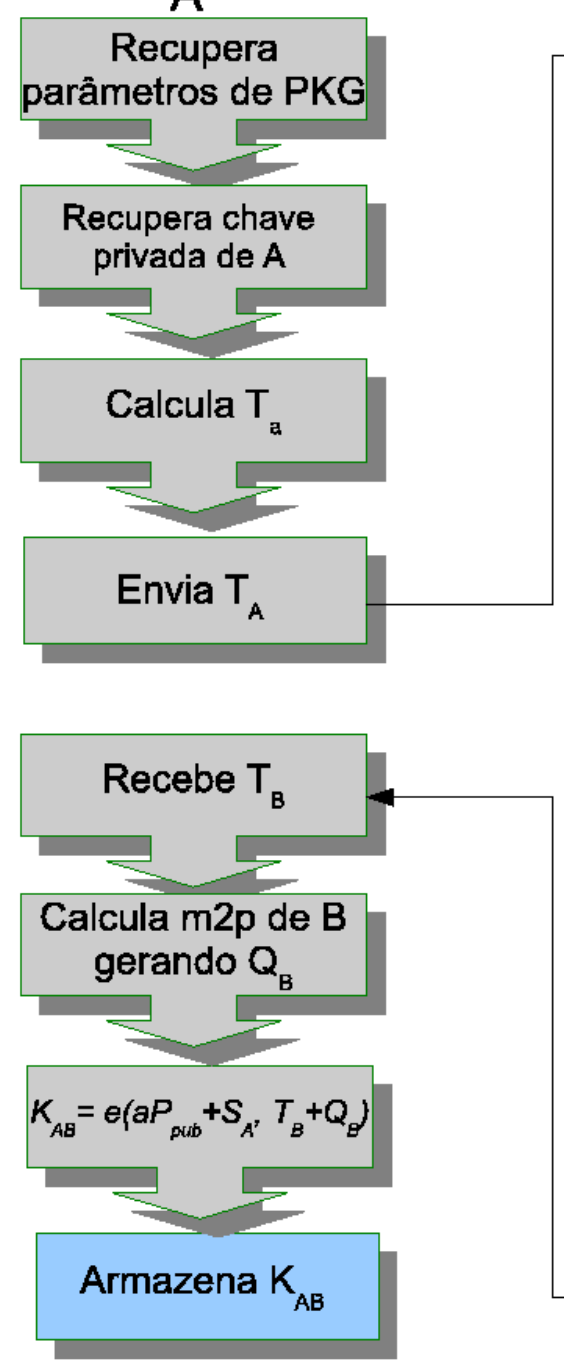

B

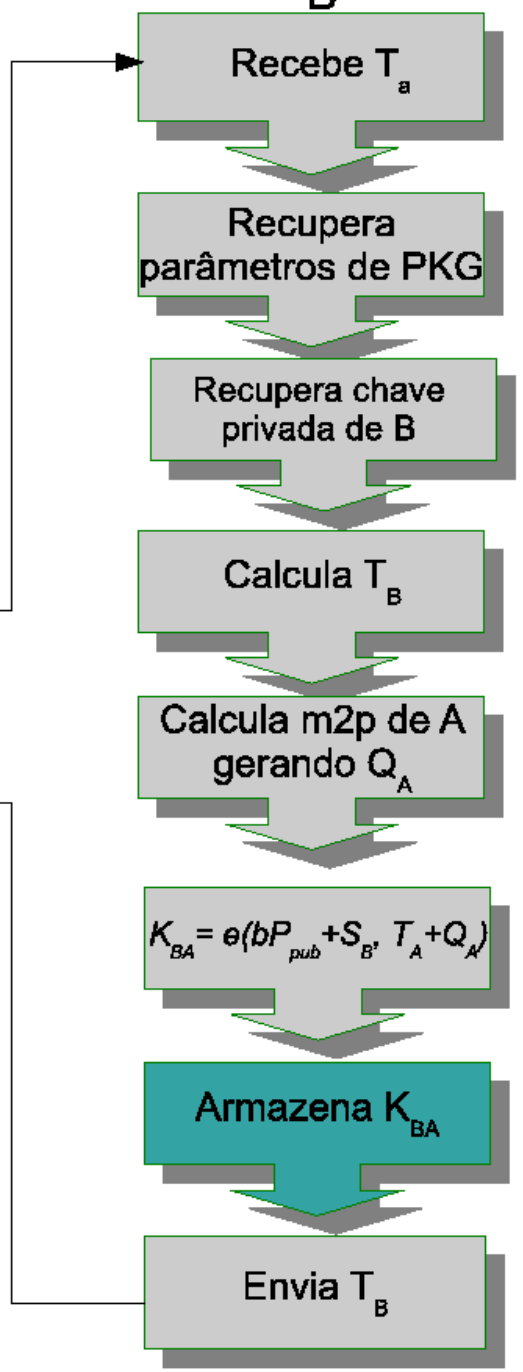

Figura 2.7: Diagrama de atividades do esquema de Shim. 
seguinte forma: $H_{1}: Z_{q}^{*} \rightarrow G_{1}$ e os parâmetros de $\left\langle G_{1}, G_{2}, e, P, P_{p u b}, H_{1}\right\rangle$ e $s$ como a chave mestra.

- EXTRAi: Para um usuário com a identidade $I D$ é dada a chave pública por $Q_{A}=H_{1}(I D)$ e o PKG gera a chave privada associada, calculando $S_{A}=s Q_{A}$.

- ACORDO DA CHAVE: O acordo da chave será feito da seguinte forma:

1. A escolhe $a \in Z_{q}^{*}$ de forma randômica, computa $T_{A}=a Q_{A}$ e envia $T_{A}$ para $B$.

2. $B$ escolhe $b \in Z_{q}^{*}$ de forma randômica, computa $T_{B}=b Q_{B}$ e envia $T_{B}$ para A.

3. A computa o segredo compartilhado $K_{A B}=e\left(S_{A}, T_{B}+a Q_{B}\right)$ e de forma semelhante, $B$ computa $K_{B A}=e\left(T_{A}+b Q_{A}, S_{B}\right)$. Se ambos seguirem este protocolo, calcularão o mesmo segredo compartilhado:

$$
K_{A} B=K_{B} A=e\left(Q_{A}, Q_{B}\right)^{s(a+b)}
$$

A figura 2.8 apresenta a sequiência de atividades realizadas no esquema de Chen e Kudla. Dessa forma, $A$, recupera os parêmetros de PKG e recupera a sua chave privada e logo calcula $T_{A}$ e envia para $B$. Assim, o $B$, recupera os parâmetros de PKG e recupera a sua chave privada e calcula $T_{B}$. Logo, $B$ pode calcular $m 2 p$ de $A$ e calcula então $K_{B A}$ e em seguida o armazena. Após armazenar o $K_{B A}$, envia $T_{B}$ para $A$.

A partir desse valor, $A$, calcula $m 2 p$ de $B$ e, em seguida, $K_{A B}$ e o armazena.

\subsubsection{Esquema de McCullagh e Barreto}

McCullagh e Barreto (2004b) propõem um esquema eficiente de acordo da chave. O esquema se destaca pela possibilidade de instanciamento com ou sem custódia da chave, sem a necessidade de ter mais passos no seu esquema. O esquema apresentado aqui é baseado na custódia da chave.

- INICIALIZA: O PKG escolhe uma chave secreta $s \in Z_{q}^{*}$ e calcula a chave pública como $P_{p u b}=s P$. Além disso, especifica uma função hash $H_{1}:\{0,1\}^{*} \rightarrow Z_{q}^{*}$. Os 
A
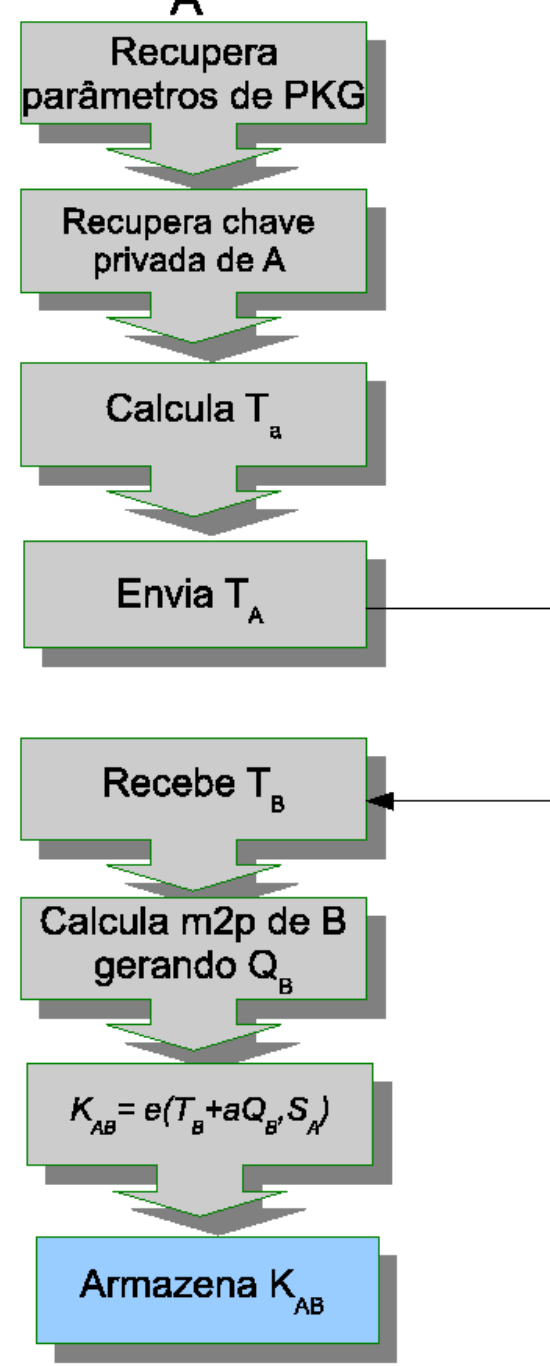

B

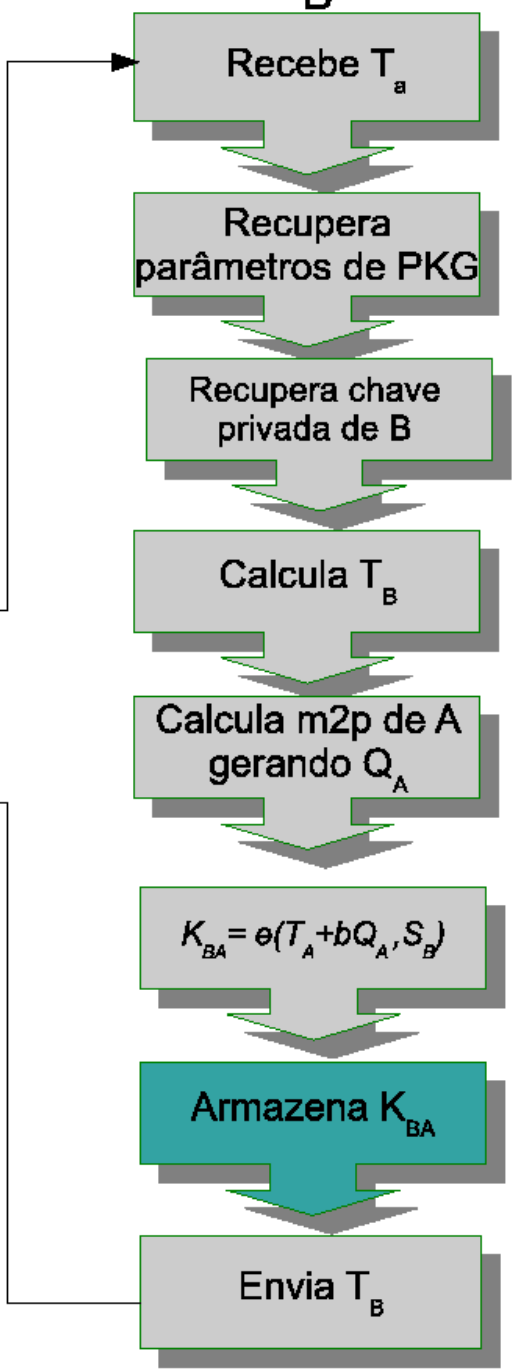

Figura 2.8: Diagrama de atividades do esquema de Chen e Kudla. 
parâmetros do sistema e a chave pública são distribuídos para os usuários através de canais autenticados.

- EXTRAI: O PKG verifica a identidade $I D_{A}$ de um usuário $A$ e calcula a respectiva chave privada $Q_{A}=(a+s) P$, onde $a=H_{1}\left(I D_{A}\right)$. Além disso, $Q_{A}$ poderá ser computado calculando $a P+P_{p u b}$. O PKG então calcula a chave privada de $A$ calculando $S_{A}=(a+s)^{-1} P$.

- ACORDO DA CHAVE: O acordo da chave será feito da seguinte forma:

1. A escolhe $x_{a} \in Z_{q}^{*}$ de forma randômica, computa $T_{A}=x_{a} Q_{B}$ e envia $T_{A}$ para $B$.

2. $B$ escolhe $x_{b} \in Z_{q}^{*}$ de forma randômica, computa $T_{B}=x_{b} Q_{A}$ e envia $T_{B}$ para A.

3. A computa $K_{A B}=e\left(T_{B}, S_{A}\right)^{x_{a}}$ e, de forma semelhante, $B$ computa $K_{B A}=$ $e\left(T_{A}, S_{B}\right)^{x_{b}}$. Se ambos seguirem esse protocolo, calcularão o mesmo segredo compartilhado:

$$
K_{A} B=K_{B} A=e(P, P)^{x_{a} x_{b}}
$$

A figura 2.9 apresenta a seqüência de atividades realizadas no esquema de $\mathrm{McCul-}$ lagh e Barreto. Dessa forma, $A$, recupera os parêmetros de PKG e recupera a sua chave privada e $\log$ o calcula $T_{A}$ e envia para $B$. Assim, o $B$, recupera os parâmetros de PKG e recupera a sua chave privada e calcula $T_{B}$. Logo, $B$ pode calcular $m 2 p$ de $A$ e calcula então $K_{B A}$ e em seguida o armazena. Após armazenar o $K_{B A}$, envia $T_{B}$ para $A$.

A partir desse valor, $A$, calcula $m 2 p$ de $B$ e, em seguida, $K_{A B}$ e o armazena. Vale a pena salientar a eficiência desse esquema, comparado com o esquema proposto por Chen e Kudla (2003) sem a necessidade de pré-computação.

\subsubsection{Comparativo de esquemas de acordo da chave}

A tabela 2.6 ilustra as diversas operações que são utilizadas nos esquemas de acordo da chave baseado em IBE. 


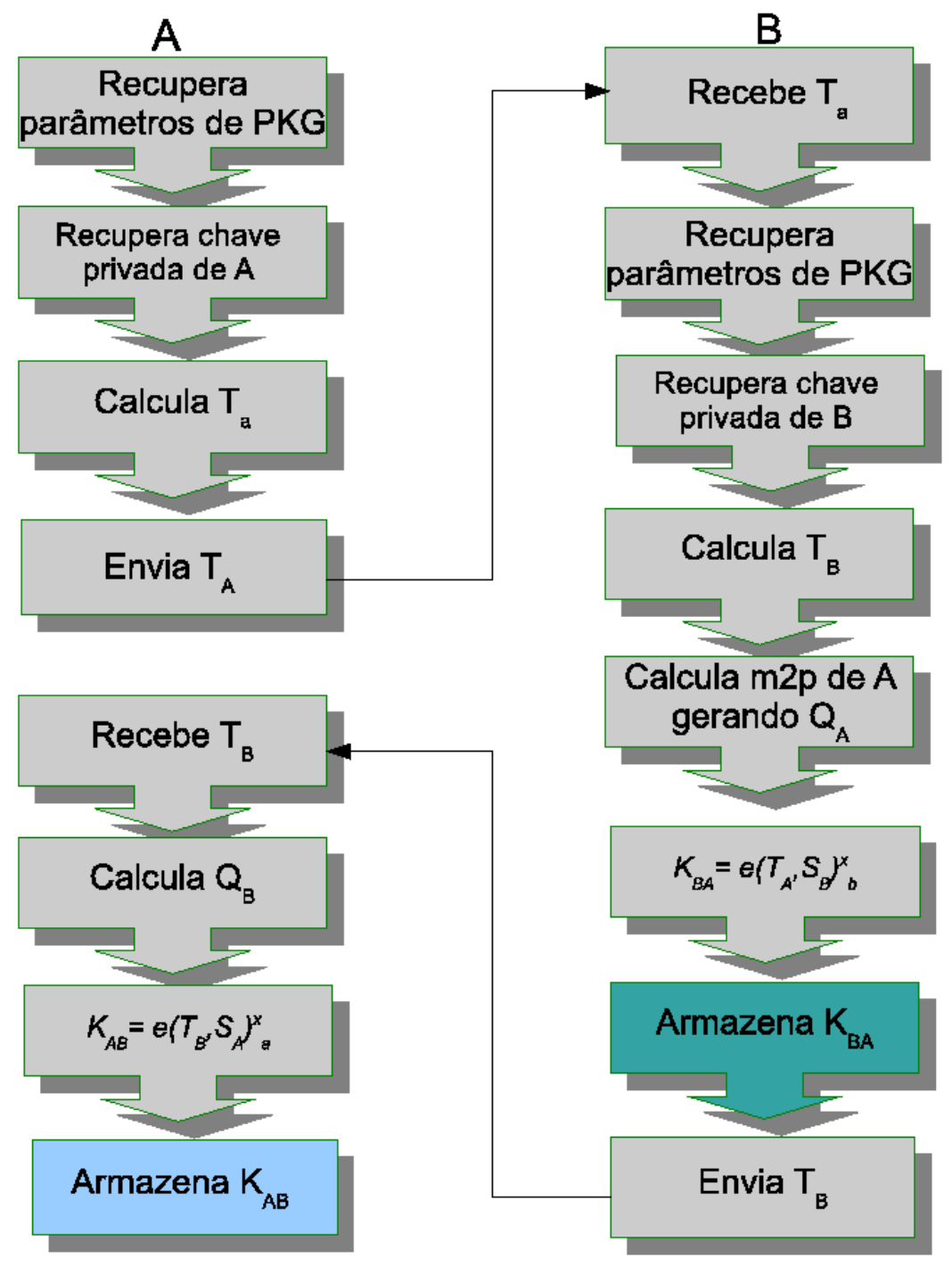

Figura 2.9: Diagrama de atividades do esquema de Barreto.

Tabela 2.6: Comparativo de esquemas de acordo da chave.

\begin{tabular}{lccccccc}
\hline Esquema & (M s) & (exp gr) & (exp) & $($ gr +) & (emp) & (h m2p) & (p a) \\
\hline Smart & 2 & - & - & - & 2 & 1 & - \\
Scott & - & 2 & - & 1 & 1 & 1 & - \\
Shim & 2 & - & - & - & 1 & 1 & 2 \\
Chen e Kudla & 2 & - & - & 1 & 1 & 2 & - \\
McCullagh e Barreto & 2 & - & 1 & 1 & 1 & - & - \\
\hline
\end{tabular}




\subsection{Aplicabilidade de IBE em diversas áreas}

Os criptossistemas baseados em identidade podem ser utilizados em diversos produtos e aplicações. O apêndice A apresenta alguns produtos e aplicações que utilizam IBE. O objetivo desta seção é apresentar as cinco aplicabilidades que IBE possui. Mont e Bramhall (2003) comentam as diversas áreas em que IBE poderá ser aplicada.

\subsubsection{Integração de PKI e IBE}

Anderson Ross em Anderson (2002) comenta que qualquer sistema de IBE pode ser adaptado de modo que seja mais seguro de modo que atenda o Forward Security ${ }^{19}$. O critério de Forward Security é um critério bastante desejável para esquemas de IBE e poderá reduzir ou amenizar o problema de custódia da chave, algo de convívio natural de maiora de esquemas de IBE.

A idéa do Anderson (2002) consiste em que o proprietário da chave aja como uma Autoridade Certificadora em um esquema de IBE e gere as chaves privadas correspondentes as identidades conforme a regra pré-estabelecida no esquema de IBE.

Através de Anderson (2002) é possível usufruir as vantagens de integração de um sistema de PKI com um sistema de IBE.

\subsubsection{Serviços com Disponibilidade Temporal}

Um dos problemas que alguns tipos de informações confidenciais enfrentam é o momento exato em que a mesma informação poderá ser divulgada ou disponibilizada. Em alguns casos, uma certa informação somente terá validade em um certo momento pré-estabelecido, nem antes e nem depois disso, tal informação poderá ser considerada confiável.

Alguns exemplos de ambientes em que IBE poderá ser aplicado são:

1. Em um ambiente de negócios, no qual, as informações confidenciais são utilizadas pelos gerentes e alguns grupos específicos. Freqüentemente, algumas partes

\footnotetext{
${ }^{19}$ Forward Security pode ser definido da seguinte forma: O comprometimento de uma chave não necessariamente expõe o tráfego de dados
} 
ou todas essas informações, poderão ser divulgadas aos empregados e partes interessadas, em datas pré-estabelecidas e horários já definidos anteriormente, conforme as regras do negócio e restrições legais.

2. Em leilões, onde o proprietário do negócio, somente poderá acessar e divulgar as ofertas dadas pelos participantes depois de terminar o tempo pré-estabelecido de negociações.

3. A apresentação de autor desta tese, que será disponibilizada após final da tese.

4. A locação virtual de um filme que será feita por download e somente funcionará no período da locação, como se fosse o ingresso de um filme.

Em geral, qualquer serviço, cuja disponibilização seja condicionada a tempo poderá ser enquadrada nos serviços com disponibilidade temporal. A abordagem criptográfica para serviços com disponibilidade temporal faz uso de geradores de chaves confiáveis. A desvantagem nesse modelo é o custo em termos de recursos de CPU, armazenamento, entre outros, a ser utilizada pelos agentes confiáveis. Uma outra alternativa é não utilizar os geradores de chaves para armazenamento das informações dadas aos usuários. Sua tarefa principal é publicar periodicamente um valor previamente secreto. A desvantagem, nesse caso, é que os usuários devem interagir com o gerador de chaves todas as vezes que necessitarem cifrar um documento confidencial (MONT; BRAMHALL, 2003).

\subsubsection{Gerenciamento Responsável de Informações Pessoais}

O problema discutido nesta área visa reforçar a confidencialidade de informação secreta em contextos dinâmicos, onde os papéis e permissões são sujeitos as mudanças freqüentes. Normalmente, as políticas ditam os termos e as condições, sob quais informações confidenciais poderão ser acessadas ou não. O aspecto importante do problema em questão é assegurar que tais políticas sejam reforçadas e não possam ser subvertidas (MONT; BRAMHALL, 2003).

Outro caso comentado em Mont e Bramhall (2003) se refere a tornar as organizações mais responsáveis no manuseio de informações pessoais, deixando-as mais confiantes no que diz respeito ao controle da sua informação pessoal. Além disso, Mont 
e Bramhall (2003) citam o comércio eletrônico como exemplo, onde os usuários fornecem a sua identidade para um site de comércio eletrônico para acessar os serviços, normalmente após aceitar um certo tipo de privacidade de dados.

\subsubsection{Pesquisa de Palavras-Chave em Dados Cifrados}

A proteção de base de dados tem sido um problema de segurança presente em muitos ambientes. O emprego de mecanismos criptográficos para aumento de proteção na base de dados tem auxiliado em alguns cenários. Uma das operações mais comuns em uma base de dados é a procura por um registro, campo ou palavra. Dessa forma, em uma base de dados cifrados, a procura por palavras-chave tem se tornado um desafio para os programadores para não exporem ou não decifrarem toda a base de dados para que a procura tenha o seu resultado esperado.

Um dos problemas encontrados em uma base de dados cifrados, é a dificuldade de pesquisar palavras-chave, ou um conteúdo específico, pois nessas ocasiões há necessidade de decifrar todos os registros, até que seja encontrada a palavra chave procurada. Dessa forma, toda ou uma parte da base de dados fica vulnerável e exposta às pessoas não devidamente autorizadas.

\subsubsection{Trabalhos relacionados}

A primeira solução prática para o problema de busca em dados cifrados foi introduzido por Song, Wagner e Perrig (2000). Nesse modelo, os documentos são cifrados palavra por palavra, utilizando um modelo cujo servidor tem a capacidade de pesquisar um documento cifrado e determinar se tal palavra existe ou não no documento específico. Após a proposta de Song, Wagner e Perrig (2000), outros esquema de busca cifrada foram propostos, sendo relacionados em (BONEH et al., 2004; BONEH; WATERS, 2007; WATERS et al., 2004; ABDALLA et al., 2005; OHTAKI, 2005; KHADER, 2006; ATTRAPADUNG et al., 2006).

Boneh et al. (2004) definiram o conceito de criptografia de chave pública com busca de palavras-chave. Por exemplo, quando um usuário envia um conjunto de mensagens cifradas e deseja que seja dada prioridade na sua mensagem que contenha palavra chave urgente, o servidor de envio de mensagens poderá procurar por esta palavra 
chave e enviar a mensagem que contenha esta palavra antes das outras mensagens, sem ter conhecimento do seu conteúdo. Os autores implementaram o modelo conforme recentes implementações de criptografia baseado em identidade.

Boneh e Waters (2007) apresentam um esquema para construção de sistemas de criptografia de chave pública com busca de dados cifrados com várias famílias de predicados. Além disso, os autores apresentam sistemas que permitem realizar consultas comparativas em vários conjuntos de consultas.

Abdalla et al. (2005) definiram diversos conceitos relacionados à busca de palavraschave em esquemas de cifração. A principal contribuição dos autores é apresentar a transformação de um esquema anônimo de cifração baseado em identidade em um esquema seguro de criptografia de chave pública com busca de palavras-chave.

Abdalla et al. (2005) destacaram alguns conceitos de busca cifrada da seguinte forma:

1. Public Key Encryption with Keyword Search (PEKS) - : Criptografia de chave pública com busca por palavra chave.

2. Public Key Encryption Temporary Keyword Searchable (PETKS) - : disponibiliza palavras-chave para buscas somente num determinado período de tempo.

3. Identity-Based Encryption with Keyword Search (IBEKS) - : Criptografia baseada em identidade com busca de palavras-chave, combinando os conceitos de criptografia baseada em identidade e PEKS para obter criptografia baseada em identidade com busca de palavras-chave. Semelhante aos esquemas baseados em identidade, este permite utilizar qualquer texto como chave pública do receptor para o esquema PEKS.

Ohtaki (2005) apresentou um modelo de busca em registros (arquivos de log) cifrados, utilizando índices invertidas cifradas. O processo de inversão de índices reduz o tempo de busca por palavras-chave. Ohtaki implementou um protótipo de sistema em questão para mostrar a sua eficiência.

Khader (2006) reforça como os algoritmos de IBE podem ser utilizados para construção de esquemas PEKS, e dessa forma, a estrutura de um esquema PEKS será muito 
semelhante a uma estrutura genérica de IBE. A maior contribuição do autor é a proposta da construção de PEKS a partir de IBE e apresentar as noções de segurança desse modelo.

Attrapadung et al. (2006) apresenta um modelo de busca cifrada que é baseada em propagação de segurança e cifração por difusão ${ }^{20}$. O esquema de cifração por difusão permite que um difusor possa cifrar uma mensagem para um subconjunto designado de usuário em um ambiente específico. Qualquer usuário, nesse subconjunto, poderá decifrar a mensagem utilizando a sua chave privada, enquanto os outros usuários não pertencentes a esse subconjunto não deveriam ser capaz de fazê-lo. A maior contribuição dos autores é a criação de um primitivo que poderá ser considerado como a generalização de cifração por difusão que inclui também a questão de hierarquia em um esquema de criptografia baseado em identidade. Waters et al. (2004) descreveram uma abordagem para construção de esquemas de busca em registros (arquivos de log) de auditoria que utiliza a cifração baseada em identidade. A principal contribuição dos autores é a aplicabilidade prática do esquema proposto.

O principal objetivo do log é saber a situação atual de um sistema, quais rotinas estão sendo executadas, e quais rotinas o sistema já executou. Atualmente, vários sistemas incluem a opção de $\log$, a fim de verificar possíveis problemas durante a execução de processos, identificar possíveis tentativas de ataques ou até mesmo identificar ataques sucedidos que não foram descobertos até então.

Juntamente com as informações dos usuários que tiveram acesso a um sistema qualquer, ou até mesmo, todas as atividades que um usuário efetuou no sistema podem ser registradas para futuras consultas, algumas informações podem ser de grande importância para a organização e talvez seja perigoso mantê-las em um arquivo de acesso geral, ou em um banco de dados que pessoas mal intencionadas possam ter acesso a fim de roubar informações.

Para isso, muitas empresas acabam criando verdadeiras muralhas para guardar seus $\log s$, evitando assim que qualquer usuário tenha lhes acesso. Outras empresas também usam a prática de cifrar a base de dados para que os usuários não autorizados não possam ter acesso a tal informação, e dessa forma, não possam compreendê-la e não a

\footnotetext{
${ }^{20}$ adequação do autor para português dos respectivos termos em inglês Forward-secure e Broadcast Encryption.
} 
utilizem de forma incorreta.

O problema de cifrar base de dados ou logs é na hora de efetuar buscas a fim de analisar as atividades efetuadas ou analisar um período qualquer, pois, para poder compreender o log é necessário decifrar todas as informações contidas nele, tornando o processo, além de lento, inseguro, pois caso algum usuário mal intencionado tenha acesso aos dados decifrados, poderá colocar em risco as informações da empresa.

Waters et al. (2004), apresenta como fazer um sistema de logs onde é possível tê-los cifrados, efetuar buscas por palavras-chave na base de dados cifrado e decifrar todos os dados referentes a um registro qualquer.

A entidade que armazena as chaves pode designar para qualquer usuário, que será chamado de investigador, a possibilidade de consultar por palavras-chave que não lhe pertençam, isso é conhecido como delegação de capacidade de busca, onde a entidade que armazena as chaves pode ceder acesso a usuários específicos conforme critérios pré-estabelecidos.

Na criptografia simétrica, fazer uma busca em um banco de dados cifrado é fácil, pois o banco de dados inteiro possui apenas uma chave, que é compartilhada por todos os registros. Com isso, não se-consegue garantir o legítimo proprietário de uma informação (registro), fazendo com que qualquer pessoa tenha acesso à informação.

Utilizando o esquema de criptografia assimétrica, como a criptografia baseado em identidade, por exemplo, somente o legítimo proprietário da informação poderá acessar aquele dado. No caso de se fazer necessário um usuário buscar informações que não sejam a respeito daquele usuário, o módulo gerador de chaves poderá conceder permissão ao usuário, como visto anteriormente, a delegação de capacidade de busca.

\subsubsection{Características de $\log$ de auditoria seguro}

As características principais do $\log$ de auditoria seguro, segundo Waters et al. (2004), são: 


\subsubsection{Proteção de Registros}

O log de auditoria seguro foi feito para prevenir a inserção de logs não desejados, garantindo assim que nenhum outro usuário, além do criador do registro do log, poderá inserir, remover ou alterar registros existentes.

\subsubsection{Verificabilidade}

É possível verificar todas as entradas do log presentes e que não foram alteradas. Para verificar um log auditor existem duas maneiras:

1. Cada entrada no log auditor conterá informações para garantir sua autenticidade. Se algumas entradas foram alteradas ou excluídas, serão detectadas, pois os dados são gravados cifrados. Caso alguma informação foi perdida ou modificada, é possível verificar as demais entradas para recuperar alguma informação útil no $\log$ danificado.

2. Os registros devem ser ligados a ponto de ser possível determinar se algum registro está faltando. Poderia se adotar, por exemplo, a utilização de um número de série para identificar se todos os registros estão presentes.

\subsubsection{Controle de Acesso aos Dados de Busca}

O controle de acesso e o controle de buscas no log de auditoria seguro é possível, sendo que este é cifrado, onde as atividades de controlar o acesso é feito através da custódia da chave privada do usuário que gravou o dado. No controle de buscas é introduzido o conceito de delegação de capacidades, onde o PKG pode fornecer a um investigador a possibilidade de efetuar buscas por palavras no banco de dados cifrado. Para a delegação ser considerada segura, enquanto não for delegada a possibilidade a um usuário, o mesmo não poderá visualizar informações que não lhe pertençam.

\subsubsection{Notações e Componentes do Log Auditor}

Utilizando um exemplo prático, onde se faz necessário registrar todas as informações dos usuários que estão acessando um ou mais banco de dados SQL. A log de 
auditoria consiste em uma série de registros de log individuais, cada registro de log possui:

1. Criptografia dos dados com uma chave $K_{i}$, com um metadata, que é a identidade do usuário, opcionalmente também pode conter o resultado da consulta executada. $\mathrm{O}$ valor de $K_{i}$ é gerado aleatoriamente para cada registro;

2. $H\left(R_{i}-1\right)$ o hash do registro anterior, a fim de manter uma corrente de hash;

3. Palavras-chave $\left(w_{a}, w_{b}, w_{c}\right)$ que poderão ser utilizadas na busca $\left(c_{w_{a}}, c_{w_{b}}, c_{w_{c}}\right)$;

4. hash da data atual.

\subsubsection{Extração de palavras-chave}

A Figura 2.10 demonstra como acontece a extração das palavras-chave. Além das informações extraídas da operação executada, são extraídas meta informações do usuário que executou a consulta, a data e a hora. Lembrando que as palavras-chave são categorizadas, e as buscas não precisam ser feitas apenas pelas palavras-chave, mas também pelas meta informações do usuário (identidade do usuário que efetuou a busca, por exemplo) ou pela data ou hora.

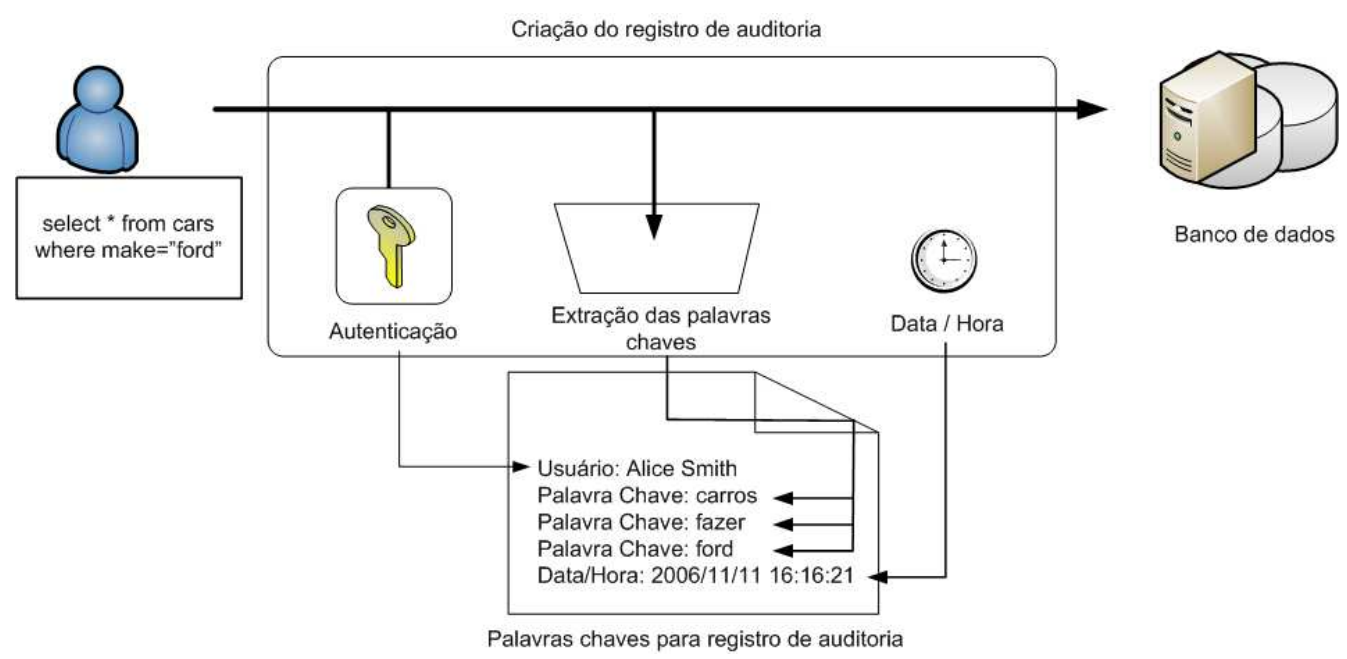

Figura 2.10: Esquema de busca de dados cifrados. Adaptado de Waters et al. (2004) 


\subsubsection{Componentes do Sistema de Busca de Dados Cifrados}

Os principais componentes do auditor de log seguro conforme Waters et al. (2004) são:

1. INICIALIZA: Inicialmente é configurada a instância do IBE utilizado. No sistema, o agente auditor escravo é determinado o IBE master secret $s$, e todos os servidores que contribuem para o auditor de log são determinados pelo parâmetro do sistema $P$.

2. CIFRA: Suponha que o servidor está cifrando a entrada do $\log m$, juntamente com as palavras-chave $w_{1}, w_{2}, \ldots w_{n}$. O servidor executa os seguintes passos:

(a) O servidor escolhe aleatoriamente uma chave simétrica $K$, para ser usada somente para está entrada do log;

(b) O servidor cifra o dado utilizando $K$, para possuir $E_{k}(m)$;

(c) Para cada palavra chave $w_{1}$, o servidor processa o IBE $c_{1}$ do texto (flag|K) usando $w_{1}$ como chave pública e $P$ como parâmetros públicos;

(d) $\mathrm{O}$ servidor escreve $E_{K(m)}, c_{1}, c_{2}, \ldots, c_{n}$ como entrada no $\log$ de auditoria.

A única forma de voltar algum registro do log é decifrar a palavra chave $c_{1}$ e obter a chave simétrica $K$.

3. BUSCA E DECIFRA: Para efetuar a busca de uma palavra chave, um investigador irá solicitar a delegação para poder pesquisar a palavra $w$. Se o agente auditor aprovar, ele irá retornar $d_{w}$ que representa a chave privada IBE da palavra chave $w$. Para cada registro do log, o investigador executa os passos seguintes:

(a) Para cada $c_{1}$, o investigador tenta decifrar usando a chave privada IBE, se o prefixo do resultado é semelhante a flag, então o investigador extrai chave $K$, caso contrário partirá, para o próximo registro;

(b) Se um dos resultados for semelhante a flag, então é computado $K$ para decifrar $E_{K}(m)$ para obter $m$. 
Como exemplo, pode-se citar o caso de um arquivo de registro de auditoria que contém as atividades realizadas sobre uma base de dados. A cifração da base de dados, reduz-lhe as vulnerabilidades e traz a garantia de que as pessoas não autorizadas, não terão acesso a tais dados. No momento em que haja necessidade de utilizar os registros de auditoria, tais dados devem ser decifrados até que o registro específico seja encontrado.

Para resolver esse problema, Waters et al. (2004) propõem a implementação de um mecanismo de procura por palavras-chave em dados cifrados através da utilização do IBE. Este modelo implementa diversos níveis de delegação, no qual a pessoa que fará auditoria, terá apenas permissão para visualizar (decifrar) os registros que lhe foram delegado a custódia da auditoria por palavras-chave. A figura $2.11^{21}$ ilustra este cenário.Conforme a figura, percebe-se que o auditor está a procura da palavra-chave Honda, mas os dados cifrados, nos quais, ele tem a custódia da procura, possuem outras palavras-chave. Dessa forma, sem a revelação das informações contidas nestes dados cifrados, ele saberá que tal palavra-chave não se encontra.

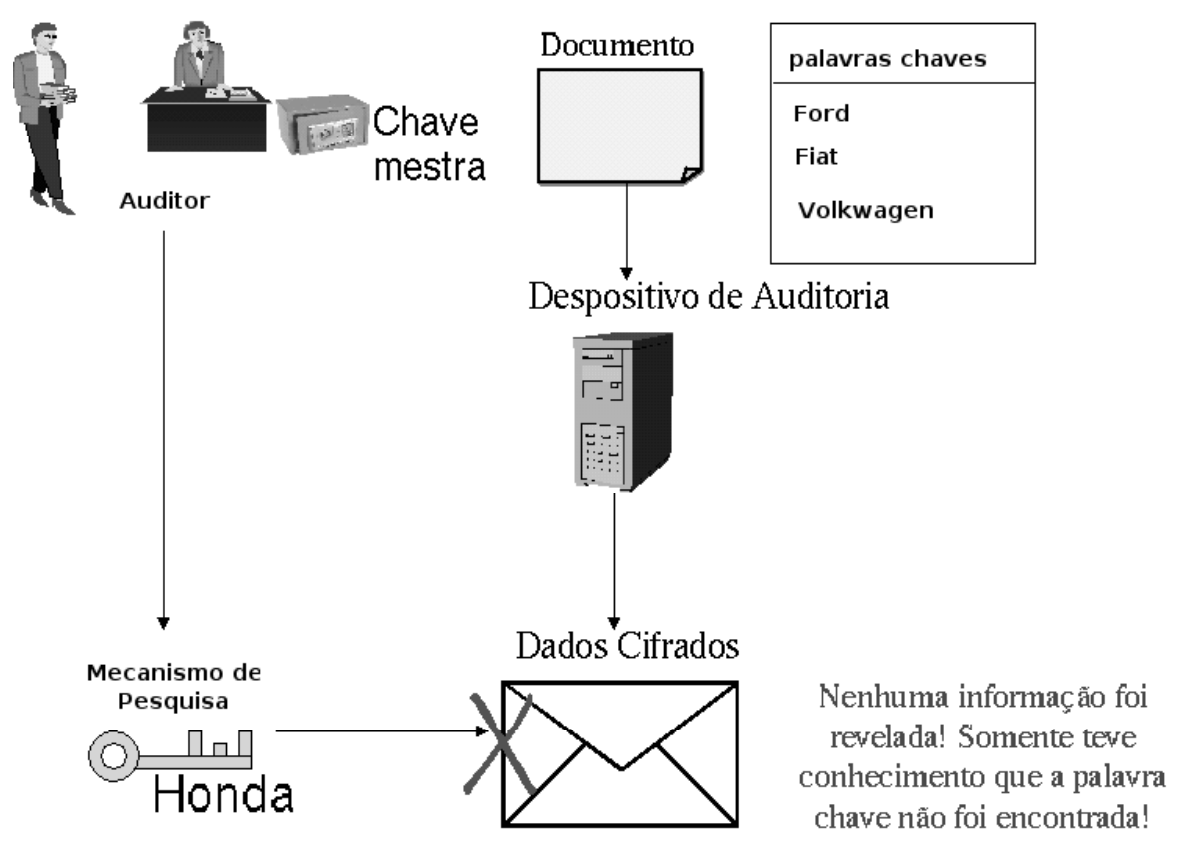

Figura 2.11: Pesquisa de palavras-chave em dados cifrados. Conforme a figura, percebe-se que o auditor está a procura da palavra-chave Honda, mas os dados cifrados, nos quais, ele tem a custódia da procura, possuem outras palavras-chave. Dessa forma, sem a revelação das informações contidas nestes dados cifrados, ele saberá que tal palavra-chave não se encontra.

\footnotetext{
${ }^{21}$ figura alterada de (WATERS et al., 2004).
} 


\subsubsection{Redes Tolerantes a Atraso}

Redes Tolerantes de Interrupção e Atraso ou Disruption-and Delay-Tolerant Networks (DTN) são redes que, por algum motivo, são desconectadas, interrompidas ou têm um certo atraso na entrega de pacotes. Nesses tipos de redes, IBC tem contribuído de forma significativa no diz respeito à confidencialidade, conforme Asokan et al. (2007). Tais redes podem ser redes ponto a ponto, fim a fim, redes em áreas rurais ou podem usar roteadores móveis em redes sensores. Podem ser em uma grande área de extensão ou até debaixo da água. Tais redes apresentam constantemente uma conectividade intermitente com grande atraso e muitos erros de conexão em diferentes arquiteturas de redes existentes.

Conforme Asokan et al. (2007), a aplicabilidade de IBC na DTN se restringe ao aspecto da confidencialidade quando comparado com a utilização da criptografia convencional. A adoção de IBC na DTN, para assegurar a confidencialidade, é uma solução eficiente em termos de carga no servidor e requisitos de rede para outros recipientes, pois uma infra-estrutura de DTN, por ser uma mais escassa, móvel, sujeita a interferência e extremamente mais barata, comparada a uma infra-estrutura de tempo real, funciona de forma adequada com uma carga menor no servidor, bem como exige menos em termos de requisitos de um servidor.

\subsection{Parâmetros de Desempenho}

Um parâmetro de desempenho ilustra, de forma quantitativa, o comportamento de um sistema em questão, com o objetivo de comparar com outros sistemas. Um conjunto de parâmetros de desempenho visa apresentar um comparativo global do sistema em questão com os outros sistemas semelhantes. Tais comparações auxiliam no planejamento correto de infra-estrutura computacional para se ter uma implementação viável e com qualidade de serviço esperado. A escolha de parâmetros de desempenho deve ser adequada para poder garantir a qualidade de serviço esperado.

Conforme apresentado nas seções 2.4 .8 e 2.5.8, os criptossistemas baseados em identidade, nos processos de cifração, decifração e verificação de assinatura, se destacam na utilização de operações de emparelhamento. As operações de emparelhamento normalmente têm custo mais elevado de operação por tempo demasiadamente grande 
em comparação com as outras operações que um criptossistema pode ter. Os testes realizados com MIRACL ${ }^{22}$ apresentam tempo de emparelhamento aproximadamente 2/3 do tempo total de cifração. A figura 2.12 apresenta o resultado de um teste que foi feito com auxílio de MIRACL para apresentar a diferença entre o processo de assinatura em criptografia de curvas elípticas de 256 bits com RSA de 1024 bits.

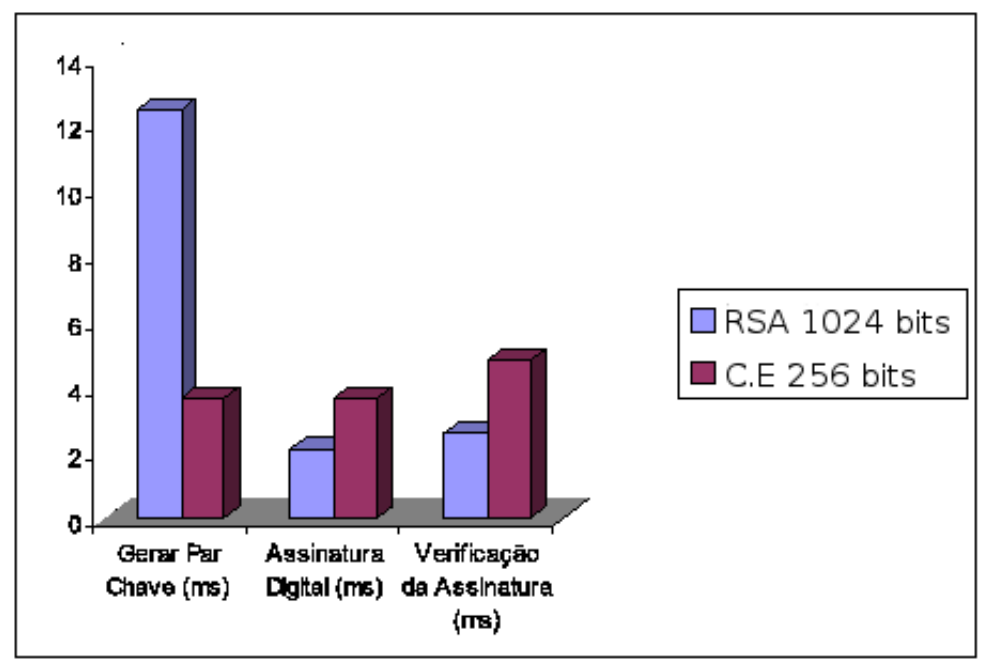

Figura 2.12: Assinatura baseada em curvas elípticas 256 bits X RSA 1024 bits. Esta comparação ilustra a diferença de tempo necessário no processo de assinatura baseado em curvas elípticas de 256 bits com RSA de 1024.

Diversas literaturas citam a respeito da escolha adequada de parâmetros de desempenho (LIM, 2006; GUPTA et al., 2002; HANKERSON; MENEZES; VANSTONE, 2004; SRIVASTAVA, 2005). Alguns parâmetros de desempenho relevantes no campo de criptografia de curvas elípticas, conforme Hankerson, Menezes e Vanstone (2004), Lim (2006) são:

1. Eficiência do Algoritmo: A eficiência de um algoritmo poderá ser medida através de recursos escassos que ele utiliza. Normalmente medido em tempo de resposta, mas, às vezes, outros parâmetros como espaço e quantidade de processos também são considerados.

2. Computação de Emparelhamento: O custo dominante para um esquema de

\footnotetext{
${ }^{22}$ MIRACL (Multiprecision Integer and Rational Arithmetic C/C++ Library) é uma biblioteca com todas as implementações necessárias para uma aplicação de criptografia utilizando grandes números, disponível em http://indigo.ie/ mscott/.
} 
IBE é a avaliação de uma operação de emparelhamento que envolve uma aplicação do algoritmo de Miller ou suas variantes.

3. Seleção de Pontos da Curva: A maioria dos esquemas de criptografia que utilizam curva elíptica necessitam trabalhar em um subgrupo de $E\left(\mathbb{F}_{p^{m}}\right)$ de ordem primo $q$ suficientemente grande de tal forma que $\mathbb{F}_{p^{k m}}$ seja um corpo finito suficientemente grande. Como o mínimo de segurança, é sugerida, $q>2^{160} \mathrm{e}$ $p^{k m}>2^{1024}$.

A operação aritmética relevante dos sistemas que utilizam as curvas elípticas é a Multiplicação Escalar, na qual é calculada $Q=k P$, ou seja, um ponto $P$ multiplicado $k$ vezes, resultando um outro ponto $Q$ na curva. A multiplicação escalar é realizada através da combinação de adição de pontos (dois pontos distintos e duplicação de pontos, que adiciona duas cópias de um ponto), conforme citado por Gupta et al. (2002).

\subsection{Comparativo entre RSA e Criptografia Baseada em Curvas Elípticas}

Esta seção tem por objetivo apresentar um comparativo entre RSA e ECC, principalmente no tamanho da chave. Ambos os esquemas criptográficos podem ter o mesmo nível de segurança, porém com tempo de processamento diferenciados e tamanho da chave diferenciado (GUPTA et al., 2002).

Dependendo da aplicação que se necessita a utilização de criptografia RSA ou ECC, deve-se considerar estes fatores, pois estes poderão ser determinantes para o sucesso do projeto.

As tabelas apresentadas a seguir, são adaptados dos testes realizados em (GUPTA et al., 2002).

Na tabela $2.7^{23}$ é possível notar um diferencial do tamanho das chaves na criptografia RSA e na criptografia ECC, mostrando a equivalência entre as chaves para diferentes tamanhos de chaves criptográficas, onde ambas possuem o mesmo nível de segurança:

\footnotetext{
${ }^{23}$ adaptado de Gupta et al. (2002)
} 
Tabela 2.7: Tamanho da Chave RSA X ECC

\begin{tabular}{cl}
\hline ECC & RSA/DH/DSA \\
\hline 163 bits & 1024 bits \\
283 bits & 3072 bits \\
409 bits & 7680 bits \\
571 bits & 15360 bits \\
\hline
\end{tabular}

Na Tabela 2.7 nota-se que para o esquema criptográfico ECC e RSA (utiliza-se os esquemas de Diffie-Hellman Digital Signature Algorithm (DSA)) terem o mesmo nível de segurança, é preciso terem tamanhos de chaves diferentes.

Com essa vantagem, a criptografia ECC é a mais recomendada para dispositivos móveis e para as redes sem fio, pois com um tamanho de chave reduzido, consegue prover o mesmo nível de segurança que a criptografia RSA, como por exemplo economizando espaço no armazenamento e manipulação, que, normalmente, nesses ambientes, é um recurso limitado.

Na Tabela $2.8^{24}$ mostra-se um comparativo entre os esquemas criptográficos RSA e ECC, ambos foram medidos num computador de $1.5 \mathrm{GHz}$.

Tabela 2.8: Desempenho RSA e ECC medida em computador $1.5 \mathrm{GHz}$.

\begin{tabular}{lrrr}
\hline Algoritmo & Instruções & Operações por Segundo & Diferença Velocidade \\
\hline RSA-1024 & 284.900 & 5.265 & $1.0 \mathrm{x}$ \\
ECC-160p & 117.032 & 12.817 & $2.4 \mathrm{x}$ \\
ECC-163b & 58.236 & 24.756 & $4.9 \mathrm{x}$ \\
ECC-163b-opt & 38.009 & 39.464 & $7.5 \mathrm{x}$ \\
\hline RSA-2048 & 1.906 .884 & 787 & $1.0 \mathrm{x}$ \\
ECC-224p & 245.330 & 6.114 & $7.8 \mathrm{x}$ \\
ECC-233b & 127.365 & 11.772 & $15.0 \mathrm{x}$ \\
\hline
\end{tabular}

Na Tabela 2.8 mediu-se o número de instruções executadas pelo RSA e pelo ECC com diferentes tamanhos de chaves. Para os testes foram comparados o RSA com um tamanho de 1024 bits com o esquema ECC de tamanho 160 bits utilizando corpos primos inteiros e de tamanho 163 bits utilizando corpos binários polinomiais, e o RSA com um tamanho de 2047 bits com o esquema ECC de tamanho 224 bits utilizando corpos primos inteiros e 233 bits utilizando corpos binários polinomiais, onde $p$ é

\footnotetext{
${ }^{24}$ Adaptado de (EBERLE et al., 2004)
} 
$G P(p)$ e $b$ é $G P\left(2^{m}\right)$.

Observando o número de instruções executadas, percebe-se que o RSA efetua menos cálculos por segundo e consecutivamente, demora mais tempo para finalizar as operações. Além disso, comparando o número de operações por segundo, nota-se que o RSA é mais demorado que o ECC, pois efetua menos operações por segundo, sendo essa diferença de tempo bem considerável.

Na coluna 'Diferença Velocidade' é feito um comparativo de velocidade, onde se percebe o quanto mais rápido a criptografia ECC é comparando-a com a criptografia RSA, a criptografia ECC de 233 bits, por exemplo, é 15 vezes mais rápida que a criptografia RSA de 2048 bits.

Na Tabela 2.9 é demonstrado o cálculo de desempenho das operações primitivas do RSA, $\mathrm{ECDH}^{25}$ e ECDSA ${ }^{26}$ usando o OpenSSL0.9.6b. (melhorado para incluir ECC). Os cálculos foram feitos em duas plataformas:

1. Yopy: um PDA com sistema operacional Linux equipado com um processador de 200MHz StrongARM;

2. Ultra 80: Um servidor Sun equipado com um processador de $450 \mathrm{MHz}$ UltraSPARC II.

Tabela 2.9: Cálculo de desempenho de algoritmos de chave pública (milisegundos).

\begin{tabular}{ccccc}
\hline & $\mathrm{RSA}_{\text {(cifra, verifica) }}$ & $\mathrm{RSA}_{\text {(decifra, assina) }}$ & $\mathrm{ECDSA}_{\text {(verifica) }}$ & $\mathrm{ECDH}_{\text {(operação) }}$ \\
\hline \multirow{2}{*}{ Ultra 80 } & 1,7 & 13,0 & 6,8 & 6,1 \\
& 6,1 & 18,1 & 9,2 & 8,7 \\
Yopy & 10,8 & 46,5 & 24,5 & 22,9 \\
& 39,1 & 76,6 & 39,0 & 37,7 \\
\hline
\end{tabular}

A Tabela 2.9 possui duas linhas para cada plataforma, onde a linha superior é para RSA, utilizando 1024 bits na chave, e ECC, utilizando 163 bits na chave. A linha inferior é para RSA, utilizando 2048 bits na chave, e ECC, utilizando 193 bits na chave.

Para simular a variedade do mundo real considerando todos os cenários, Gupta et al. fizeram um teste comparando RSA e ECDH-ECDSA em cada um dos casos abaixo:

\footnotetext{
${ }^{25} \mathrm{ECDH}$ - Elliptic Curve Diffie-Hellman.

${ }^{26}$ ECDSA - Elliptic Curve Digital Signature Algorithm.
} 
1. Caso 1: Um Yopy com outro Yopy no cenário ponto a ponto na rede sem fio dos dispositivos.

2. Caso 2: Um cliente Yopy conversando com um servidor Ultra 80 (para simular um cenário da web em rede sem fio, onde um dispositivo móvel (Yopy) solicita uma página para um servidor (Ultra 80).

3. Caso 3: Um Ultra 80 conversando com outro Ultra 80 (para o modo normal de iteração entre um desktop e um servidor web)

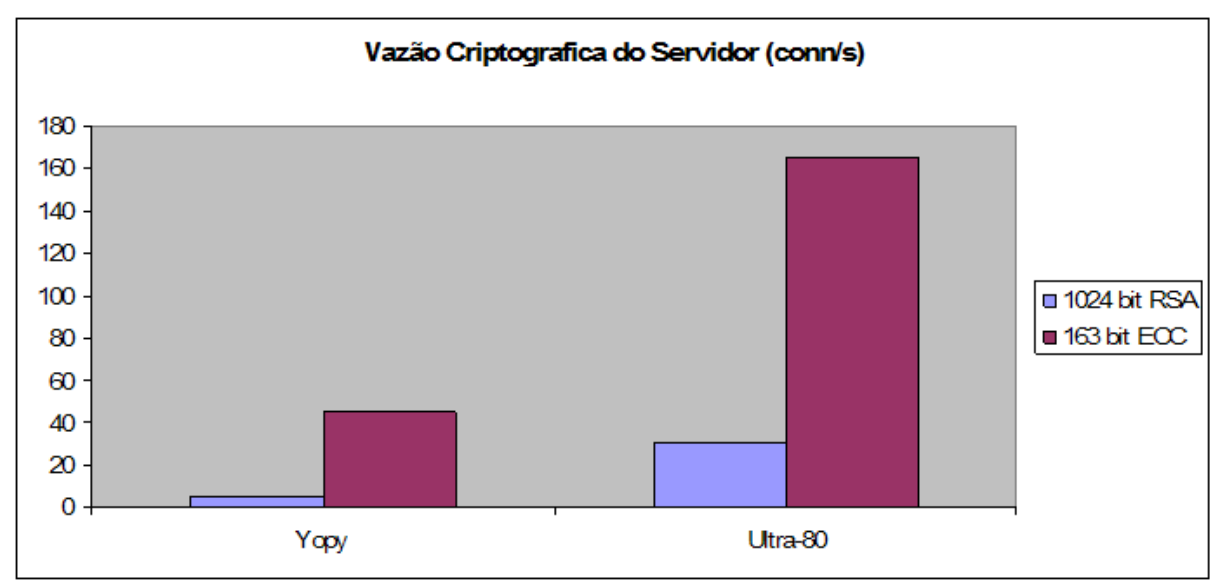

Figura 2.13: Taxa de criptografia do servidor sem autenticação.

A comparação na Figura $2.13^{27}$ utiliza chaves de 1024 bits para RSA e 163 bits para ECC e não utiliza autenticação do cliente, em termos de rendimento máximo, ECC é mais que cinco vezes melhor do que RSA nas duas plataformas consideradas.

Em termos de latência do servidor, a comparação é mais interessante, quando o cliente SSL e o servidor são da mesma plataforma (Caso 1 e Caso 3), ECC é aproximadamente duas vezes mais rápido que RSA. De qualquer forma, no caso em que o cliente é um Yopy e o servidor um Ultra 80 (Caso 2), o RSA é melhor que o ECC, conforme demonstra a Figura $2.14^{28}$.

\footnotetext{
${ }^{27}$ figura adaptada de (GUPTA et al., 2002)

${ }^{28}$ figura adaptada de (GUPTA et al., 2002)
} 


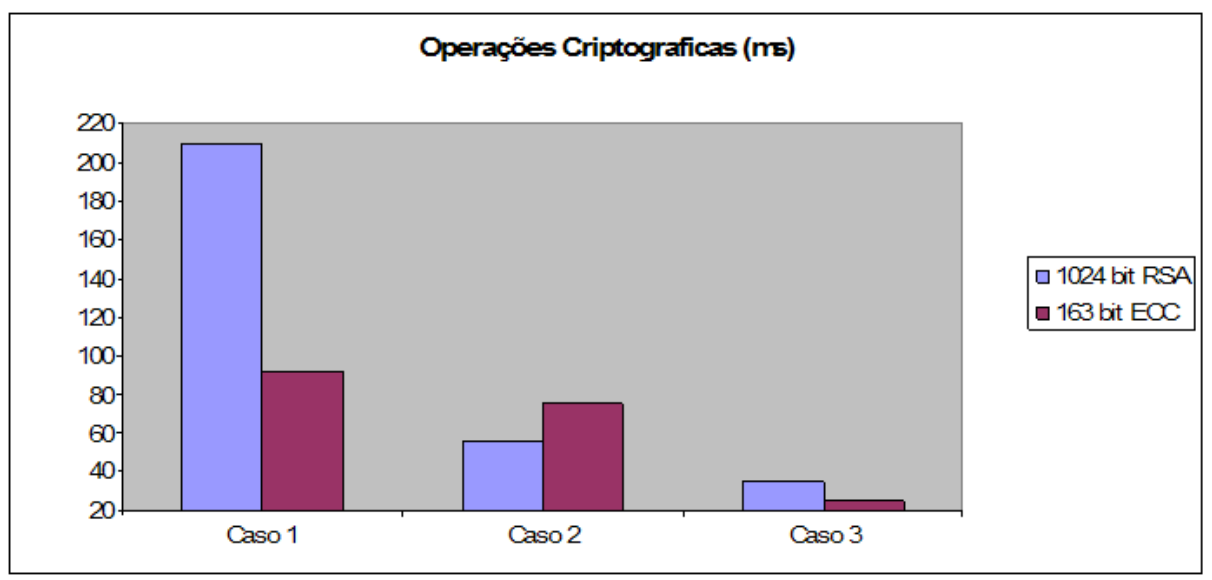

Figura 2.14: Latência criptográfica do Handshake sem autenticação

A diferença de desempenho visualizado no 'Caso 1' e no 'Caso 2' se justifica analisando a tabela 2.9, onde se percebe nas operações que, na plataforma Yopy, as operações de curva elípticas têm um desempenho melhor.

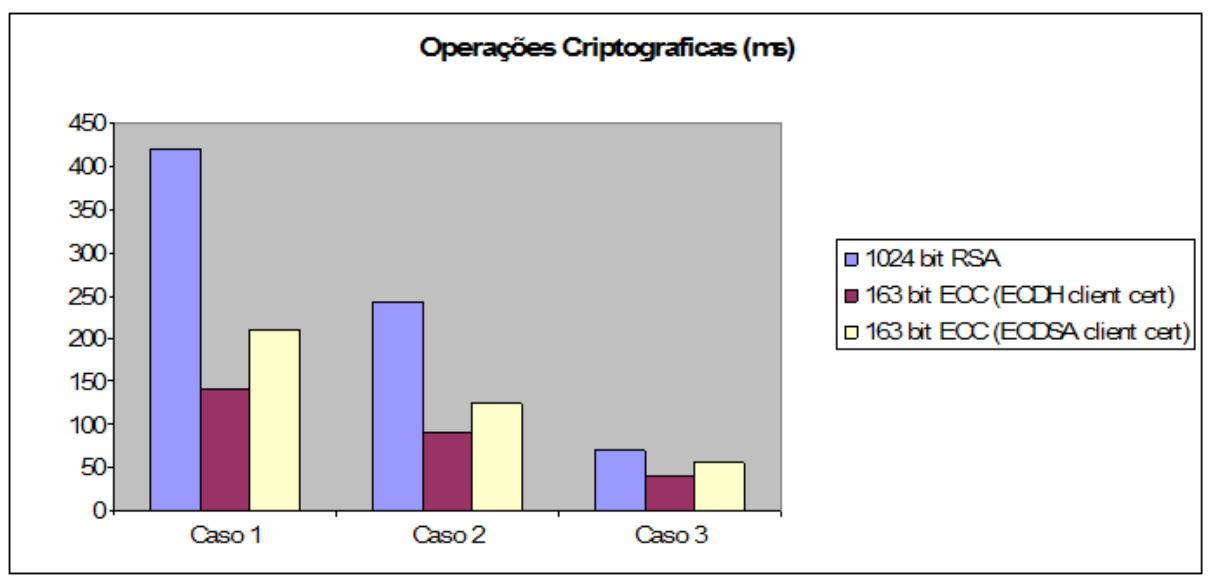

Figura 2.15: Latência criptográfica do Handshake com autenticação

As Figuras 2.15 e 2.16 utilizam o mesmo cenário que as Figuras 2.14 e 2.13 porém utilizando a autenticação do cliente.

Na Figura 2.15 a utilização do certificado ECDH no cliente teve um desempenho melhor que a ECDSA. Mais importante que isso é que ECC teve melhores desempenhos que RSA. No entanto, quando analisada a média de conexões por segundo, na 


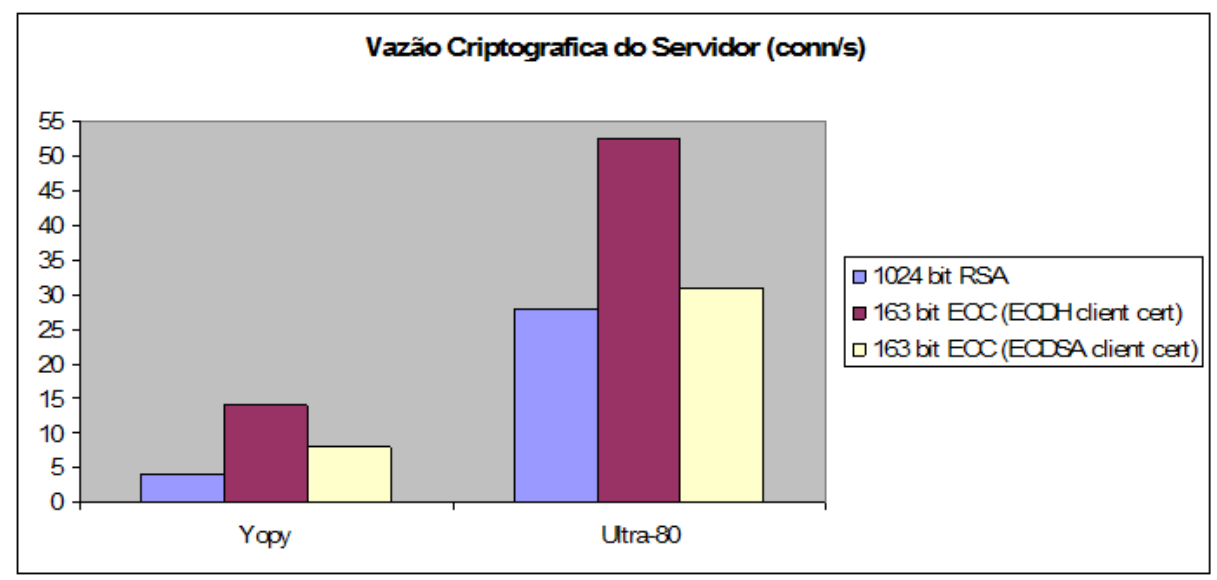

Figura 2.16: Taxa de criptografia do servidor com autenticação

Figura 2.16, a criptografia RSA teve melhor desempenho que ECC, principalmente quando o certificado ECDH é utilizado.

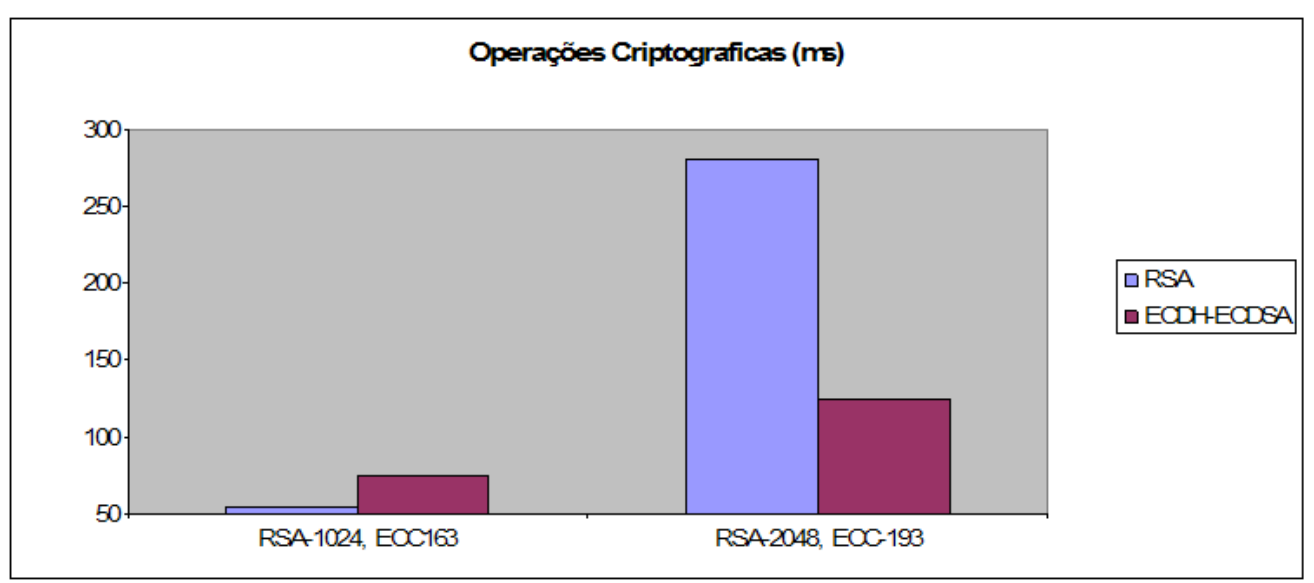

Figura 2.17: Latência criptográfica sem autenticação RSA2048 e ECC193

Os mesmos testes relacionados acima foram realizados utilizando chave de 2048 bits em RSA e chave de 193 bits em ECC. Nos testes verificaram-se resultados melhores para ECC que RSA, sem nenhuma exceção, menos para o 'Caso 2' sem autenticação do cliente. A Figura 2.17 mostra o impacto em utilizar tamanhos de chaves maiores no Yopy comunicando-se com um Ultra 80 (Caso 2) e sem autenticação do cliente. Fica clara na Figura 2.19, a vantagem de desempenho entre ECC e RSA quando trabalhando com chaves criptográficas grandes. 


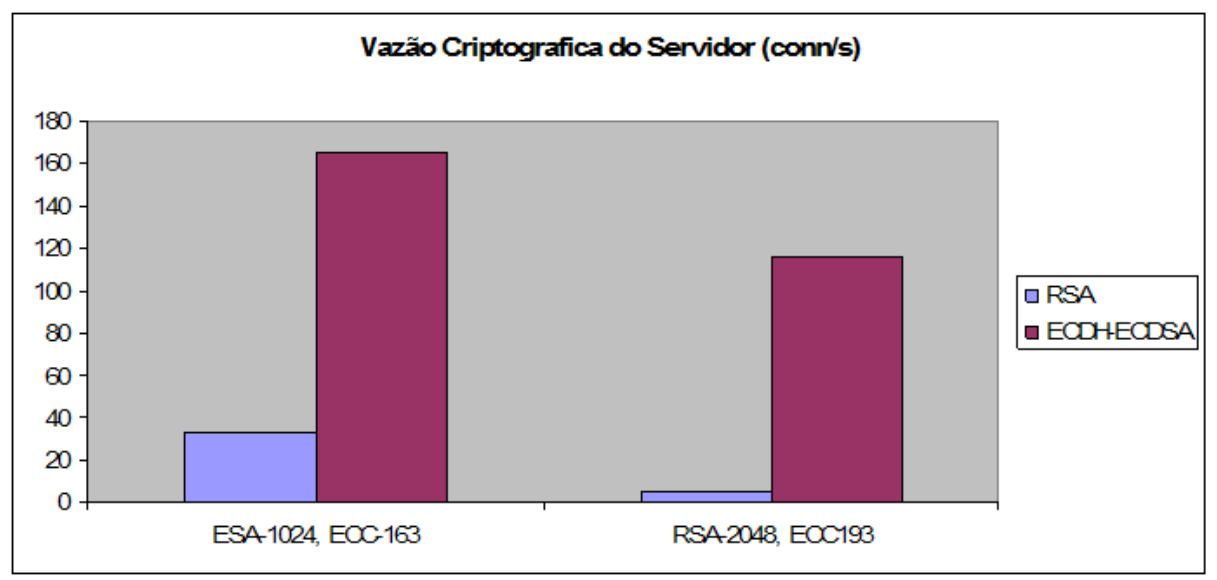

Figura 2.18: Criptografia servidor sem autenticação RSA2048 e ECC193

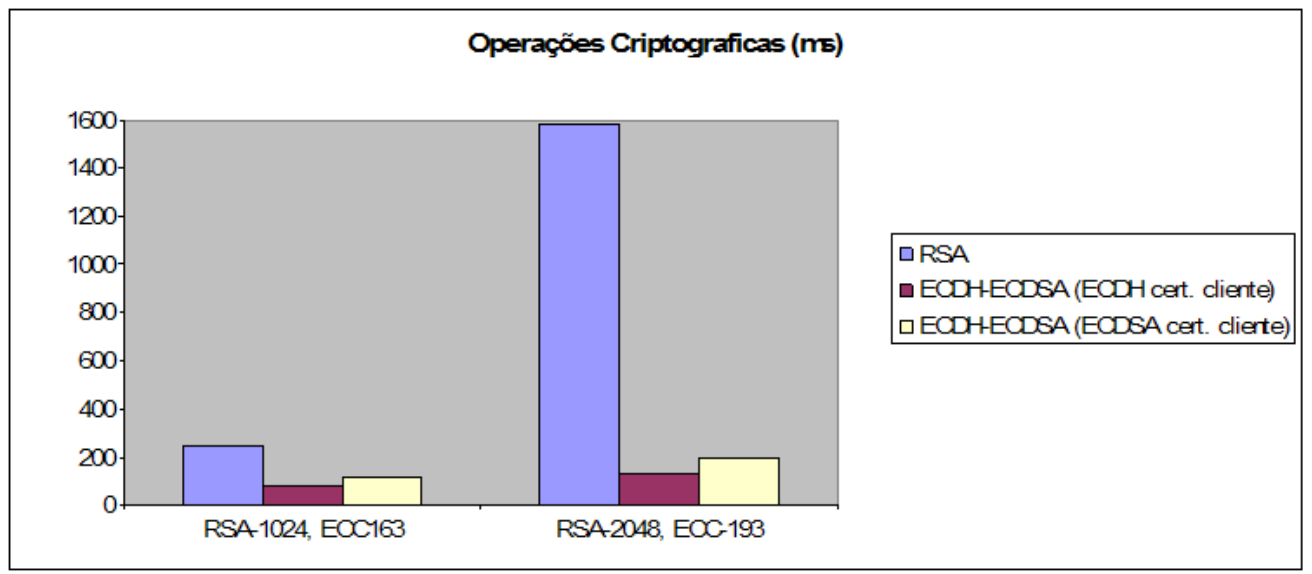

Figura 2.19: Latência criptográfica com autenticação RSA2048 e ECC193

\subsection{Conclusões}

Este capítulo apresentou os principais conceitos envolvidos em criptossistemas baseados em identidade, bem como os esquemas de assinatura baseados em identidade.

Os diversos modelos apresentados se destacam pela utilização da operação de emparelhamento, bem como a multiplicação escalar que, de fato, encarece o custo computacional nos processos de cifração, decifração e verificação de assinatura.

De acordo com as comparações realizados de custo computacional das operações 


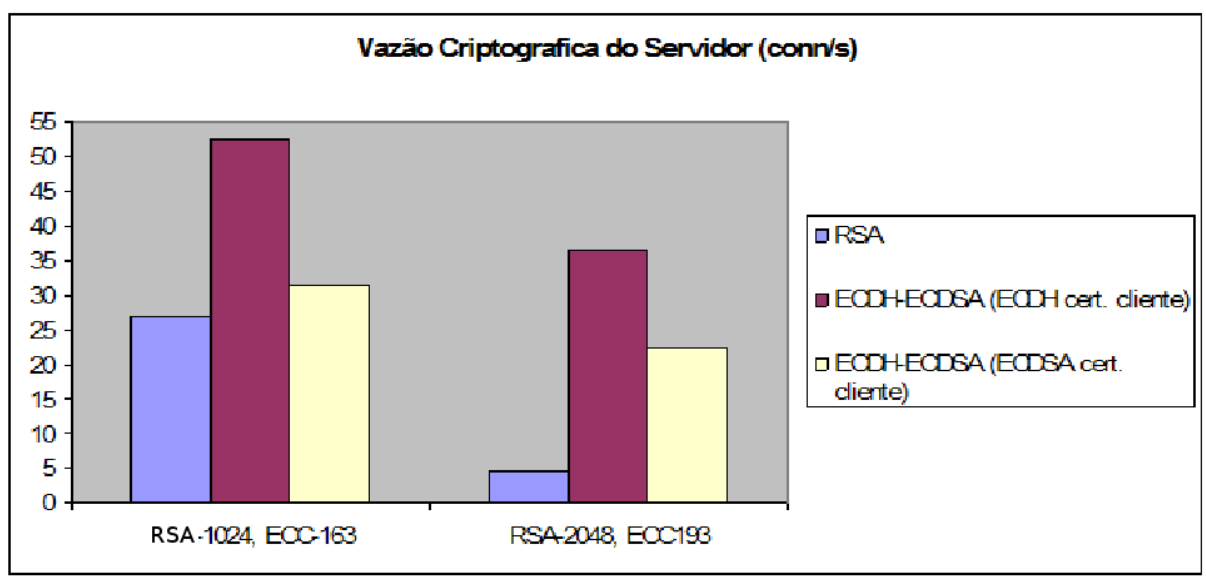

Figura 2.20: Criptografia servidor com autenticação RSA2048 e ECC193.

envolvidas e outras características apresentadas neste capítulo, o esquema de cifração proposto por Waters (2005) é sugerido como esquema se apresenta melhores condições. Para esquema de assinatura, com base no mesmo critério, é sugerido o esquema de (BARRETO et al., 2005) e da mesma forma para esquemas de acordo de chave, sugere-se o esquema de (MCCULLAGH; BARRETO, 2004b).

Certamente, a análise dos parâmetros de desempenho citados como eficiência do algoritmo, computação de emparelhamento e seleção adequada de pontos da curva auxiliam de forma relevante na redução de necessidades de recursos computacionais envolvidos como memória, espaço e velocidade de processamento, resultando em um custo computacional mais viável na implementação dos esquemas de IBE citados neste trabalho. 


\section{Ambiente Criptográfico Baseado na Identidade}

\subsection{Introdução}

O capítulo 2 apresentou os diversos esquemas de cifração, assinatura e acordo de chaves baseados na identidade com comparação de custo computacional envolvida nas operações. Além disso, o capítulo 2 destacou os esquemas de cifração, assinatura e acordo de chaves que tiveram melhor resultado em termos de custo computacional nas operações envolvidas. Alguns dos esquemas apresentados foram objetos de experimentos realizados que serão apresentados no capítulo 4.

Em prática, existem situações em que há necessidade de cifrar e assinar ou cifrar e estabelecer acordo de chaves ou até cifrar, assinar e estabelecer acordo de chaves.

Para atender a necessidade de tais situações, este capítulo define um ambiente criptográfico baseado na identidade com os pré-requisitos necessários para a sua implementação. Além disso, serão apresentados diversos modelos possíveis para criação de tal ambiente.

Para implementar um ambiente criptográfico baseado em identidade, primeiramente é necessário implementar um esquema de cifração, um esquema de assinatura e um esquema de acordo de chaves todos baseados em identidade. A segunda etapa consiste na otimização do esquema de (BONEH; FRANKLIN, 2001), que servirá como esquema base para implementação nesta tese, através da implementação das propostas de melhoria nos esquemas de cifração. 


\subsection{Modelos possíveis de ambiente criptográfico base- ado em identidade}

Existem alguns modelos possíveis para um ambiente criptográfico baseado em identidade que serão apresentados neste capítulo. Antes de apresentar tais modelos, segue uma definição formal que explica o que é um ambiente criptográfico baseado em identidade.

Definição 1. Um Ambiente Criptográfico Baseado em Identidade (ACBI) ${ }^{1}$ consiste em um ambiente que permite os processos de cifração, assinatura e acordo de chaves estejam interligados e otimizados para obter menor custo computacional.

Para obter menor custo computacional deve ser utilizado o mesmo método apresentado no capítulo 2. Os esquemas devem ser comparados em termos de utilização de operações, relacionando seus respectivos custos computacionais. Além disso, devem ser levados em consideração alguns parâmetros de desempenho, como por exemplo, o tempo necessário para cifração, decifração, bem como o tempo necessário para estabelecimento de acordo e verificação de assinatura. Tais operações se destacam por apresentarem os maiores custos computacionais associados. As seções a seguir apresentarão diversas formas e possibilidades para implementar este ambiente.

\subsection{Modelo Convencional}

Este modelo conta com esquema de cifração, assinatura e estabelecimento de acordo de chaves de modo separado. Como o ambiente deve ter o menor custo computacional das operações envolvidas, tal ambiente consiste em implementar:

- Modelo IBE de Boneh e Franklin (2003) com as melhorias propostas por Naccache (2005);

- Modelo IBS de Barreto et al. (2005);

- Modelo IBKA de McCullagh e Barreto (2004a).

\footnotetext{
${ }^{1} \mathrm{O}$ termo sugerido em inglês é Identity-Based Cryptography Environment (IBCE).
} 
Tais esquemas foram selecionados conforme comparações de custo computacional apresentados no capítulo 2. Após implementar tais esquemas, deve ser verificado a forma de integração de tais módulos. Certamente a integração entre os módulos deve encarecer o custo computacional. Desta forma, a implementação do modelo convencional não é viável.

\subsection{Modelos Não Convencionais}

A idéia de um modelo não convencional consiste em calcular ou transformar um processo a partir de outro processo. Por exemplo, tendo IBS, calcular IBKA. Outro exemplo seria calcular IBKA a partir de um IBE. Desta forma, tais modelos certamente contribuem na redução do custo computacional envolvido. Além disso, tal ambiente poderá ser implementado ainda com esquema de criptoassinatura, no qual ocorre cifração e assinatura no mesmo esquema, envolvendo um menor custo computacional quando comparado com dois esquemas distintos de cifração e assinatura.

\subsubsection{ACBI com criptoassinatura}

Os esquemas de cifração e assinatura fornecem confidencialidade e autenticidade e apesar de serem esquemas distintos como foi apresentado no capítulo 2 desta tese, em algumas situações há necessidade de assegurar simultaneamente confidencialidade e autenticidade em mensagens trafegadas. Isto pode ser conseguido através da utilização de esquemas de criptoassinatura.

O conceito de criptoassinatura foi proposto por Zheng (1997). A idéia de utilizar esquema de criptoassinatura baseada em identidade foi de Malone-Lee (2002) que também elaborou um modelo de segurança para esquemas de criptoassinatura baseado em identidade ou simplesmente Identity-Based Signcryption (IBSC).

Tais esquemas garantem confidencialidade e autenticidade das mensagens trafegadas. Um esquema de criptoassinatura genérico consiste em três algoritmos eficientes: um algoritmo de geração de chaves, um algoritmo de criptoassinatura e um algoritmo de de-criptoassinatura ${ }^{2}$.

\footnotetext{
${ }^{2}$ Termo adotado por autor na 1 livre do termo original em inglês de de-signcryption.
} 
O algoritmo de geração de chaves gera um par de chaves, uma para assinatura e decifração que deverá ser armazenada de forma segura e outra para cifração e verificação que ficará disponível publicamente. O algoritmo de criptoassinatura recebe a chave privada do usuário e a mensagem e a identidade do recipiente como entrada para produzir a saída criptoassinada. De forma semelhante o algoritmo de de-criptoassinatura recebe a chave privada do usuário, o texto criptoassinado e a identidade do remetente como entrada (DODIS, 2005).

O esquema de Zheng e Imai (1998) é um esquema eficiente de criptoassinatura, pois compartilha a mesma exponenciação na cifração e assinatura. Tal eficiência também contribui significativamente no nível de segurança do esquema de Zheng e Imai (1998), como é demonstrado no trabalho de Baek, Steinfeld e Zheng (2007). Baek, Steinfeld e Zheng (2007) provam que o esquema proposto por Zheng e Imai (1998) assegura confidencialidade e propõe noções de segurança que poderão ser aplicadas aos outros esquemas de criptoassinatura.

Outro esquema eficiente de IBSC é o esquema proposto por Barreto et al. (2005), que foi descrito no capítulo 2 desta tese.

\subsubsection{Acordo de Chave a partir de Assinatura}

Após a implementação do esquema de criptoassinatura, pode se utilizar o modelo de Chow e Choo (2007) para construção de um esquema de acordo de chaves a partir de um esquema de assinatura. Chow e Choo propõe um esquema de acordo de chaves baseado em identidade de alto desempenho que utiliza assinaturas tipo desafioresposta. Este esquema se destaca também pelo fato de implementar o esquema de acordo de chaves de forma anônima, que é uma propriedade bastante desejável em certas ocasiões.

O esquema proposto por Chow e Choo (2007) também propõe um esquema de acordo de chaves sem custódia da chave. O problema de custódia da chave, como comentado no capítulo 2, compromete a segurança das outras chaves, através do conhecimento da chave mestre.

Desta forma é possível implementar o ACBI inicialmente com implementação de um esquema de criptoassinatura, como por exemplo, o esquema de Zheng e Imai 
(1998) e a partir daí, transformá-lo em um esquema de acordo de chaves, conforme o esquema de Chow e Choo (2007). Vale a pena ressaltar que tal ambiente permitirá as operações de cifração, assinatura e acordo de chaves, e assegura algumas propriedades que são necessárias em ocasiões específicas. Desta forma, o ambiente proposto garante confidencialidade, autenticidade e anonimato em acordo de chaves com alto desempenho e está livre de problema de custódia da chave. A figura 3.1 ilustra o cenário deste ambiente.

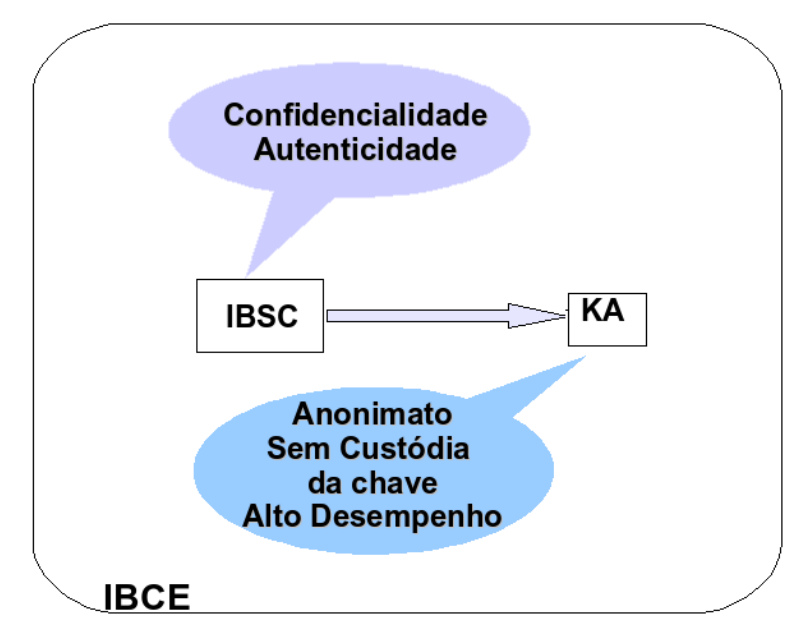

Figura 3.1: IBCE com criptoassinatura

\subsubsection{ACBI sem criptoassinatura}

No caso de um ambiente sem esquemas de criptoassinatura, precisa-se de duas transformações. Inicialmente deve-se transformar um esquema de IBE em um esquema de IBS e logo depois o esquema de IBS será transformado em um esquema de IBKA.

Conforme Boneh e Franklin (2001), um esquema IBE pode ser convertido em um esquema de assinatura de chave pública. A principal idéia consiste na utilização do próprio PKG para fazer a assinatura, sendo que o PKG é o responsável por fornecer as chaves privadas necessárias para qualquer receptor de mensagem em um esquema de $\mathrm{IBE}^{3}$. No fornecimento de tais chaves, o PKG possui a sua chave mestre, denominada aqui como $K_{\text {mestre }}$. Supondo que Mehran solicite sua chave privada ao PKG, o PKG

\footnotetext{
${ }^{3}$ Este esquema não está livre do problema de custódia da chave
} 
ao fornecer a chave privada do Mehran que é denominada de $K P_{\text {mehran }}$, está assinando de forma implícita esta chave com a $K_{\text {mestre }}$ Pois, $K P_{\text {mehran }}$ foi emitida pelo PKG de forma que irretratabilidade está garantida. Desta forma, PKG de fato, assinou tal chave, ou seja, $K P_{\text {mehran }}$ vem assinada pelo $K_{\text {mestre }}$. Esta transformação é conhecida como transformação Naor. Cui et al. (2007) propõe esta transformação de forma genérica para um esquema baseada em identidade. Segundo Cui et al. (2007), a transformação consiste em três fases:

- Geração de Assinatura. Nesta fase através da masterkey (msk), o PKG emite uma chave privada. Esta própria emissão e utilização do $m s k$, resulta em geração da chave de assinatura SigK.

- Assinatura. Nesta fase a mensagem $m$ é 2 a string ID. A chave de decifração $S K_{I D}$ é na verdade resultado da extração da chave de assinatura $\operatorname{Sig} K$, e a chave de verificação $V K$ que finalmente é atribuída ao $\theta$ e retorna a mensagem $m$ com assinatura $\theta$.

- Verificação da Assinatura. Consiste na execução do algoritmo de verificação de assinatura que recebe como parâmetro a chave de verificação $V K$, a assinatura $\theta$ e a mensagem $m$.

Após a transformação de um esquema IBE em um esquema IBS, basta utilizar então Chow e Choo (2007) para transformar tal esquema em um esquema de IBKA. Desta forma, este ambiente utiliza duas transformações para produzir um esquema de acordo de chaves, comparado com o ambiente anterior que utilizava apenas uma transformação para alcançar este objetivo. Uma característica relevante deste ambiente é o fato de que o esquema inicia com o problema de custódia da chave antes da transformação de IBE para IBS e no final da segunda transformação, tal problema não existe mais. A figura 3.2 apresenta este cenário.

\subsection{Análise de Segurança dos Ambientes Descritos}

As seções anteriores apresentaram as diversas formas de implementar um ambiente criptográfico baseado em identidade. O capítulo 2 apresentou as noções de segurança 


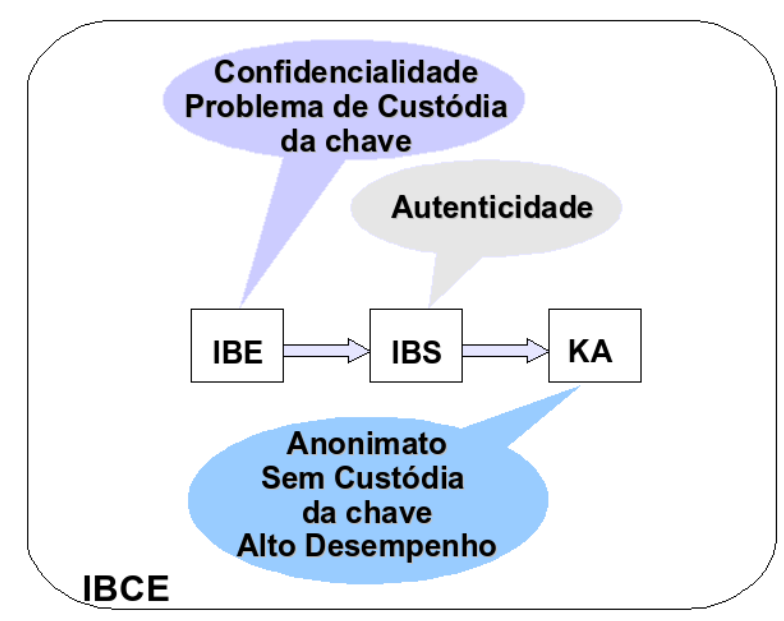

Figura 3.2: IBCE sem criptoassinatura

para os esquemas de cifração baseado em identidade. Pode-se presumir que as noções são extensíveis para os esquemas de cifração, quando os mesmos foram utilizados.

As noções de segurança para esquemas de acordo de chave em geral são muito difíceis de serem provadas. Desta forma, o que resta é fazer uma conjectura de possibilidades de ataques e adotar o modelo de segurança de forma parcial para momentos de cifração e assinatura. Por outro lado, fica difícil descrever uma noção de segurança para este ambiente como um todo, já que conta com uma ou duas transformações. $\mathrm{O}$ esquema de cifração originalmente proposto por Boneh e Franklin (2003) tem nível de segurança IND-ID-APE com o problema BDH adotado e poderá ser transformado em um modelo com segurança de nível IND-ID-ACE (LIBERT, 2007).

\subsubsection{Ambiente com criptoassinatura}

Baek, Steinfeld e Zheng (2007) utilizam o conceito de capacidade de indistinção, de Bellare et al. (1998), apresentado no capítulo 2 desta tese, para definir alguns conceitos de segurança para esquemas de criptoassinatura. Segue as definições de (BAEK; STEINFELD; ZHENG, 2007):

Definição 2. Um esquema de criptoassinatura é considerado seguro contra incapacidade de distinção, quando não existe adversário algum em tempo polinomial que possa aprender qualquer informação à respeito do texto plano, a partir de um texto criptoassinado, exceto o seu comprimento. 
A definição 2 é considerada uma noção de segurança para esquemas de criptoassinatura e poderá ser apresentada como FSO/FUO-IND-AACE, onde Flexible Signcryption Oracle/Flexible Unsigncryption Oracle (FSO/FUO) são na realidade os oráculos aleatórios flexíveis de criptoassinatura e decriptoassinatura. Neste modelo o adversário tem o objetivo de quebrar a confidencialidade de mensagens. Baek, Steinfeld e Zheng (2007) demonstram que o esquema de (ZHENG; IMAI, 1998) atende o critétrio de confidencialidade.

Desta forma, segue a seguinte assertiva a respeito de IBKA nesse ambiente:

Conjectura 1. Um esquema IBKA obtido a partir de um IBSC tem nível de segurança de IND-ID-AACE, se e somente se o IBSC tiver o nível de segurança de FSO/FUOIND-AACE.

Desta forma, o ambiente criptográfico com criptoassinatura tem nível de segurança FSO/FUO-IND-AACE na fase de criptoassinatura condicionada a não existência de adversário que atenda a definição 2 e nível de segurança de IND-ID-AACE para IBKA, por conjectura. Vale apena salientar que este ambiente não possui problema de custódia da chave e permite implementação do anonimato. A figura 3.3 apresenta a análise de segurança deste ambiente.

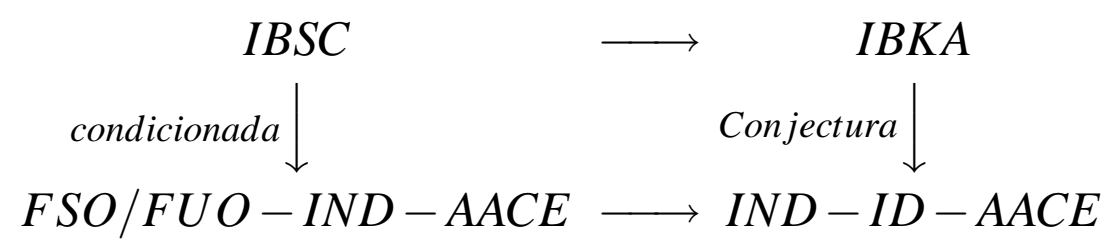

Figura 3.3: Análise de Segurança do Ambiente com Criptoassinatura

\subsubsection{Ambiente sem criptoassinatura}

Para poder analisar o nível de segurança do ambiente sem criptoassinatura, segue as definições de Chosen-Message Attack (CMA) e Existencial Unforgeability against Chosen-Message Attacks (EUF-CMA) para esquemas de assinatura, conforme Abdalla (2007):

Definição 3. Um cenário de ataque é considerado CMA, no qual, o adversário pode de forma adaptativa perguntar por assinaturas de mensagens pela sua própria escolha. 
Definição 4. Um esquema tem nível EUF-CMA de segurança, quando todo adversário tipo CMA for incapaz de criar assinaturas forjadas.

Baseada nas definições de Boneh e Franklin (2003), Waters (2005), pode-se afirmar que:

Proposição 1. Se o IBE utilizado no ambiente descrito em 3.4.2 que envolve a transformação de Naor tiver nível de segurança IND-ID-AACE, pode se garantir que o IBS resultante terá o nível EUF-CMA de segurança.

Com relação a transformação de IBS para IBKA de (CHOW; CHOO, 2007):

Conjectura 2. Se o IBE utilizado no ambiente descrito em 3.4.2 tiver nível de segurança IND-ID-AACE, pode se presumir que o IBKA resultante terá o nível IND-IDAACE de segurança, sem problema de custódia da chave e permitindo anonimato.

A figura 3.4 apresenta o resumo da análise de segurança no ambiente descrito em 3.4.2. Nesta figura $T-$ Naor é a transformação de Naor e $T-$ Choow é a transformação de Chow e Choo (2007).

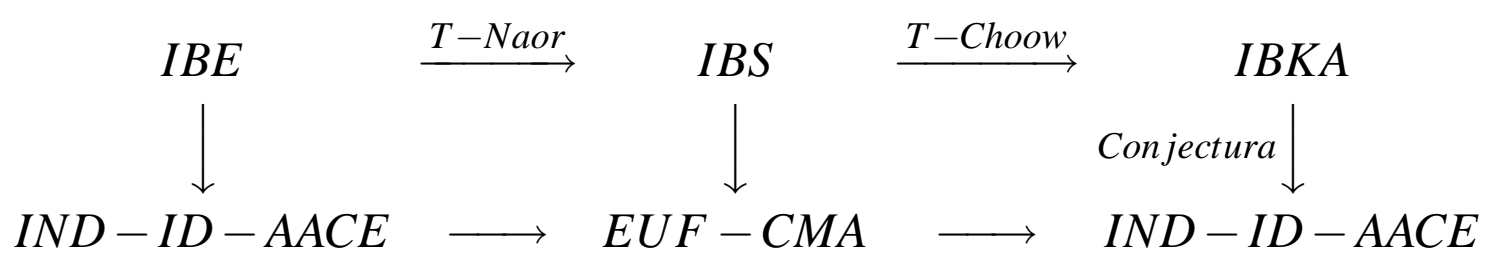

Figura 3.4: Análise de Segurança do Ambiente sem Criptoassinatura

Desta forma, o nível de segurança do ambiente descrito em 3.4.2 como um todo poderá ser descrito da seguinte forma:

Conjectura 3. O ambiente criptográfico sem criptoassinatura tem o nível de segurança IND-ID-AACE nos momentos de cifração e acordo de chaves e o nível de segurança EUF-CMA no momento de assinatura. 


\subsection{Otimização do Ambiente Criptográfico Baseado na Identidade}

Como foi visto no capítulo 2 desta tese, os diversos esquemas apresentados diferem pelo custo computacional das operações envolvidas que dependendo da implementação em questão poderão se tornar até inviáveis. Isto, de fato, é o caso de implementação em dispositivos móveis, no qual há escassez de recursos computacionais.

Nestas situações, a otimização e melhoria de desempenho certamente contribuem de forma significativa para que as implementações sejam viáveis. Quanto menor for a quantidade de operações com maior custo computacional, melhor será o desempenho do ambiente em questão. $\mathrm{O}$ ambiente proposto nesse capítulo conta com uma ou duas transformações, conforme o modelo escolhido. Tais transformações também implicam no custo computacional das operações envolvidas.

Como visto no capítulo 2, a escolha adequada da curva tem um papel fundamental no que tange o desempenho de um esquema criptográfico baseado em identidade. Esta seção apresenta algumas classes de curvas, bem como algumas otimizações feitas para aumentar a rapidez no cálculo de operações sobre a curva, como multiplicação escalar, operação de emparelhamento e operação m2p. O anexo B.3 apresenta os conceitos básicos sobre curvas e apresenta alguns emparelhamentos. O desempenho de um sistema criptográfico baseado na identidade poderá ser melhorado através de algumas observações listadas a seguir:

- Aumentar a rapidez no cálculo das operações de curvas elípticas através da utilização de bibliotecas mais eficientes como por exemplo MIRACL.

- Calcular de forma mais rápida os emparelhamentos bilineares, utilizando endomorfismo, através de Scott (2005) melhorando até 20\%.

- Reduzir os custos de multiplicação em $\mathbb{F}_{p}^{*}$ através do emprego de automorfismo, conforme Zhao, Zhang e Huang (2006). Além disso, (ZHAO; ZHANG; HUANG, 2006) reduz pela metade as iterações feitas no algoritmo de Miller.

- Reduzir o tempo computacional para o cálculo de emparelhamento através da proposta de hÉigeartaigh (2005). hÉigeartaigh otimiza o cálculo da última exponenciação do algoritmo Miller em até 30\%. 
- Feng e Wu (2007) apresentam um método baseado (SCOTT, 2005) que reduz mais $14 \%$ o custo comparado com o algoritmo de Scott.

- Barreto e Naehrig (2005) apresentam um algoritmo simples de curva com emparelhamentos amigáveis de ordem prima, chamado de curvas $B N$, que permite calcular de forma mais rápida a última exponenciação depois do algoritmo Miller e requer menos espaço de armazenamento.

- Devegili, Scott e Dahab (2007) apresentam a primeira implementação eficiente de (BARRETO; NAEHRIG, 2005) com emparelhamentos Tate e ate, que calcula ainda mais rápido a última exponenciação e requer menos memória.

- Kim e Kim (2007) apresentam métodos para reduzir custos de pontos de adição que resultou em tornar mais rápido a multiplicação escalar entre 15 a $20 \%$.

- Vercauteren (2008) apresenta noções de emparelhamentos ótimos que resulta em reduzir o número de iterações de algoritmo Miller e propôs um procedimento que cria de forma automática emparelhamentos ate ótimos baseado em curvas elípticas amigáveis.

- Galbraith e Scott (2008) apresentam homomorfismos eficientemente computáveis de grupos $\mathbb{G}_{2}$ e $\mathbb{G}_{T}$ que permite acelerar as exponenciações em $\mathbb{G}_{2}$ e é apresentado de forma $e: \mathbb{G}_{1} \times \mathbb{G}_{2} \rightarrow \mathbb{G}_{T}$.

- Zhao, Zhang e Huang (2007) apresentam uma variação do emparelhamento ate para reduzir o comprimento do loop do algoritmo de Miller, através da seleção de algumas curvas de emparelhamentos amigáveis. A figura 3.5 apresenta um comparativo de comprimento de loop entre emparelhamentos Tate, ate e a proposta de Zhao, Zhang e Huang (2007).

Naturalmente as técnicas citadas poderão ser aplicadas em criptossistemas baseados em identidade. A tabela 3.1 apresenta de forma resumida as diversas técnicas para otimizar um criptossistema baseado na identidade. Os valores apresentados nessa tabela têm como referência o algoritmo original de Miller utilizado em Boneh e Franklin (2003). 


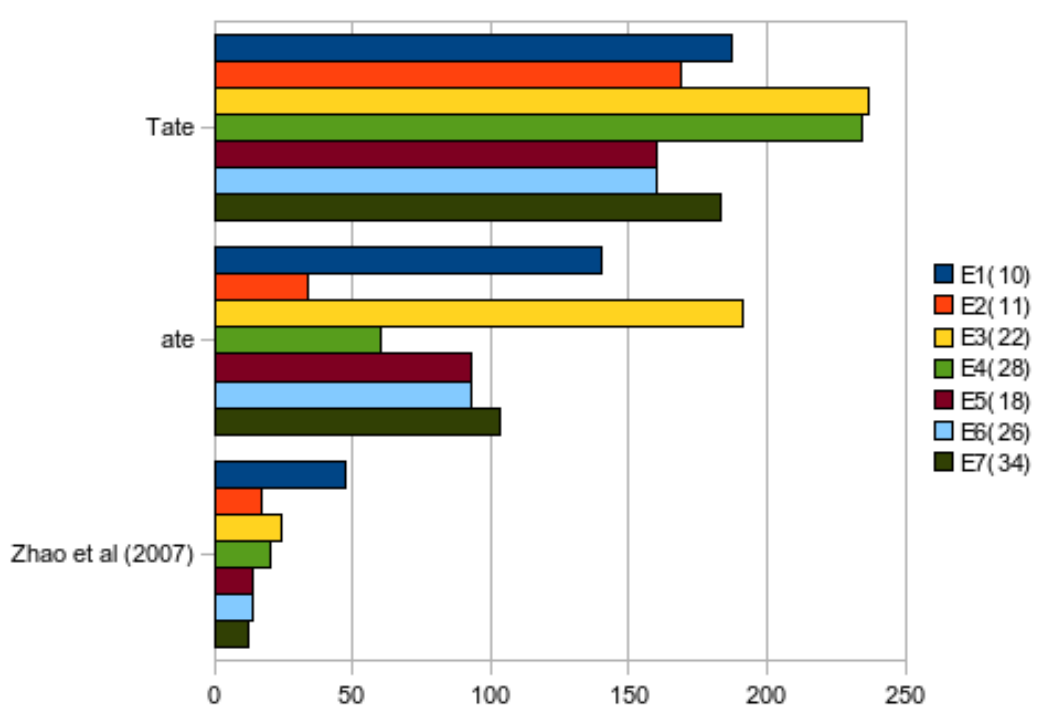

Figura 3.5: Variação do comprimento de loop

Tabela 3.1: Técnicas de otimização para IBE.

\section{Técnica}

1. Algoritmo Miller

2. Endomorfismo

3. Automorfismo

4.Homomorfismo

5. Variante ate

6. Emparelhamentos

Ótimos

7. Emparelhamentos

Amigáveis

8. Curvas BN

9. Curvas BN

10. Pontos de Adição (KIM; KIM, 2007)

(SCOTT, 2005)

Proposta por Eficiência

(HÉIGEARTAIGH, 2005)

(ZHAO; ZHANG; HUANG, 2006)

(GALBRAITH; SCOTT, 2008)

(ZHAO; ZHANG; HUANG, 2007)

(VERCAUTEREN, 2008)

(FENG; WU, 2007)

(BARRETO; NAEHRIG, 2005)

(DEVEGILI; SCOTT; DAHAB, 2007) de iterações
$30 \%$

$20 \%$

redução de metade

exponenciação acelerada de $\mathbb{G}_{2}$ redução significativa de iterações redução significativa de iterações $22,80 \%$

cálculo mais eficiente da última exponenciação cálculo mais eficiente do que 6 Multiplicação escalar 15-20\% mais rápida. 


\subsection{Conclusões}

Este capítulo inicialmente definiu o que é um ambiente criptográfico baseado em identidade e modelos possíveis de tal implementação. Descreveu diversas formas para implementar tal ambiente. Além disso, foram citadas diversas técnicas para melhorar desempenho e reduzir o tempo gasto com cálculo de emparelhamento.

A adoção de cada técnica citada para redução do tempo de cálculo depende de particularidades da curva e emparelhamentos envolvidos em um criptossistema. As principais formas de otimizar as operações envolvidas em criptossistemas que utilizam emparelhamentos que foram apresentados são: redução do tempo do algoritmo de Miller, redução do custo da última exponenciação, utilização de técnicas de endomorfismo e automorfismo, redução do tempo de cálculo de pontos de adição e a utilização e implementação de curvas BN que poderá resultar em cálculo mais eficiente da última exponenciação. Tais melhorias resultam em até $30 \%$ de redução no algoritmo Miller utilizado em (BONEH; FRANKLIN, 2003). 


\section{Experimentos Realizados em um Ambiente Criptográfico Baseado na Identidade}

Este capítulo tem por objetivo apresentar detalhes e resultados dos experimentos realizados em um ambiente criptográfico baseada na identidade. Tais experimentos permitem visualizar as diversas funcionalidades que sistemas criptográficos baseados na identidade possuem. Dessa forma, poderão ser as seguintes funcionalidades em especial:

- Implementação de níveis adicionais de segurança, como por exemplo, uma senha, uma combinação aleatória de números mediante fornecimento de dados constantes em uma tabela ou cartão distribuída previamente (caso do protótipo será feito desta forma);

- Revogação Temporal, mediante de fornecimento de algum critério para revogação como limite de tempo, não obediência de algum critério, expiração do modo de licenciamento, tamanho da quota excedida, mudança de data, entre outras possíveis condições para revogar poderá implicar não-decifração de um texto já cifrado ou expiração de acordo previamente estabelecido de chaves. Tal revogação poderá ser também implementada em esquemas de assinatura baseada na identidade.

- Busca cifrada com funcionalidades adicionais de segurança baseado em IBE:

1. Flexibilidade em cifração ou revogação. 


\subsection{Implementação do modelo de Boneh e Franklin com disponibilidade temporal}

Esta seção aborda o desenvolvimento de esquema de Boneh e Franklin conforme (BONEH; FRANKLIN, 2001) em JAVA. Tal desenvolvimento é necessário para apresentar de forma bastante didática as funções de temporalidade.

Como o desenvolvimento teve ênfase educacional, o programa desenvolvido mostra todas as variáveis do sistema, onde é exibido o tamanho máximo dos números primos gerados aleatoriamente, o valor do master key utilizado pelo servidor PKG, o valor da variável 'q', a função de hash utilizada e qual curva está sendo utilizada, conforme demonstra a Figura 4.1.

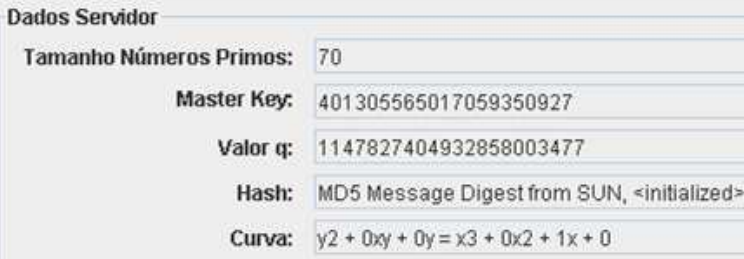

Figura 4.1: Implementação Boneh Franklin - Variáveis disponíveis.

A aplicação é dividida em 2 componentes:

1. Servidor PKG: servidor que possui todo o processamento da criptografia IBE, é responsável por cifrar, decifrar, gerar todas as variáveis do servidor e gerar a chave privada dos usuários.

2. Cliente: aplicação que se conecta no servidor PKG e solicita a cifração de mensagens, a decifração de mensagens e a geração de sua chave privada. O cliente foi desenvolvido para permitir várias instâncias no mesmo computador.

Para iniciar a aplicação cliente primeiramente necessita ter um servidor PKG disponível e para esta finalidade se-inicia o servidor conforme mostrada na Figura 4.2. 


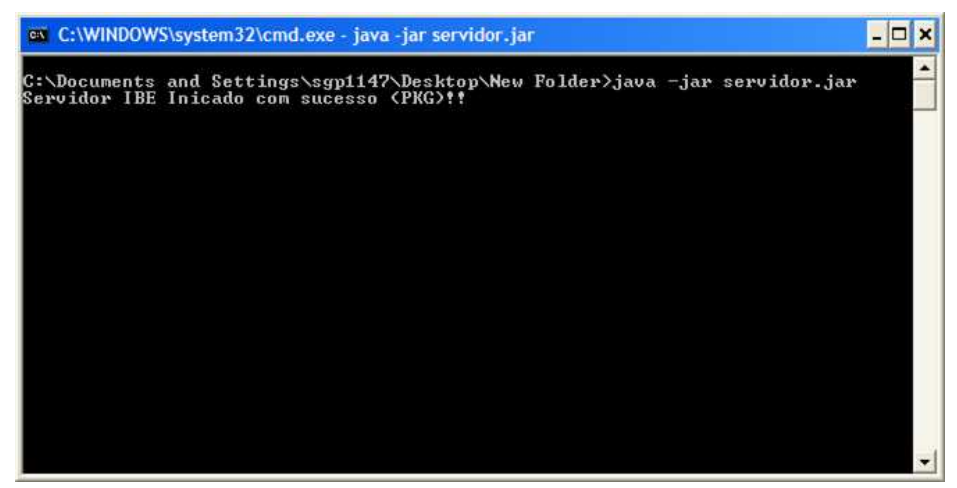

Figura 4.2: Implementação Boneh Franklin - Servidor PKG.

A Figura 4.3 mostra a aplicação cliente iniciada, assim que o usuário abrir a aplicação cliente deverá efetuar a configuração do servidor PKG clicando no botão 'Configuração Servidor' e em seguida informar o 'Nome' do 'Servidor RMI' e efetuar a parametrização da identidade utilizada informando em 'Servidor Local' o número da porta, sendo que o 'Nome' em 'Servidor Local' é assumido por padrão como o endereço de IP do computador, conforme mostra Figura 4.4.

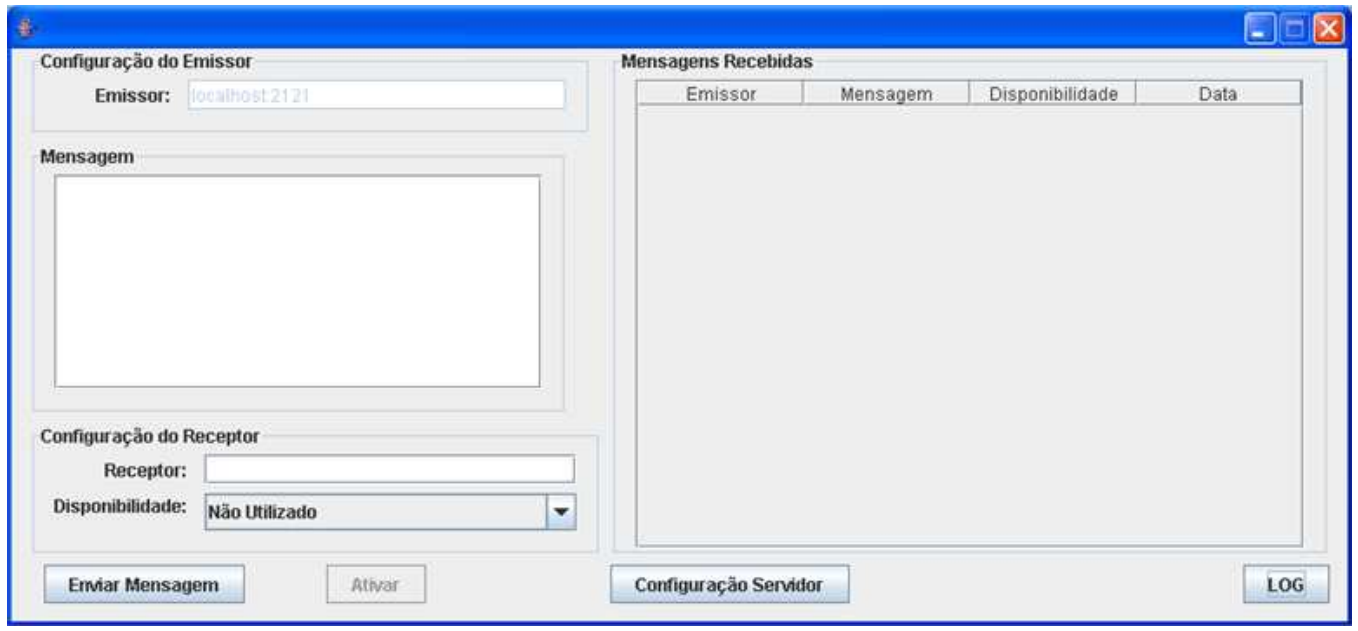

Figura 4.3: Implementação Boneh Franklin - Tela Principal.

Na Figura 4.4 é parametrizado o servidor PKG, a comunicação com o servidor PKG é feita através do protocolo RMI, assim deverá ser informado a localização do servidor RMI para parametrização do servidor PKG. Após informado o servidor PKG deverá ser informado a porta que será recebido as mensagens, a porta fará parte da 


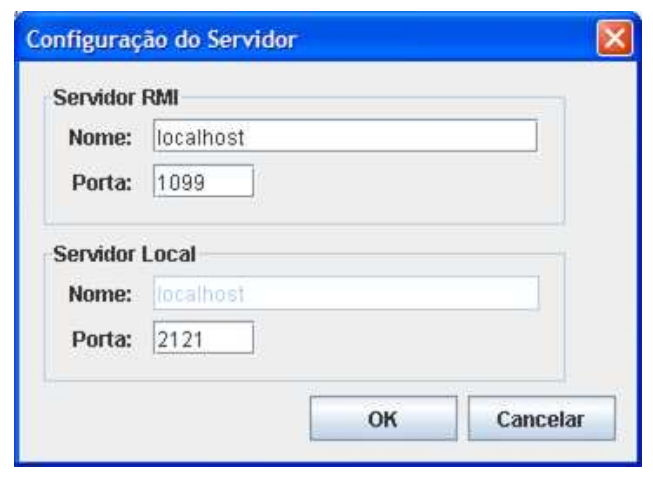

Figura 4.4: Implementação Boneh Franklin - Configuração servidor PKG e configuração da Identidade.

identidade do usuário juntamente com o endereço de IP do computador.

A identidade utilizada pelo cliente é nada mais do que uma informação que distingue o usuário na rede, possibilitando assim que outros computadores utilizando o cliente possam conversar com ele.

Desta forma, a identidade utilizada é o IP do computador (na Figura 4.4 não podese informar o nome do computador pois sempre é assumido o computador local) somado da porta configurada para receber as mensagens.

Após efetuar as parametrizações acima, o usuário precisa ativar o cliente, nesta operação o cliente se conecta no servidor PKG, utilizando o protocolo RMI e também irá ficar ouvindo a porta configurada para receber novas mensagens, assim que uma mensagem for recebida, a tabela da direita intitulada de 'Mensagens Recebidas' será alimentada, conforme mostra a Figura 4.5.

Assim que a mensagem for recebida o usuário poderá clicar sobre ela na tabela da direita e assim poderá exibir a mensagem decifrada, conforme mostra a Figura 4.6.

A configuração da disponibilidade temporal é feita sempre antes de enviar a mensagem, assim pode-se limitar a data máxima de leitura da mensagem. Inicialmente o cliente permite fornecer disponibilidade 'Não Utilizado', 'Diária', 'Mensal' ou 'Anual', sendo que é possível utilizar qualquer unidade de tempo para a disponibilidade temporal. 


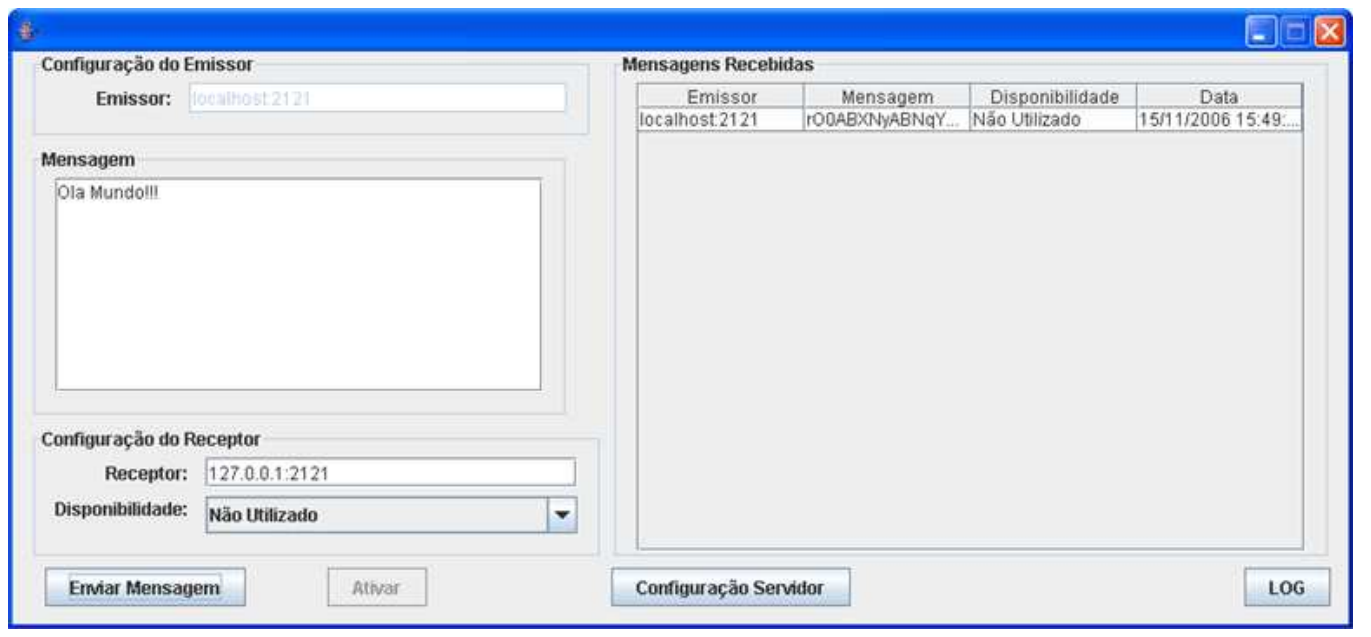

Figura 4.5: Implementação Boneh Franklin - Mensagem recebida.

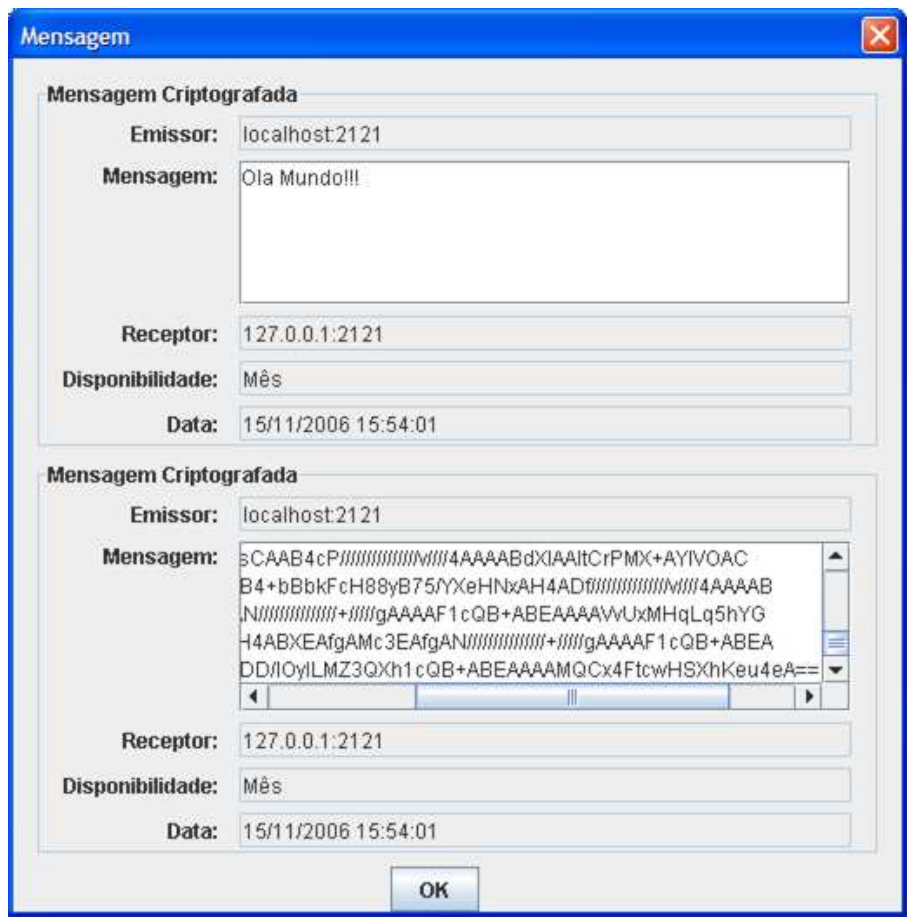

Figura 4.6: Implementação Boneh Franklin - Mensagem recebida cifrada e decifrada. 
A chave pública no cliente atualmente é composta das seguintes informações:

Endereço de IP : Porta recebedora de mensagens

Onde levando para exemplo acima ela seria:

$$
\text { 127.0.0.1:2121 }
$$

Sendo que este cliente está configurado para receber mensagens na porta 2121. Para a implementação de disponibilidade foi somado no final da identidade do cliente a disponibilidade temporal aplicada. Agora a chave pública do cliente tem o seguinte formato:

Endereço de IP : Porta recebedora de mensagens : Disponibilidade

Utilizando o exemplo acima e imaginando que a disponibilidade temporal seja mensal, partindo da data referência como 01/11/2006, a identidade do usuário seria a seguinte (a aplicação utiliza meses partindo de Janeiro com valor 0 (zero) até dezembro com valor 11 (onze)):

$$
\text { 127.0.0.1:2121:10/2006 }
$$

Desta forma quando o receptor receber a mensagem terá que verificar a disponibilidade temporal aplicada ('Não Utilizado', 'Diária', 'Mensal' ou 'Anual').

A utilização de disponibilidade temporal fica visível no programa visualizando a seção de log, onde o programa grava todos os passos do sistema, conforme mostra a Figura 4.7.

Caso um usuário tentasse visualizar uma mensagem com a disponibilidade temporal vencida não iria conseguir visualizar a mensagem tendo um retorno semelhante a Figura4.8. 


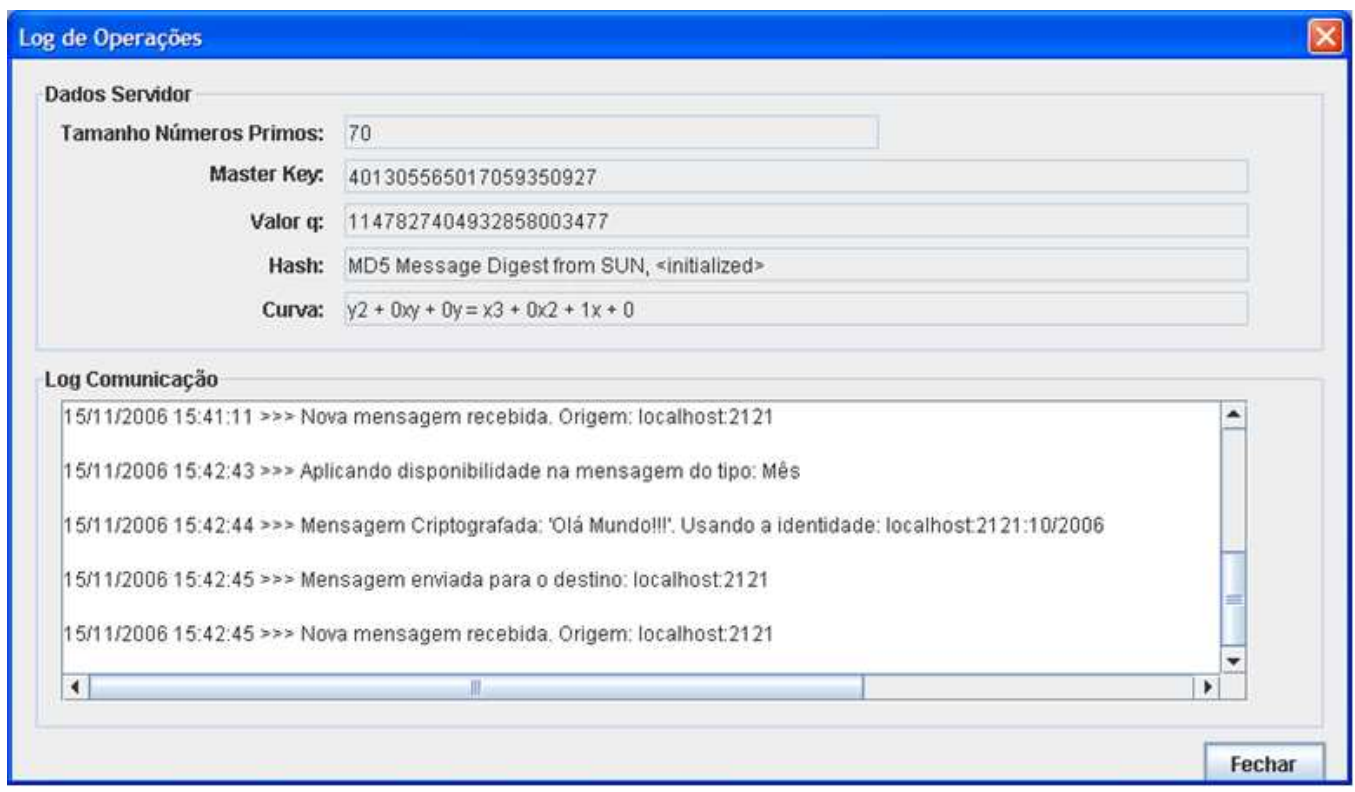

Figura 4.7: Implementação Boneh Franklin - Tela de Log.

\subsection{Implementação de Pesquisa em Banco de Dados Ci- frados}

O desenvolvimento da aplicação que efetua busca de palavra em banco de dados cifrado foi baseado no artigo de Waters (WATERS et al., 2004). O sistema desenvolvido é simples e tem como principal objetivo exemplificar a utilização do esquema e apresentar os benefícios da sua utilização. Neste projeto somente foram utilizadas duas tabelas que são denominadas como record e keyword neste artigo e são definidas conforme o modelo de entidade e relacionamento da Figura 4.9.

No modelo apresentado na Figura 4.9, nota-se que as informações persistidas para o record são:

1. id: Código primário para o registro;

2. data: Informação guardada cifrada usando criptografia simétrica, no caso AES, o dado inserido informado pelo usuário;

3. date: Data da inserção do registro;

4. user: Usuário que efetuou a inserção, utilizado como filtro na busca. 


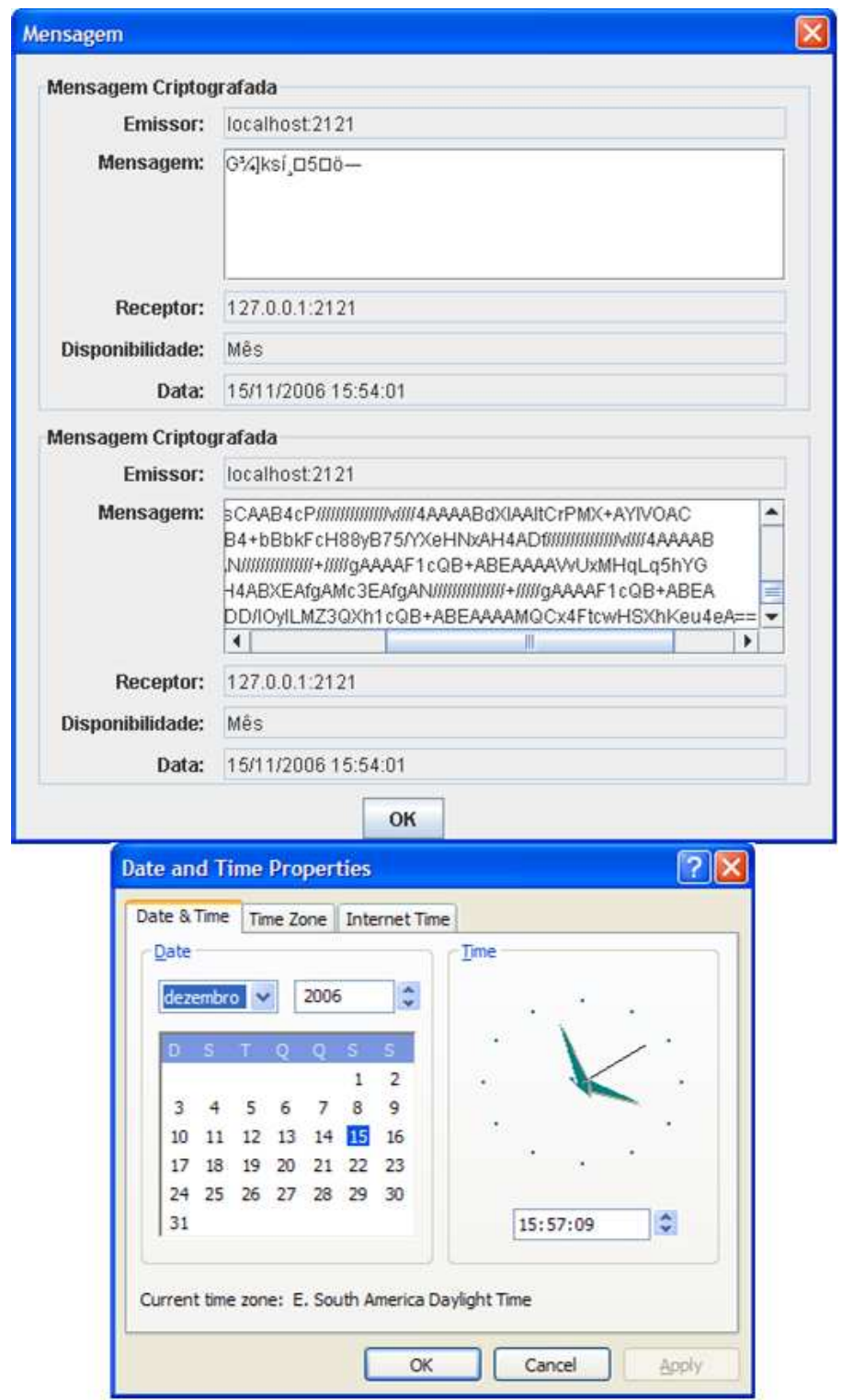

Figura 4.8: Implementação Boneh Franklin - Mensagem com disponibilidade temporal vencida.

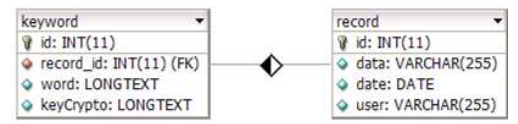

Figura 4.9: Implementação de busca de palavra em banco de dados cifrados Modelo de entidades e relacionamento. 
Para a tabela keyword as informações persistidas são as seguintes:

1. id: Código primário para a palavra-chave;

2. record id: Código primário do registro a qual esta palavra-chave representa;

3. word: Palavra-chave cifrada utilizando criptografia assimétrica IBE, a identidade utilizada é a mesma palavra;

4. keyCripto: Chave secreta utilizada para cifrar o registro (record), a chave secreta é guardada cifrada utilizando criptografia simétrica IBE, a identidade utilizada é a palavra-chave (word).

Para cifração de dados foi utilizada a criptografia simétrica AES. O objetivo da aplicação desenvolvida é a garantia da privacidade dos dados, sendo assim somente quem realmente souber da existência da palavra poderá buscá-la.

As atividades de inserção e de busca na aplicação são enfileiradas. Este enfileiramento é feito por causa do elevado tempo de processamento para finalizar as atividades que dependem de alguns fatores conforme abaixo:

1. Inserção: pode variar o tempo dependendo do tamanho da informação a ser inserida. Como toda palavra com mais de quatro caracteres é considerado uma palavra chave, caso a informação inserida contenha muitas palavras chaves o sistema irá demorar muito tempo na geração da criptografia IBE de cada palavra.

2. Busca: caso a base de dados contenha muitos dados o sistema irá demorar muito para efetuar a busca na base inteira. Na medida que a busca é efetuada, os dados na tabela chamada de 'Resultados Busca' serão alimentados, mas para a busca finalizar por completo pode-se levar alguns minutos dependendo do tamanho da base de dados.

O processo abaixo exemplifica os processos de "Inserção"e "Busca"com um detalhamento das atividades realizadas, conforme abaixo:

O processo de inserção efetua os passos conforme demonstra a Figura 4.10. 


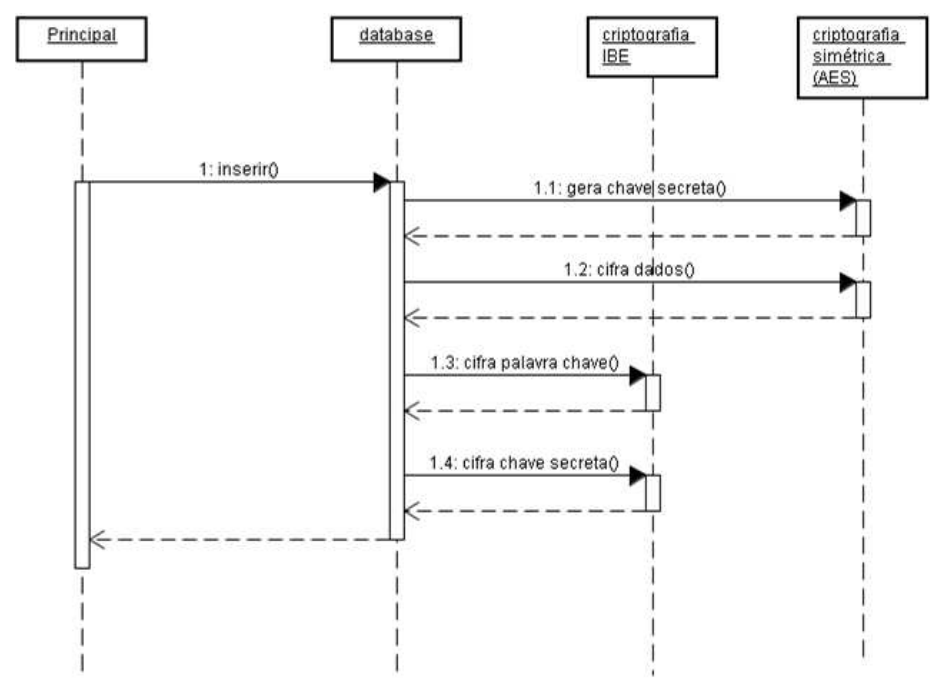

Figura 4.10: Implementação de busca de palavra em banco de dados cifrado Diagrama de seqüência - Operação inserir.

A Figura 4.10 exemplifica o processo de inserção. O primeiro processo a ser executado é a geração da chave secreta, representado pelo processo 1.1 e é utilizada pela criptografia simétrica. Após, o processo 1.2 é executado, neste processo os dados inseridos no campo 'Informação' serão cifrados utilizando a chave secreta gerada no processo 1.1. Após estes dois processos o registro record já está pronto para ser inserido. O próximo passo a ser executado é cifrar cada palavra chave utilizando a própria palavra chave como chave pública (identidade), este processo é representado pelo passo 1.3. O último processo executado é o processo 1.4 , onde juntamente com cada palavra chave é guardado a chave secreta da criptografia simétrica, esta chave é guardada cifrada pelo esquema IBE, a chave pública utilizada é a mesma utilizada para cifrar a palavra.

O próximo passo no sistema é efetuar buscas. Para efetuar buscas deverá ser preenchido no mínimo o campo 'Palavra Chave' . O processo de busca de palavras esta exemplificado na Figura 4.11.

A Figura 4.11 exemplifica o processo de busca em um banco de dados cifrado. O primeiro processo a ser executado é o 1.1, onde é efetuada a pesquisa de todas as 


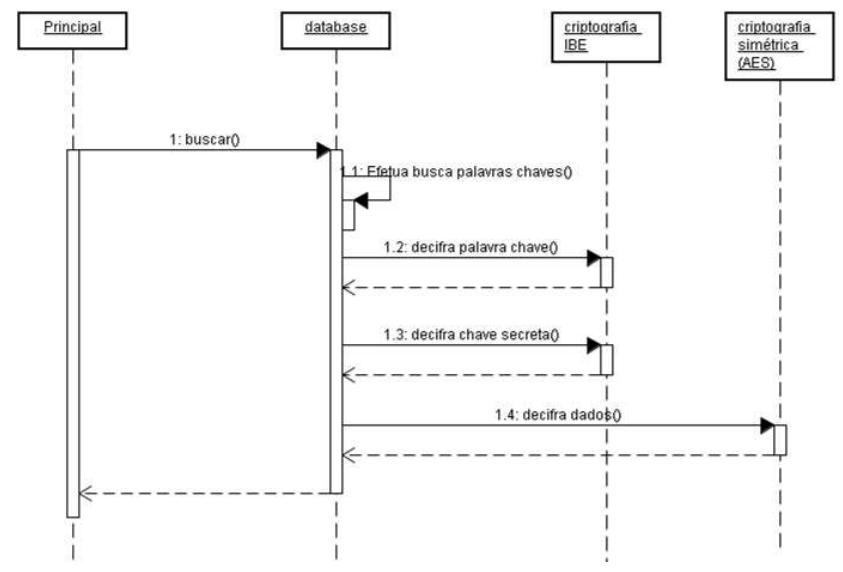

Figura 4.11: Implementação de busca de palavra em banco de dados cifrado Diagrama de seqüência - Operação buscar.

palavras chaves, no processo 1.2 tenta-se decifrar cada palavra chave buscada do banco de dados utilizando a palavra que está sendo buscada como chave pública (identidade). Caso a palavra resultante da decifração da palavra chave resgatada do banco de dados seja igual a palavra chave fornecida na busca, então parte-se para o item 1.3, caso contrário o próximo registro é tentado. No processo 1.3, decifra a chave secreta da criptografia simétrica utilizando a palavra buscada como chave pública. Com a chave secreta em mãos, os dados do registro são decifrados. Após estes processos é retornado o registro para a interface do usuário.

\subsubsection{Exemplificando o funcionamento da Busca Cifrada}

Para entender o funcionamento do sistema, consideramos o seguinte frase como exemplo:Computadores não resolvem problemas, eles executam soluções.

Para criação de palavras chaves é necessário dividir as frases e somente as palavras que tiverem mais que quatro letras serão consideradas como uma palavra chave. Dessa forma, teremos seis palavras chaves para esta frase: Computadores, resolvem, problemas, eles, executam e soluções.

Para cada frase inserida no sistema, o sistema gera uma chave privada e cifra o registro inteiro. Para cada palavra chave encontrada na frase, o sistema cifra, utilizando 
a própria palavra como chave assimétrica. Desta forma, teremos um total de 8 processos de criptografia ( 7 processos utilizando a criptografia assimétrica IBE, 6 palavras chaves e 1 criptografia utilizando simétrica. A tabela 4.1 apresenta os tempos para execução do processo de inserção para esta frase:

\begin{tabular}{llr}
\hline Processo & Palavra & Tempo \\
\hline Criptografia assimétrica (AES) & & 0 \\
Geração chave simétrica & Computadores & 0 \\
Criptografia simétrica (IBE) da palavra & Computadores & 1953 \\
Geração chave simétrica & resolvem & 0 \\
Criptografia assimétrica (AES) & resolvem & 1953 \\
Geração chave simétrica & problemas & 0 \\
Criptografia simétrica (IBE) da palavra & problemas & 2047 \\
Geração chave simétrica & eles & 0 \\
Criptografia simétrica (IBE) da palavra & eles & 2031 \\
Geração chave simétrica & executam & 0 \\
Criptografia simétrica (IBE) da palavra & executam & 2016 \\
Geração chave simétrica & soluções & 0 \\
Criptografia simétrica (IBE) da palavra & soluções & 1953 \\
\hline Total de tempo para inserção & & $\mathbf{1 1 9 5 3}$ \\
\hline
\end{tabular}

Tabela 4.1: Tempo de Inserção de palavras chaves.

Conforme os dados apresentados, conclui-se que o processo de inserção de palavras chaves é lento. Neste exemplo foi necessário 11953 milisegundos para esta operação.

Para cada busca, o sistema resgata todos os registros, efetua o processo de decifração (IBE) em cada registro utilizando a chave privada como a palavra buscada. Caso o retorno do registro tenha o mesmo valor da palavra, quer dizer que o registro foi buscado corretamente, sendo assim ele decifra a chave privada utilizada para cifrar o dado. A tabela 4.2 apresenta estes dados:

\subsection{Infra-estrutura de um modelo de acordo de chaves baseado na identidade}

Para demonstrar a viabilidade da utilização prática dos esquemas de acordo de chaves utilizando criptografia baseada em identidade, foram utilizados dois programas: um PKG e um Chat Seguro. 


\begin{tabular}{llr}
\hline Processo & Palavra & Tempo \\
\hline Tempo para resgatar a chave privada IBE & executam & 187 \\
Tempo para decifrar & Palavra 1 & 953 \\
Tempo para decifrar & Palavra 2 & 969 \\
Tempo para decifrar & Palavra 3 & 953 \\
Tempo para decifrar & Palavra 4 & 938 \\
Tempo para decifrar & Palavra 5 & 984 \\
Tempo para decifrar chave privada AES & Palavra 5 & 922 \\
Tempo para decifrar a informação & Palavra 5 & 16 \\
Tempo para decifrar & Palavra 6 & 922 \\
\hline Total de tempo para busca & & $\mathbf{6 8 5 9}$ \\
\hline
\end{tabular}

Tabela 4.2: Tempo de Busca de palavras chaves.

$\mathrm{Na}$ implementação desses dois programas foram utilizados a biblioteca MIRACL versão 5.20 da Shamus Software Ltd e a IDE Borland C++Builder Enterprise Suite versão 6.0. Também foi utilizado um conjunto de componentes para comunicação TCP/IP chamado INDY que vem distribuído junto com a IDE C++Builder.

\subsubsection{Ambiente de Acordo de Chaves}

No programa do PKG foi implementado o esquema IBE de Boneh e Franklin que faz parte dos exemplos disponibilizados junto com a biblioteca MIRACL. O programa de Chat Seguro foi implementado com intuito de apresentar de forma didática os esquemas de acordo de chaves apresentados no capítulo 2. Os esquemas Smart e Shim foram implementados para fins de comparação e apresentação. Tais esquemas foram apresentados de forma sucinta no III Workshop em Segurança da Informação - SEGINFO no formato de uma palestra e de forma mais detalhada em prática, em um minicurso na $4^{\text {th }}$ International Conference on Cyber Crime Investigation.

Tais esquemas foram implementados com cunho acadêmico para auxiliar no entendimento dos esquemas propostos. Alguns aspectos de segurança não foram levados em consideração nesta implementação:

1. A chave mestre do PKG é armazenada em um arquivo na mesma pasta do seu executável, não havendo qualquer política de segurança restringindo o acesso a esse arquivo;

2. A chave privada solicitada ao PKG deveria ser guardada em local seguro. No 
Chat Seguro é gerado um arquivo com essa chave e armazenado na mesma pasta onde está o programa executável;

3. O gerador de números randômicos utilizado é um seed em tempo extraído do sistema operacional, sendo assim, é um gerador de números pseudo randômicos, não confiável para outros usos que não o acadêmico;

4. A curva elíptica utilizada foi $y^{2}=\left(x^{3}+1\right) \bmod p$, sugerido nos exemplo disponibilizados junto com a biblioteca MIRACL.

Para demonstrar o funcionamento desses dois programas, são apresentadas várias telas capturadas durante a simulação de uma comunicação entre duas pessoas, envolvendo a geração dos parâmetros iniciais do PKG, a solicitação e geração das chaves primárias para os dois identificadores particulares, nesse caso jp.lenz@gmail.com e mehran@sociesc.com.br, a criação da chave resultante do esquema de Shim, mostrando que os dois lados calculam a mesma chave de sessão, pré-requisito básico para que ocorra a comunicação, já que os dois lados cifram e decifram as mensagens recebidas usando um algoritmo simétrico de criptografia, nesse exemplo o AES com uma chave de 256 bits gerada através de um hash sobre a chave de sessão calculada.

Para utilizar o esquema de acordo, inicialmente é necessário configurar o ambiente. Definir os parâmetros de PKG, bem como o identificardor pessoal e o tempo de validade do acordo de chaves. A figura 4.12 apresenta este cenário.

A figura 4.13 apresenta a geração dos parâmetros pelo PKG.

A figura 4.14 apresenta a solicitação da chave privada.

\subsubsection{Chat Seguro}

Chat seguro é um aplicativo que permite visualizar o cálculo simultâneo de acordo de chaves em ambos os lados da comunicação. Além disso, ilustra como ocorre a revogação e cálculo de um novo acordo. Este aplicativo opera nos esquemas propostos por Smart e Shim.

\subsubsection{Operações realizadas}

1. O usuário que inicio o acordo (A) obtem parâmetros necessários do PKG; 


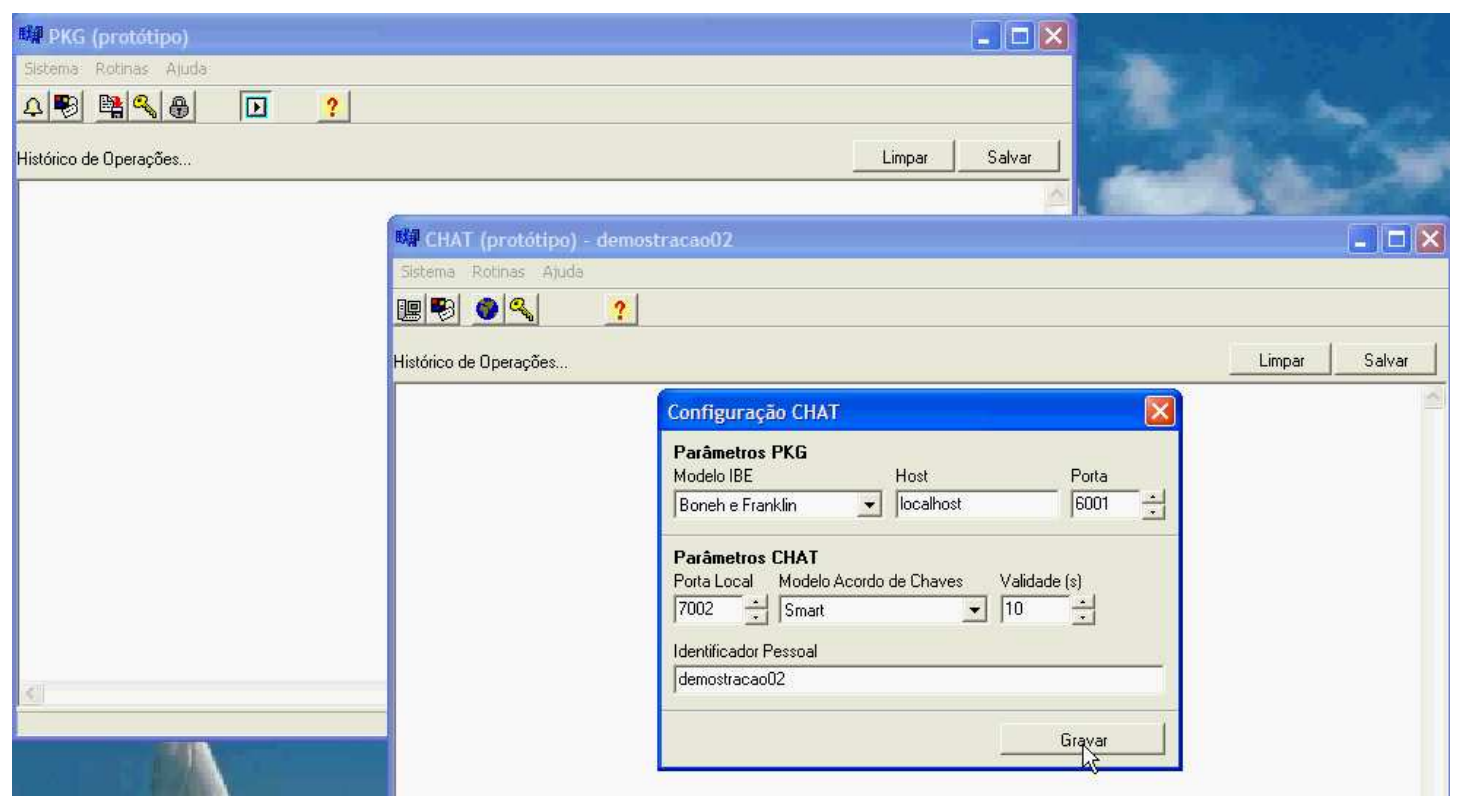

Figura 4.12: Configuração do Ambiente.

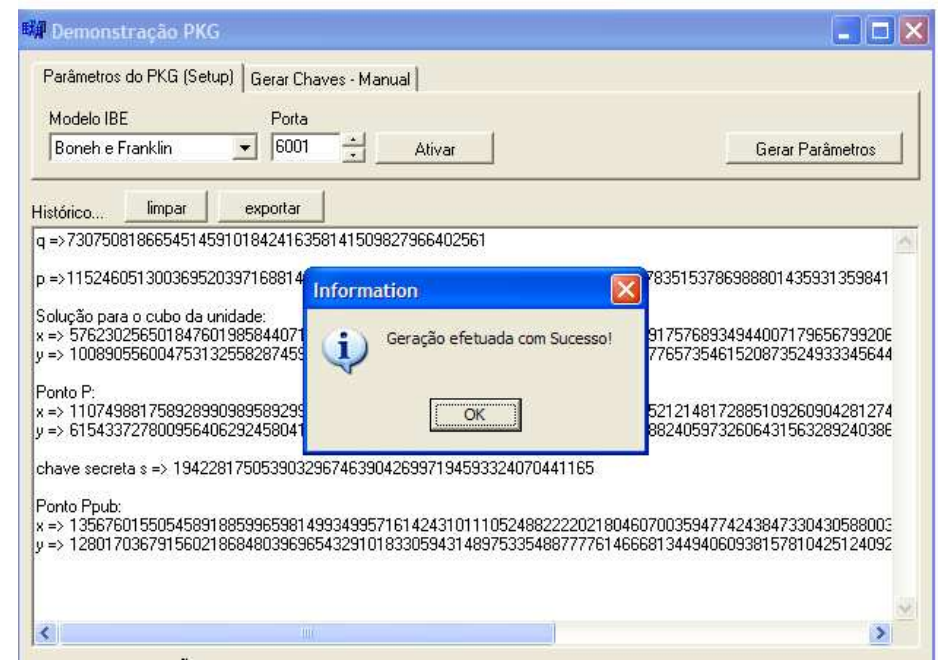

Figura 4.13: Geração de parâmetros iniciais do PKG. 


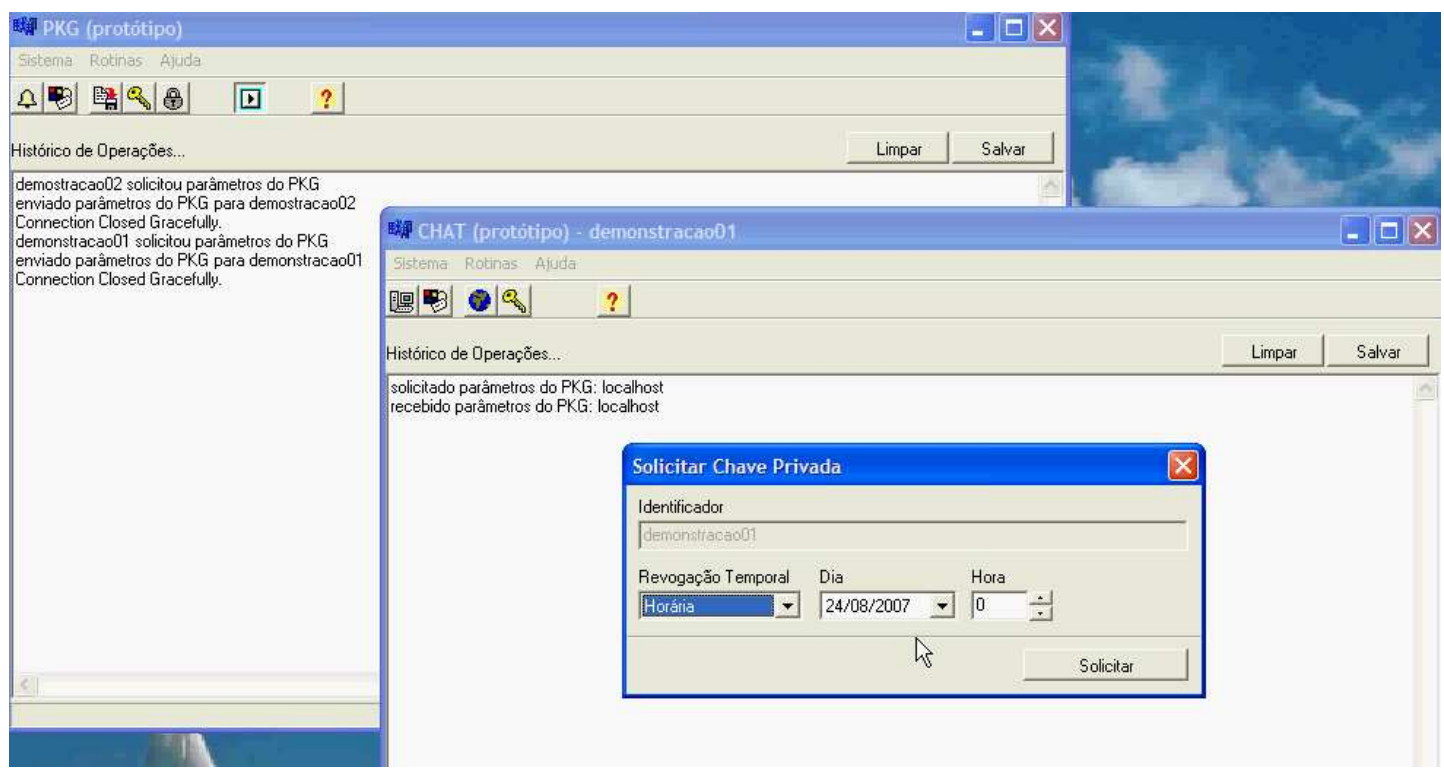

Figura 4.14: Solicitação da Chave Privada.

2. Recupera chave privada do usuário que inicio o acordo (A);

3. Calcula o valor de $T_{A}: T_{A}=a P$

4. Envia $T_{A}$ para o usuário B;

5. O usuário B recebe $T_{A}$;

6. O usuário B obtem parâmetros necessários do PKG;

7. Recupera chave privada do usuário B;

8. Calcula o valor de $T_{B}: T_{B}=b P$;

9. O usuário B de posse de $T_{A}$, executa um mapeamento da chave pública de A para um ponto da curva elíptica definida pelo $\mathrm{PKG}$;

10. Então o usuário B, para o cálculo da chave $K$, aplica a equação $K_{B A}=e\left(b P_{p u b}+\right.$ $\left.S_{B}, T_{A}+Q_{A}\right)$

11. O usuário B envia $T_{B}$ para o usuário A;

12. O usuário A recebe $T_{B}$;

13. O usuário A de posse de $T_{B}$, executa um mapeamento da chave pública de B para um ponto da curva elíptica definida pelo $\mathrm{PKG}$; 
14. Então o usuário A, para o cálculo da chave $K$, aplica a equação $K_{A B}=e\left(a P_{p u b}+\right.$ $\left.S_{A}, T_{B}+Q_{B}\right)$.

Algumas considerações podem ser feitas a medida que, o usuário A que iniciou o acordo, após enviar $T_{A}$ para o usuário $\mathrm{B}$, aguarda o usuário $\mathrm{B}$ completar todo o processo de cálculo da sua variável e enviá-la. Além disso a chave $K$ compartilhada não é enviada em nenhum momento do acordo, mas assim, calculada independentemente por ambos os lados do acordo.

A partir deste momento, estabelece-se uma conexão TCP/IP com o outro lado que deseja conversar. Após acontecer essa conexão os dois lados calculam a mesma chave $K$, independente um lado do outro, lembrando que o lado do usuário mehran@sociesc.com.br tem que efetuar todo o procedimento de recuperação dos parâmetros do PKG, geração e envio da sua chave privada.

A figura 4.15 apresenta o cenário da revogação de acordo de chave.

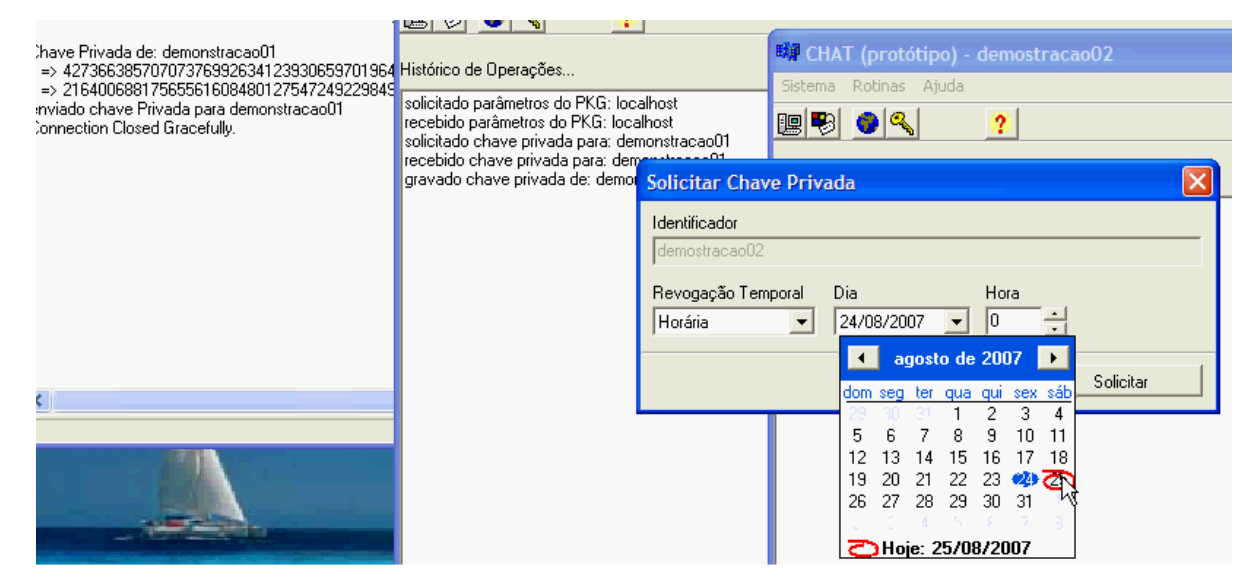

Figura 4.15: Revogação de Acordo de Chave.

A figura 4.16 apresenta o funcionamento da opção da validade do acordo de chave.

A figura 4.17 apresenta um novo acordo de chaves realizado a patir do momento de estabelecimento de validade.

Para ilustrar como ocorre a mudança do acordo após expiração da condição previamente estabelecida (dia 25/08/2007, às 22 horas), mudou-se o tempo, conforme ilustado na figura 4.18 .

Após a mudança da condição, muda-se também o acordo, conforme ilustrada na 


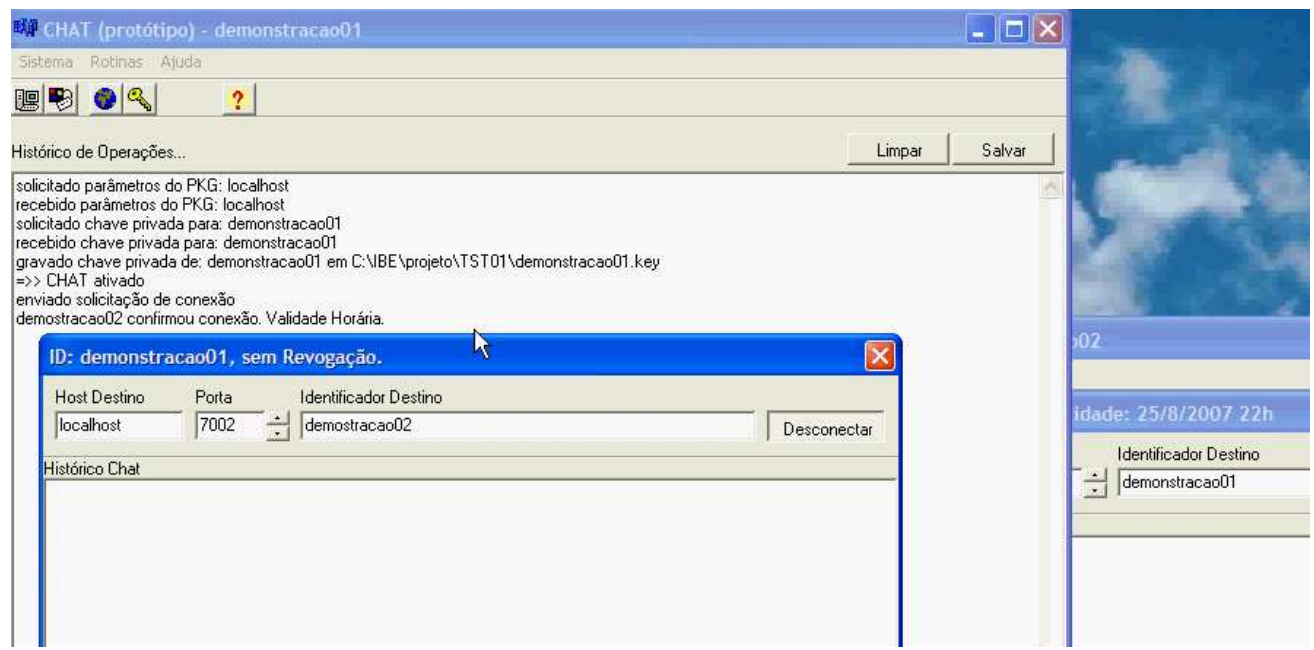

Figura 4.16: Validade de Acordo de Chave.

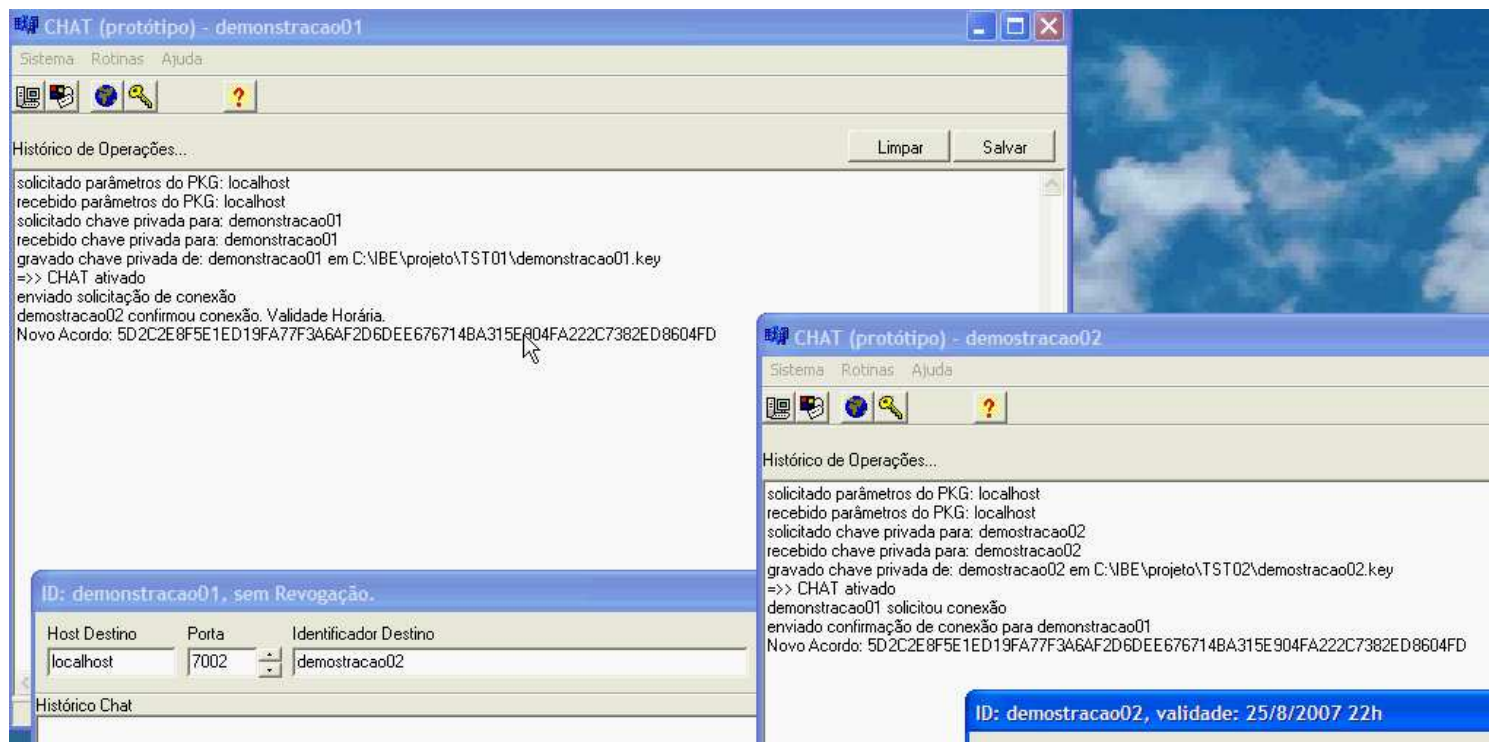

Figura 4.17: Novo Acordo de Chave.

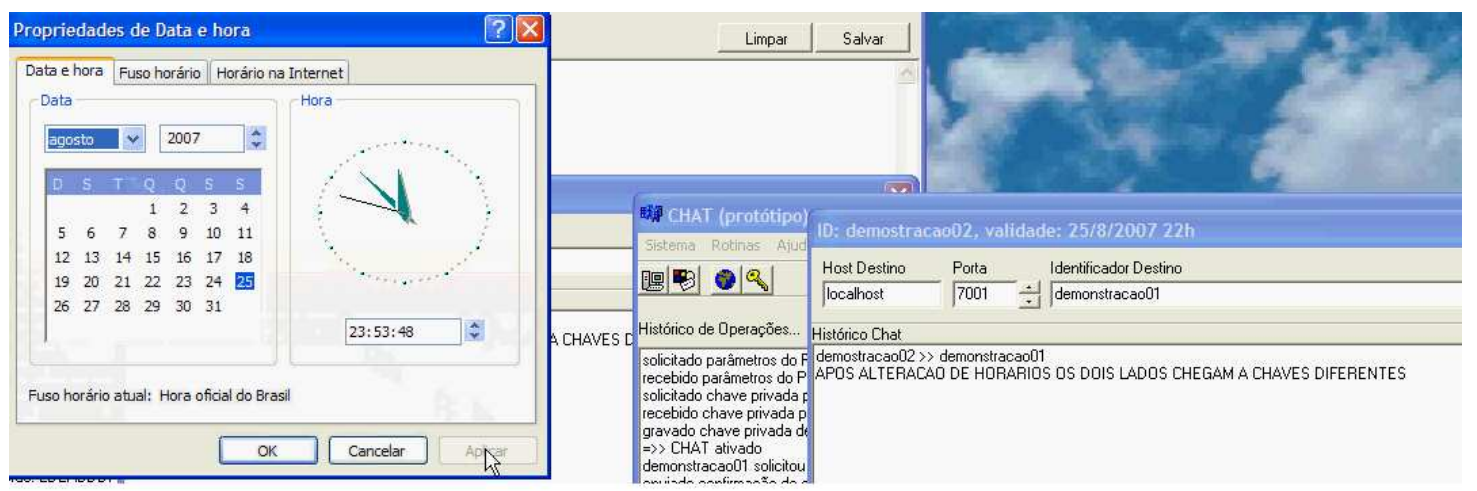

Figura 4.18: Revogação da Condição do Acordo. 
figura 4.19.

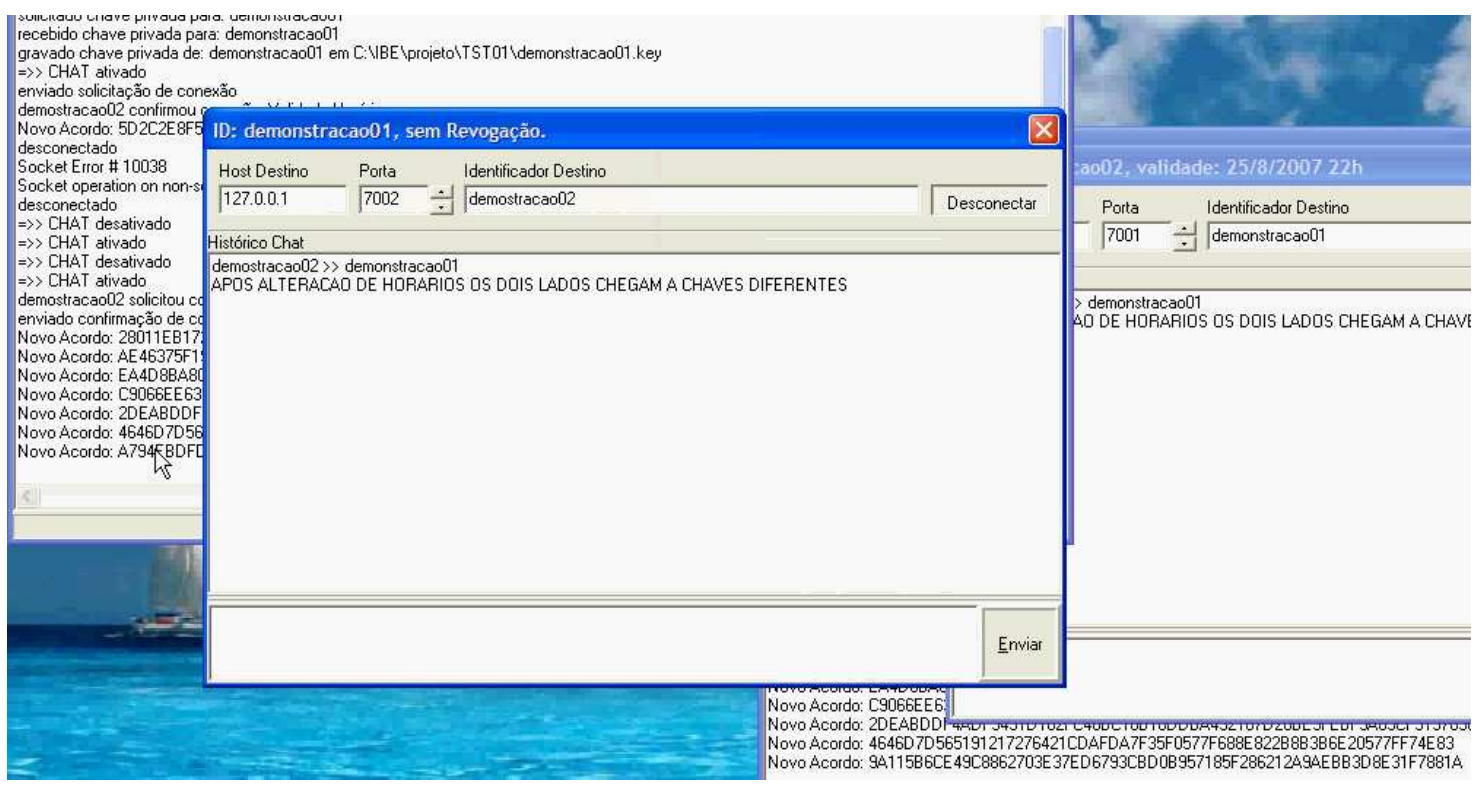

Figura 4.19: Mudança do Acordo.

Conforme ilustra a figura 4.20, ocorre a conversação, mas de forma cifrada e de impossível compreensão. Os acordos de chaves calculados continuam sendo diferentes, pois houve uma revogação anterior e o critétrio de ter a mesma chave foi violado.

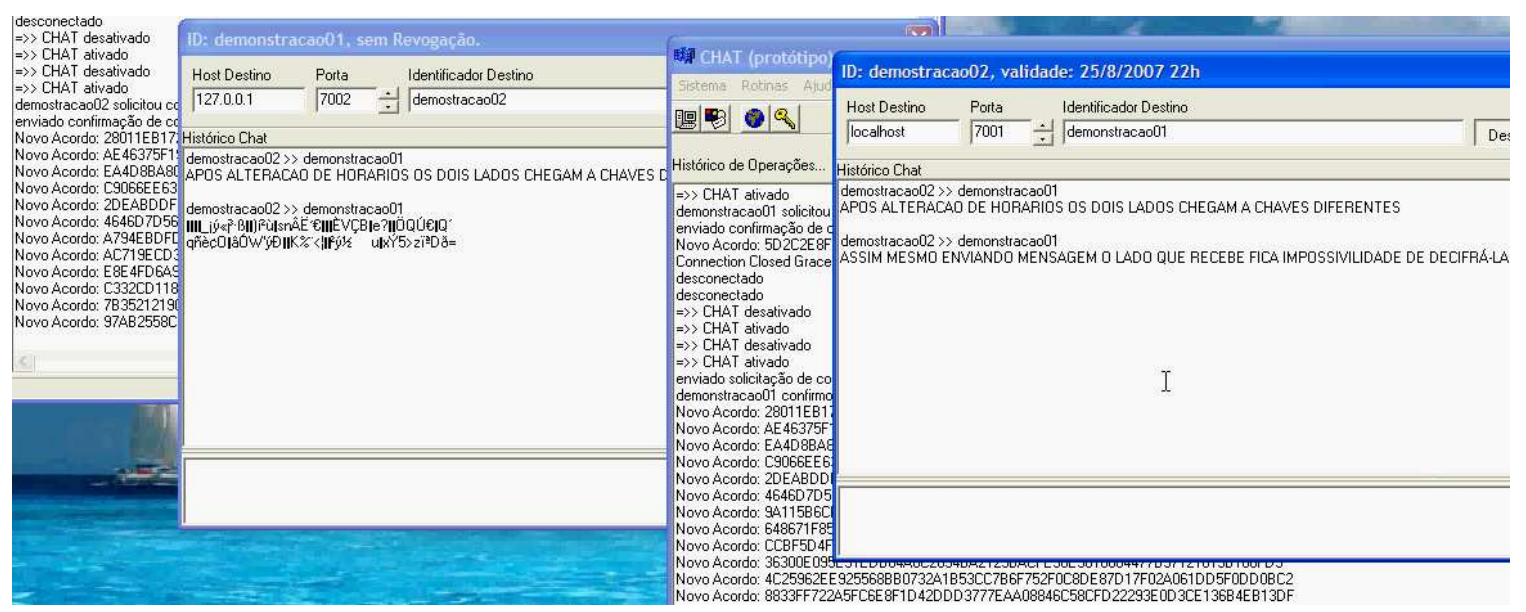

Figura 4.20: Conversação cifrada.

Após do retorno do critério (dia 25/08/2007, 22 horas), será estabelecido um novo acordo que permite a conversação de forma não cifrada, conforme ilustada na figura 4.21 . 


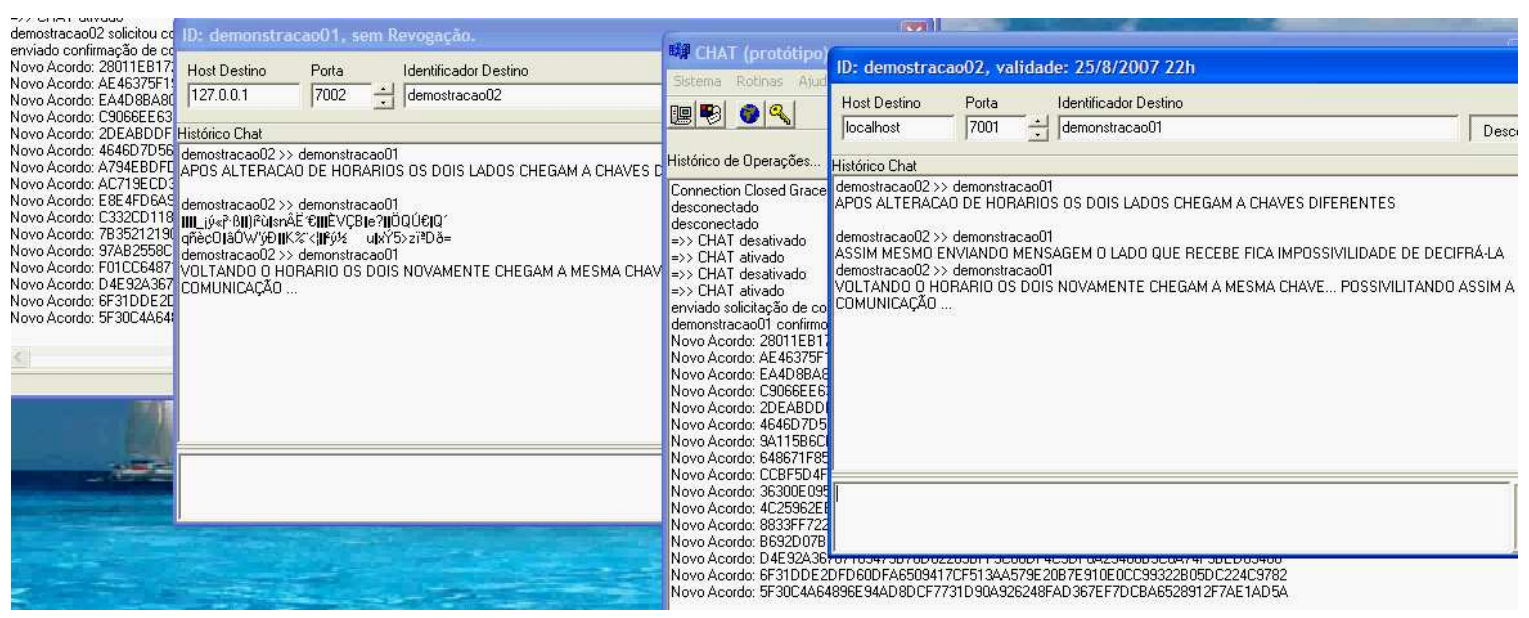

Figura 4.21: Novo Acordo.

\subsubsection{Comparativo entre os modelos de Smart e Shim}

Esta seção pretende ilustar um comparativo entre os esquemas de Smart e Shim para melhor entendimento e diferenças em termos de tempo das operações envolvidas.

A diferença entre os esquemas de Smart e Shim se concentra no momento do cálculo dos segredos compartilhados, enquanto no esquema proposto por SMART $K_{A B}$ e $K_{B A}$ utilizam dois emparelhamentos, no esquema proposto por SHIM acontece apenas um, como mostra a tabela 4.3.3:

Tabela 4.3: Comparativo SMART x SHIM no números de emparelhamentos

\begin{tabular}{lll}
\hline Esquema & $K_{A B}$ & $K_{B A}$ \\
\hline$S M A R T$ & $K_{A B}=e\left(a \cdot Q_{B}, P_{p u b}\right) e\left(S_{A}, T_{B}\right)$ & $K_{B A}=e\left(b \cdot Q_{A}, P_{p u b}\right) e\left(S_{B}, T_{A}\right)$ \\
$S H I M$ & $K_{A B}=e\left(a P_{p u b}+S_{A}, T_{B}+Q_{B}\right)$ & $K_{B A}=e\left(b P_{p u b}+S_{B}, T_{A}+Q_{A}\right)$ \\
\hline
\end{tabular}

A inclusão de três temporizadores permite obter os valores dos tempos de acordo e comunicação, utilizados para comparar os dois esquemas como mostra a figura 4.22:

O comparativo entre os dois esquemas foi feito da seguinte maneira:

a) Foram estipulados três tempos a serem utilizados:

1. Tempo 1: esse tempo representa um valor de unidade temporal(ms), cal- 


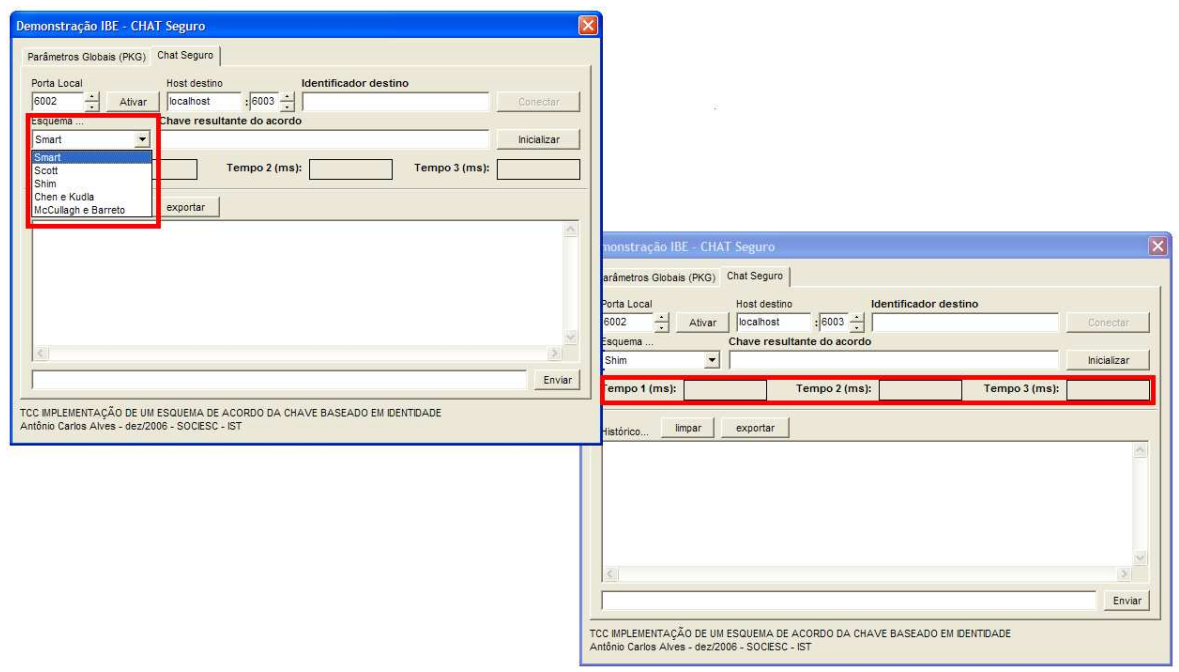

Figura 4.22: Identificação dos campos: Tempo 1, Tempo 2, Tempo 3.

culado a partir do momento o lado iniciante começa o processo e envia a variável $T_{A}$ para o outro participante.

2. Tempo 2: esse tempo representa um valor de unidade temporal(ms), calculado a partir do momento em que o participante receptor recebe a variável $T_{A}$ e é finalizado quando envia ao participante iniciante a variável $T_{B}$;

3. Tempo 3: esse tempo representa um valor de unidade temporal(ms), calculado a partir do momento em que o participante que iniciou a conversação recebe $T_{B}$ e finaliza após armazenar a chave $K$ calculada;

b) A figura 4.23 apresenta os tempos de acordo com o diagrama proposto. 

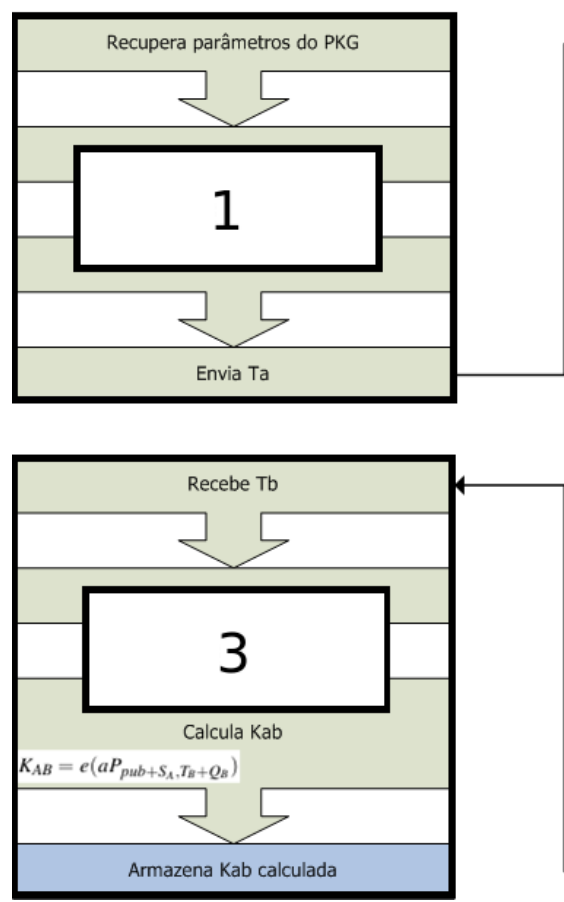

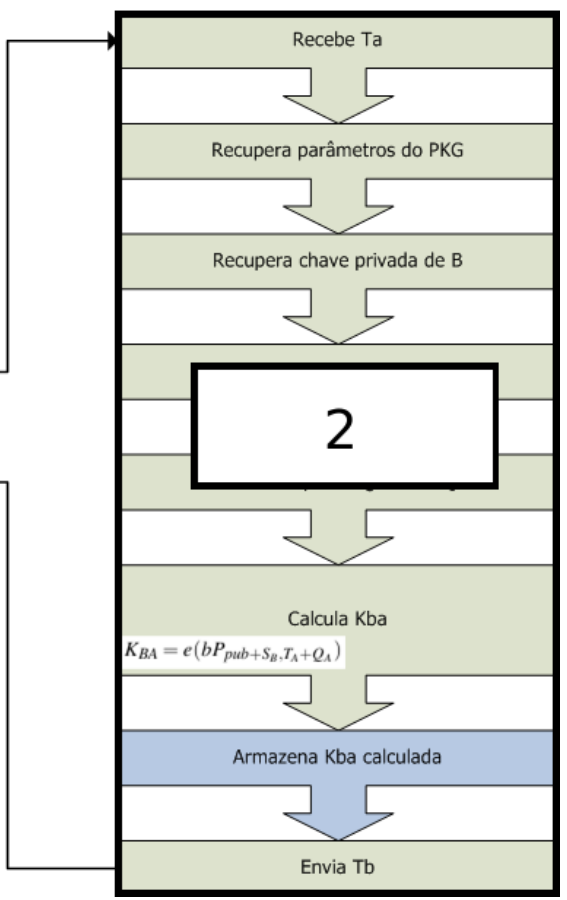

Figura 4.23: Diagrama da disposição dos tempos.

c) Baseado nesses três tempos, criou-se uma tabela, na qual, estão contidos os resultados(tempos) obtidos por cada modelo implementado.

Tabela 4.4: Comparativo SMART x SHIM de acordo com os temporizadores

\begin{tabular}{lllll}
\hline Esquema & Tempo 1 & Tempo 2 & Tempo 3 & Tempo Total \\
\hline SMART & $17,4 \mathrm{~ms}$ & $59,3 \mathrm{~ms}$ & $46,2 \mathrm{~ms}$ & $122,9 \mathrm{~ms}$ \\
SHIM & $17,1 \mathrm{~ms}$ & $33,2 \mathrm{~ms}$ & $24,1 \mathrm{~ms}$ & $74,4 \mathrm{~ms}$ \\
\hline
\end{tabular}

Nota-se que os tempos são muito parecidos na primeira parte do comparativo, relacionado ao Tempo 1, isso se dá, pela razão de que tanto Shim quanto Smart seguem os mesmos passos até que, o participante que inicia a conversa (A), envia a variável $T_{A}$ para o outro participante (B).

O Tempo 2 que está relacionado ao momento que o participante B recebe a variável $T_{A}$ e inicia a sua sequência, neste momento nota-se uma grande diferença entre os resultados encontrados. Como descrito na tabela 4.3.3, isso se explica porque, Smart 
no instante em que calcula a chave compartilhada $K_{B A}$ utiliza 2 emparelhamentos, já Shim utiliza apenas 1 para o mesmo cálculo. Isso faz com que o custo computacional do Tempo 2 seja praticamente o dobro para Smart, com relação ao Tempo 2 para Shim.

Da mesma forma o Tempo 3 tem um resultado bem diferente para os dois esquemas. Enquanto o participante A, no modelo proposto por Smart, rebece a variável $T_{B}$ e inicia sua sequência para o cálculo da chave compartilhada $K_{A B}$ utilizando 2 emparelhamentos, o mesmo participante A, agora no modelo proposto por Shim, utiliza apenas 1 emparelhamento, justificando a grande de diferença entre os resultados para o Tempo 3 dos dois modelos.

\subsubsection{Implementação de Segurança Adicional}

A implementação de níveis adicionais de segurança foi feita através de:

- Disponibilidade Temporal. O Acordo de Chave fica disponível em certo periodo pré-estabelecido de tempo.

- Dupla Autenticação:

- Senha;

- Tabela Aleatória de Posições.

\subsection{Aplicabilidades}

Órgãos governamentais, Instituições de pesquisa com troca freqüente de dados, embutir nos ERP's existentes, criar módulos para protocolos de Web, redes móveis. O modelo de busca cifrada contendo tais funcionalidades poderá ser aplicado em diversos cenários, como por exemplo:

- Controle de licença flutuante de aplicativo;

- Licença de avaliação de um aplicativo;

- Verificação genuína de um aplicativo. A verificação genuína de um aplicativo auxilia na prevenção contra eventuais cópias piratas. Por exemplo, um aplicativo 
que possui uma condição de limitação de tempo, não funcionará corretamente após expiração do seu tempo pré-estabelecido.

- Níveis adicionais de segurança. Podem ser implementados outros níveis de segurança, como senha, condições temporais e outros controles de autenticação via software e hardware que aumentam o nível de segurança, no caso de algum ataque ou comprometimento de toda ou uma parte da chave.

\subsection{Conclusões}

Este capítulo inicialmente apresentou de forma objetiva os detalhes dos experiementos realizados com esquemas de cifração, esquema de pesquisa de dados cifrados e esquemas de acordo de chave. A apresentação de tais experimentos com este nível de detalhamento auxilia na aprendizagem didática dos diversos componentes de um ambiente criptográfico baseado na identidade, no qual, pode cifrar dados, buscar dados cifrados em uma base de dados cifrados e fazer acordo de chaves com níveis adicionais de segurança.

O estado da arte do mecanismo de busca por palavras chaves em dados cifrados baseado em identidade de forma sucinta foi apresentado neste capítulo. Os modelos propostos se diferenciam pelo método de interação com as palavras chaves. Além disso, o presente artigo apresentou as principais contribuições dos diversos modelos de busca de dados cifrados baseados em identidade. Em especial, foi implementado o modelo de Waters, por se tratar de uma aplicação extremamente importante que é auditoria de registros $(\log )$.

A implementação do modelo proposto por (WATERS et al., 2004) permitiu visualizar as características relevantes do modelo abordado, de forma didática e fácil. Desta forma, este modelo pode ser um ponto de partida para futuros desenvolvimentos do sistema com mais funcionalidades presentes e destacados por os autores em outros artigos relacionados neste trabalho.

Existem várias aplicações que podem usufruir os benefícios de busca de dados cifrados baseado em identidade e desta forma contribuir com a redução da vulnerabilidades existentes em um ambiente corporativo, em destaque, os servidores de bases de dados. 
Através das medições realizadas de tempo em esquema de busca do (WATERS et al., 2004), pode-se perceber a demora da cifração e a busca dos dados na base de dados. Sugere-se como trabalhos futuros, implementar a otimização de curvas para obter melhores resultados em termos de tempo de resposta para viabilizar o projeto como um todo.

Os esquemas de cifração implementados neste capítulo servem para visualização do que é possível e quanto tempo demora o estabelecimento de acordo. O comparativo entre os dois esquemas apresentados ilustrou claramente a tal diferença em termos de tempo de resposta. Os níveis adicionais de segurança abordados foram apresentados através do experimento realizado. A sugestão para os trabalhos futuros no que se refere aos esquemas de acordo de chaves, é implementar outros esquemas abordados no capítulo 2 do presente trabalho e fazer um comparativo em termos de sobrecarga na rede, bem como tempo de resposta e estudar outros níveis adicionais de segurança, como por exemplo a utilização de dispositivos de hardware como mecanismos de autenticação biométrica. 


\section{Integração de Criptografia Baseada na Identidade e Criptografia de Chave Pública}

Este capítulo tem por objetivo citar sucintamente as propriedades interessantes de criptografia de chave pública e modelo de criptografia baseada na identidade. Logo em seguida será apresentada formas de integração de ambos para aproveitar as melhores características de cada modelo, e dessa forma, implementar um ambiente contendo propriedades interessantes de ambos os modelos.

\subsection{Infra-estrutura de Chaves Pública}

A criptografia de chave pública providencia um par de chaves para que os usuários não necessitem compartilhar nenhum segredo entre eles. Enquanto a chave privada é utilizada para o processo de assinatura e cifração de mensagens ou arquivos, a pública é para decifração e verificação de assinaturas.

Desta forma, há necessidade de uma estrutura de armazenamento e gerenciamento de tais chaves. Além disso, precisa-se a finalidade de cada tipo de chave, bem como a sua validade e no caso de comprometimento da chave, a mesma precisa ser revogada. A infra-estrutura de chaves pública é um conjunto de software e hardware implementada com criptografia de chave pública que providencia meios para emissão, armazenamento e gerenciamento de certificados e poderá ser utilizado em uma aplicação específica ou um conjunto de aplicações.

Tal infra-estrutura possui uma autoridade raiz (AR), uma ou mais autoridade certificadora, um conjunto de serviço de diretórios para armazenamento de certificados 
e uma Lista de Certificados Revogados. A figura 5.1 apresenta a arquitetura de ICP. Como exemplo de ICP podem ser comentados, bancos, provedores de serviços e comércio eletrônico em geral. Tais infra-estruturas providenciam um ambiente de confiança para fornecedor e comprador de serviço.

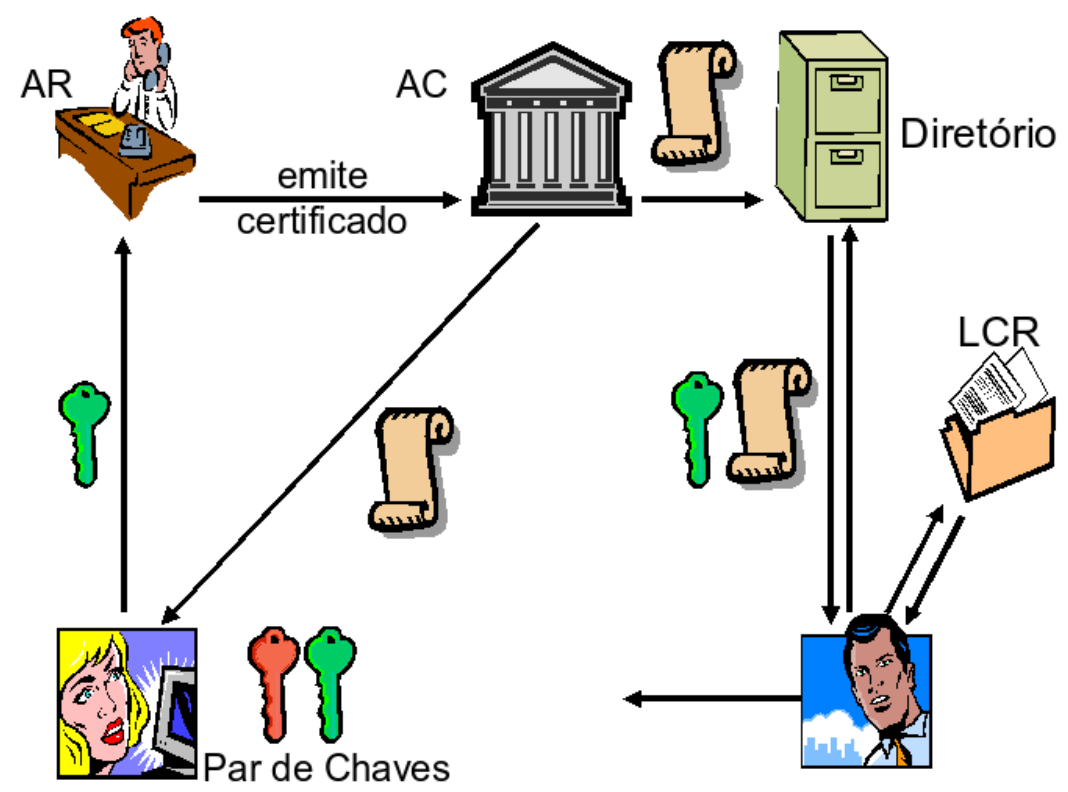

Figura 5.1: Arquitetura de ICP

Infra-estrutura de Chaves Públicas Brasileira como é normalmente conhecido como ICP-Brasil, através do MP 2.200-2 é responsável pela emissão e geração de certificados digitais no Brasil. Tal infra-estrutura oferece serviços que suportam autenticação, confidencialidade, Integridade, irretratabilidade e estabelecimento de chaves. A figura 5.2 representa a estrutura resumida do $\mathrm{ICPBr}$, apenas com as Autoridades Certificadoras de $1^{o}$ e $2^{o}$ nível $^{1}$.

Infelizmente uma infra-estrutura de chaves públicas tem os seguintes problemas:

- Custo elevado em escala para registro de usuários;

- Necessidade de proteção para chaves privadas dos usuários;

\footnotetext{
${ }^{1}$ Figura extraída do site de ICPBrasil.
} 


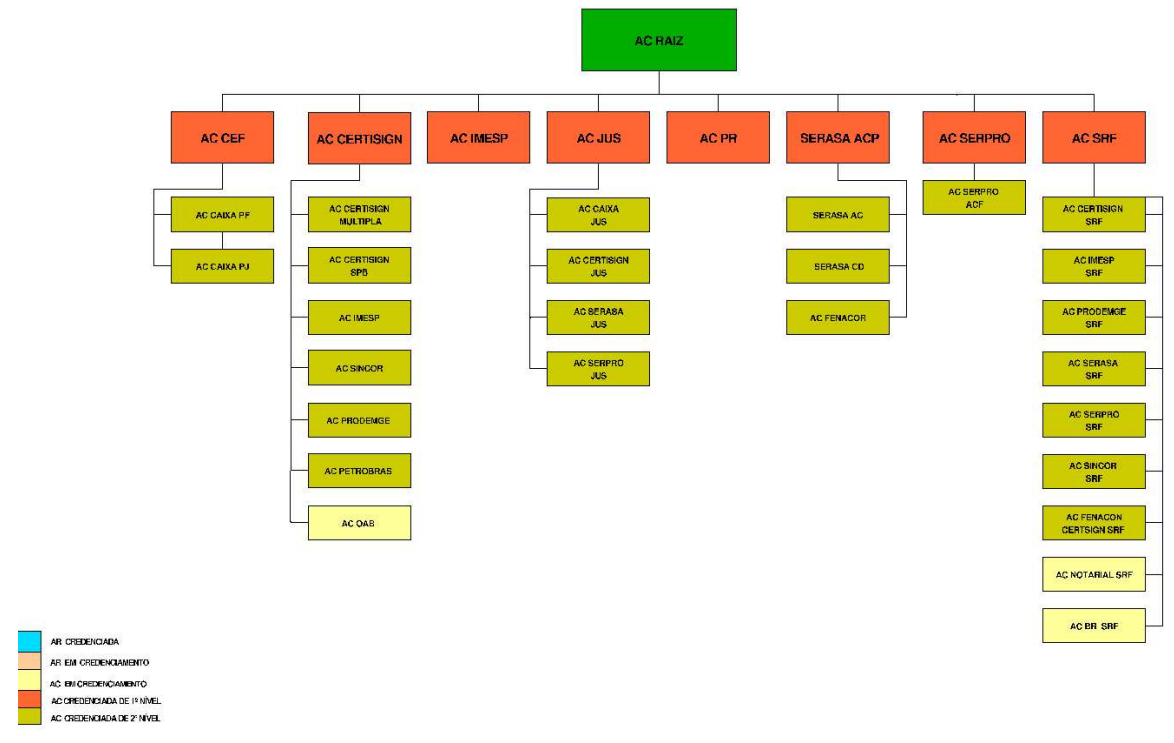

Figura 5.2: Estrutura de ICPbr

- Gerenciamento ineficiente de revogação;

- Impossibilidade de implementar níveis adicionais de segurança junto com o certificado digital.

\subsection{Criptografia baseada na identidade}

O capítulo 2 apresentou de modo detalhado as principais características de um sistema criptográfico baseado na identidade. Vale apena ressaltar algumas características novamente:

- Sem necessidade de emissão, distribuição e gerenciamento de certificados;

- Revogação simplificada, através de implementação de disponibilidade temporal;

- Recuperação de chave privada embutida;

- Implementação de Níveis Adicionais de Segurança;

- Problema de custódia da chave.

O problema de custódia da chave ocorre devida à existência da chave-mestra, que com o seu comprometimento, poderá ser totalmente comprometido toda estrutura de 
sistema criptográfico baseado na identidade. Além disso, é difícil de implementar e garantir a irretratabilidade em sistemas criptográficos baseados na identidade.

Uma possível solução para garantir a irretratabilidade e reduzir o problema de custódia da chave é a integração de uma infra-estrutura de chave pública e um sistema criptográfico baseado na identidade para aproveitar as vantagens existentes em cada modelo. A próxima seção descreve outro modelo que pode servir como um modelo intermediário entre um sistema de criptografia chave pública e um sistema de criptografia baseado na identidade.

\subsection{Criptografia de Chave Pública Sem Certificado}

Um sistema de criptografia de chave pública sem certificado, ou Certificateless Public Key Cryptography (CL-PKC), introduzido por Al-Riyami e Paterson (2003), é um sistema que consiste em cinco algoritmos (inicializar, extrair, publicar, cifrar e decifrar). Este modelo também dispensa a utilização de certificado digital, pois a chave de cifração é uma concatenação de identidade com a chave pública. Um CLPKC combina algumas propriedades interessantes de PKC e IBC. Um CL-PKC não tem o problema de custódia da chave e não necessita de uma Autoridade Certificadora para gerar a confiança. Tal confiança já existe de forma implícita (BLAKE et al., 2005). Desta forma um CL-PKC é um sistema confiável que garante a irretratabilidade e não possui a infra-estrutura complexa de um PKC.

A tabela 5.1 apresenta um comparativo de propriedades existentes em cada modelo e modelos integrados.

Tabela 5.1: Comparativo de propriedades em diversos modelos.

\begin{tabular}{lcccc}
\hline Prop-Modelo & PKC & IBC & IBC + PKC & IBC + CL-PKC \\
\hline Custódia da Chave & não & $\operatorname{sim}$ & não & não \\
Irretratabilidade & $\operatorname{sim}$ & não & $\operatorname{sim}$ & $\operatorname{sim}$ \\
Estrutura Complexa & $\operatorname{sim}$ & não & não & não \\
Disponibilidade Temporal & não & $\operatorname{sim}$ & $\operatorname{sim}$ & $\operatorname{sim}$ \\
Revogação Facilitada & não & $\operatorname{sim}$ & $\operatorname{sim}$ & $\operatorname{sim}$ \\
Amparo Legal & $\operatorname{sim}$ & não & $\operatorname{sim}$ & não \\
\hline
\end{tabular}




\subsection{Conclusões}

Este capítulo apresentou, de forma sucinta, uma forma possível de integração entre sistemas de criptografia de chave pública e sistema de criptografia baseado na identidade. A integração auxilia na redução dos problemas de irretratabilidade e custódia da chave de um sistema de criptografia baseado na identidade. Dessa forma, um ambiente criptográfico baseado na identidade pode ser utilizado de forma confiável e amparado legalmente quando utilizado com uma infra-estrutura de chave pública brasileira. 


\section{Consideraç̧̃es Finais}

O presente trabalho apresentou, inicialmente, fundamentos de criptografia baseada na identidade através de especificação de alguns esquemas de cifração, assinatura e acordo de chaves e um comparativo de custo computacional de operações envolvidas no capítulo 2. Além disso, o capítulo apresentou um comparativo entre criptografia RSA e criptografia baseada em curvas elípticas.

O capítulo 3 definiu um ambiente criptográfico baseado na identidade, apresentando detalhes importantes na otimização dos esquemas já existentes e ilustrou diversas formas de implementar tal ambiente. Também foram apresentadas formas de otimização do ambiente.

Alguns experimentos foram realizados para melhor visualização dos conceitos apresentados no capítulo 2. Dessa forma, o capítulo 4 relatou os experimentos de cifração, acordo de chaves e busca cifrada para evidenciar as aplicabilidades de criptografia baseada na identidade com disponibilidade temporal.

O capítulo 5 apresentou formas de integrar uma infra-estrutura de chaves públicas à uma infra-estrutura baseada na identidade, aproveitando das vantagens existentes em cada modelo e o que pode usufruir em modelos mistos.

No capitulo 6, apresentam-se as considerações finais e um resumo das contribuições da tese e algumas sugestões para prosseguimento de trabalhos futuros.

\subsection{Resumo das Contribuições}

O presente trabalho gerou a publicação de seguintes artigos, tutoriais e apresentações: 
1. Identity-Based Cryptography: From Theory to Practice, (MISAGHI; ZUFFO, 2007a), in Proceeding of the Fourth International Conference on Cyber Crime Investigation, volume 2, number 1, p. 37, ICCyber 2007 Guarujá, Setembro 2007.

2. Esquemas de Acordo de Chaves baseados em Identidades e suas Aplicações, (MISAGHI; SILVA; ZUFFO, 2007), Revista do IST, Volume 7, núm 8, p. 24 31, Joinville, Santa Catarina, Dez 2007.

3. Implementação de Pesquisa de Dados Cifrados Baseada em Identidade do modelo Waters, (MISAGHI; ZUFFO, 2007b), V CONGED, pp 90 -99 dos anais de "V Congresso de Gestão de Dados e Metadados Conesul", (CONGED 2007), Cascavel, Paraná, Agosto de 2007.

4. Criptossistemas Baseados em Identidade e Suas Aplicabilidades, palestra apresentada e constante no evento "Congresso de Segurança da Informação", (III SEGiNFO),UFRJ, Rio de Janeiro, Agosto de 2007.

5. Criptografia Baseada em Identidade, (MISAGHI; ZUFFO, 2006), tutorial apresentado de 33 páginas, constante nos anais do evento "8th International Symposium on Systems and Information Security", (SSI²006), São José dos Campos, São Paulo, Novembro 2006.

6. Criptossistemas Baseados em Identidade e Suas Aplicações, palestra apresentada e constante no evento "Congresso de Segurança da Informação", (I SEGiNFO),UFRJ, Rio de Janeiro, Agosto de 2005.

Os artigos e tutoriais supracitados concretizam as seguintes contribuições:

1. Foi apresentado um comparativo entre esquemas de acordo de chaves com foco nas suas aplicações existentes;

2. Foi implementada a aplicação da pesquisa de dados cifrados baseada em identidade:

- A implementação tem propósito didático para demonstrar a viabilidade de implementação e facilidade de uso da aplicação; 
- Foi apresentado um estudo comparativo entre modelos existentes;

- Foi apresentado o comparativo de tempos de busca e inserção baseado no modelo de (WATERS et al., 2004).

3. O tutorial de 4 horas apresentou de forma sucinta, os princípios de criptografia baseada na identidade e a infra-estrutura de ambiente ambiente criptográfico baseado em identidade:

- Foram apresentados esquemas de cifração baseado em identidade e um compartivo de operações em termos de custos computacionais;

- Foram apresentados esquemas de assinatura baseado em identidade e um compartivo de operações em termos de custos computacionais;

- Foram apresentados esquemas de acordo de chaves baseado em identidade e um compartivo de operações em termos de custos computacionais;

- Foi apresentada a estrutura simplificada de busca de dados cifrados.

\subsection{Trabalhos Futuros}

A ênfase especial deste trabalho foi apresentar formas de criação de um ambiente criptográfico baseado na identidade. Os aspectos práticos e funcionamento do sistema foram levados em consideração para atender, da melhor forma possível, os objetivos pré-estabelecidos. Como trabalhos futuros, é possível sugerir:

- Aspectos Teóricos:

- Propor modelos teóricos para sistemas baseados na identidade;

- Estudar os esquemas de criptoassinatura e fazer comparativos;

- Estudar as aplicabilidades de diversas formas de assinatura, como em anel, grupo e assinaturas curtas, por exemplo.

- Aspectos de Implementação

- Implementar esquemas de assinatura baseadas na identidade;

- Implementar outros esquemas de cifração; 
- Implementar outros esquemas de busca cifrada;

- Implementar esquemas mistos.

- Aspectos de Segurança

- Desenvolver noções de segurança para ambiente criptográfico baseada na identidade. 


\section{REFERÊNCIAS}

ABDALlA, M. A Survey of Cryptographic Schemes with Special Properties. 2007. IV Workshop on Cryptographic Algorithms and Protocols - WCAP 2007 Lectures. Disponível em: http://www.ic. unicamp.br/ rdahab/WCAP07/Welcome_files/ Abdalla-slot1.pdf. Acesso em: novembro de 2007.

ABDALLA, M.; BELLARE, M.; CATALANO, D.; KILTZ, E.; KOHNO, T.; LANGE, T.; MALONE-LEE, J.; NEVEN, G.; PAILLIER, P.; SHI, H. Searchable encryption revisited: Consistency properties, relation to anonymous ibe, and extensions. In: Advances in Cryptology-Crypto 2005. [S.1.]: Springer-Verlag, 2005. (Lecture Notes in Computer Science, v. 3621), p. 205-222. ISBN 3-540-28114-2. Acesso em: março de 2006.

AL-RIYAMI, S. S.; PATERSON, K. G. Certificateless public key cryptography. In: LAIH, C.-S. (Ed.). ASIACRYPT. [S.1.]: Springer, 2003. (Lecture Notes in Computer Science, v. 2894), p. 452-473. ISBN 3-540-20592-6.

ANDERSON, R. Two remarks on public key cryptology. 2002. University of Cambridge, Thecnical Report 549. Disponível em: http://www.cl.cam.ac.uk/ techreports/UCAM-CL-TR-549.pdf. Acesso em: abril de 2008.

APPENZELLER, G.; LYNN, B. Minimal-Overhead IP Security using Identity-Based Encryption. 2002. Disponível em: http://rooster.stanford.edu/〜ben/pubs/ ipibe.pdf. Acesso em: janeiro de 2006.

ASOKAN, N.; KOSTIAINEN, K.; GINZBOORG, P.; OTT, J.; LUO, C. Applicability of identity-based cryptography for disruption-tolerant networking. In: MobiOpp '07: Proceedings of the 1st international MobiSys workshop on Mobile opportunistic networking. New York, NY, USA: ACM, 2007. p. 52-56. ISBN 978-1-59593-688-2.

ATTRAPADUNG, N.; CUI, Y.; GALINDO, D.; HANAOKA, G.; HASUO, I.; IMAI, H.; MATSUURA, K.; YANG, P.; ZHANG, R. Relations among notions of security for identity based encryption schemes. In: Latin American Theoretical Informatics Symposium (LATIN '06). [S.1.]: Springer, Berlin, 2006. (Lect. Notes Comp. Sci., v. 3887), p. 130-141.

BAEK, J.; NEWMARCH, J.; SAFAVI-NAINI, R.; SUSILO, W. A Survey of Identity-Based Cryptography. 2004. AUUG 2004. Disponível em: http: //jan. netcomp.monash.edu. au/publications/. Acesso em: abril de 2006.

BAEK, J.; STEINFELD, R.; ZHENG, Y. Formal proofs for the security of signcryption. Journal of Cryptology, Springer Verlag, v. 20, p. 203-235, April 2007. 
BARBOSA, M. F. P. Efficient Identity-based Key Encapsulation to Multiple Parties. 2005. Cryptology ePrint Archive, Report 2005/217. Disponível em: http: //eprint . iacr .org/2005/217. Acesso em: maio de 2006.

BARRETO, P. S. L. M.; LIBERT, B.; MCCULLAGH, N.; QUISQUATER, J.-J. Efficient and provabley-secure identity-based signatures and signatures and signcryption from bilinear maps. In: ROY, B. (Ed.). Asiacrypt 2005. [S.1.]: Springer, 2005. (Lecture Notes in Computer Science, v. 3788), p. 515-532. ISBN 3-540-30684-6.

BARRETO, P. S. L. M.; NAEHRIG, M. Pairing-friendly elliptic curves of prime order. In: PRENEEL, B.; TAVARES, S. E. (Ed.). Selected Areas in Cryptography. [S.1.]: Springer, 2005. (Lecture Notes in Computer Science, v. 3897), p. 319-331. ISBN 3-540-33108-5.

BELLARE, M.; DESAI, A.; POINTCHEVAL, D.; ROGAWAY, P. Relations among notions of security for public-key encryption schemes. In: CRYPTO '98: Proceedings of the 18th Annual International Cryptology Conference on Advances in Cryptology. London, UK: Springer-Verlag, 1998. p. 26-45. ISBN 3-540-64892-5.

BELLARE, M.; NAMPREMPRE, C.; NEVEN, G. Security proofs for identity-based identification and signature schemes. In: CACHIN, C.; CAMENISCH, J. (Ed.). EUROCRYPT. [S.1.]: Springer, 2004. (Lecture Notes in Computer Science, v. 3027), p. 268-286. ISBN 3-540-21935-8.

BENITS, W. D. Sistemas Criptográficos Baseados em Identidades Pessoais. Dissertação (Mestrado) - Instituto de Matemática e Estatística, Universidade de São Paulo, 2003.

BENTAHAR, K.; FARSHIM, P.; MALONE-LEE, J.; SMART, N. Generic Constructions of Identity-Based and Certificateless KEMs. 2005. Cryptology ePrint Archive, Report 2005/058. Disponível em: http: //eprint . iacr .org/2005/058. Acesso em: novembro de 2005.

BLAKE, I.; SEROUSSI, G.; SMART, N.; CASSELS, J. W. S. Advances in Elliptic Curve Cryptography (London Mathematical Society Lecture Note Series). New York, NY, USA: Cambridge University Press, 2005. ISBN 052160415X.

BONEH, D.; BOYEN, X. Efficient selective-ID secure identity based encryption without random oracles. In: Advances in Cryptology-EUROCRYPT 2004. [S.1.]: Berlin: Springer-Verlag, 2004. (Lecture Notes in Computer Science, v. 3027), p. 223-238. Disponível em: http: //www.cs. stanford.edu/ xb/eurocrypt04b/.

BONEH, D.; BOYEN, X.; GOH, E.-J. Hierarchical Identity Based Encryption with Constant Size Ciphertext. 2005. Cryptology ePrint Archive, Report 2005/015. Disponível em: http: //eprint .iacr .org/2005/015. Acesso em: junho de 2006.

BONEH, D.; CRESCENZO, G. D.; OSTROVSKY, R.; PERSIANO, G. Public key encryption with keyword search. In: CACHIN, C.; CAMENISCH, J. (Ed.). 
EUROCRYPT. [S.1.]: Springer, 2004. (Lecture Notes in Computer Science, v. 3027), p. 506-522. ISBN 3-540-21935-8.

BONEH, D.; FRANKLIN, M. Identity-based encryption from the weil pairing. SIAM J. Comput., Society for Industrial and Applied Mathematics, Philadelphia, PA, USA, v. 32, n. 3, p. 586-615, 2003. ISSN 0097-5397. Acesso em: maio de 2006.

BONEH, D.; FRANKLIN, M. K. Identity-based encryption from the weil pairing. In: CRYPTO '01: Proceedings of the 21st Annual International Cryptology Conference on Advances in Cryptology. London, UK: Springer-Verlag, 2001. p. 213-229. ISBN 3-540-42456-3.

BONEH, D.; WATERS, B. Conjunctive, subset, and range queries on encrypted data. In: Theory of Cryptography Conference - TCC 2007. [S.1.]: Springer-Verlag, 2007. p. 535-554. ISBN 3-540-25910-4.

BOYEN, X.; MEI, Q.; WATERS, B. Direct Chosen Ciphertext Security from Identity-Based Techniques. 2005. Cryptology ePrint Archive, Report 2005/288. Disponível em: http://eprint.iacr.org/2005/288. Acesso em: fevereiro de 2006.

BOYEN, X.; WATERS, B. Anonymous Hierarchical Identity-Based Encryption (Without Random Oracles). 2006. Cryptology ePrint Archive, Report 2006/085. Disponível em: http://eprint.iacr.org/2006/085. Acesso em: fevereiro de 2006.

CHA, J. C.; CHEON, J. H. An identity-based signature from gap diffie-hellman groups. In: PKC '03: Proceedings of the 6th International Workshop on Theory and Practice in Public Key Cryptography. London, UK: Springer-Verlag, 2003. p. 18-30. ISBN 3-540-00324-X.

CHEN, L.; HARRISON, K.; MOSS, A.; SMART, N. P.; SOLDERA, D. Certification of public keys within an identity based syste. In: CHAN, A. H.; GLIGOR, V. (Ed.). A.H. Chan, V. Gligor (Eds.): Information Security : ISC 2002. [S.1.]: Springer-Verlag LNCS 2433, 2002. p. 322-333.

CHEN, L.; KUDLA, C. Identity based authenticated key agreement protocols from pairings. csfw, IEEE Computer Society, Los Alamitos, CA, USA, v. 00, p. 219, 2003. ISSN 1063-6900. Acesso em: abril de 2006.

CHOW, S. S. M.; CHOO, K.-K. R. Strongly-secure identity-based key agreement and anonymous extension. In: GARAY, J. A.; LENSTRA, A. K.; MAMBO, M.; PERALTA, R. (Ed.). ISC. [S.1.]: Springer, 2007. (Lecture Notes in Computer Science, v. 4779), p. 203-220.

COCKS, C. An identity based encryption scheme based on quadratic residues. In: Proceedings of the 8th IMA International Conference on Cryptography and Coding. London, UK: Springer-Verlag, 2001. p. 360-363. ISBN 3-540-43026-1. 
CUI, Y.; FUJISAKI, E.; HANAOKA, G.; IMAI, H.; ZHANG, R. Formal Security

Treatments for IBE-to-Signature Transformation: Relations among Security

Notions. 2007. Cryptology ePrint Archive, Report 2007/030. Disponível em: http: //eprint .iacr.org/2007/30. Acesso em: fevereiro de 2007.

DEVEGILI, A. J.; SCOTT, M.; DAHAB, R. Implementing cryptographic pairings over barreto-naehrig curves. In: TAKAGI, T.; OKAMOTO, T.; OKAMOTO, E.; OKAMOTO, T. (Ed.). Pairing. [S.1.]: Springer, 2007. (Lecture Notes in Computer Science, v. 4575), p. 197-207. ISBN 978-3-540-73488-8.

DODIS, Y. Signcryption - Short Survey. 2005. Signcryption Central. Disponível em: http://www.signcryption.net/publications/. Acesso em: janeiro de 2008.

EBERLE, H.; GURA, N.; SHANTZ, S. C.; GUPTA, V.; RARICK, L.; SUNDARAM, S. A public-key cryptographic processor for rsa and ecc. In: ASAP '04: Proceedings of the Application-Specific Systems, Architectures and Processors, 15th IEEE International Conference on (ASAP'04). Washington, DC, USA: IEEE Computer Society, 2004. p. 98-110. ISBN 0-7695-2226-2.

EISENTRAEGER, K.; LAUTER, K.; MONTGOMERY, P. L. Improved Weil and Tate pairings for elliptic and hyperelliptic curves. 2003. Cryptology ePrint Archive, Report 2003/242. Disponível em: http://eprint.iacr.org/2003/242.

FENG, R.; WU, H. Efficient Pairing Computation on Curves. 2007. Cryptology ePrint Archive, Report 2007/138. Disponível em http://eprint .iacr .org/138. Acesso em: novembro de 2007.

GALBRAITH, S. D.; SCOTT, M. Exponentiation in pairing-friendly groups using homomorphisms. 2008. Cryptology ePrint Archive, Report 2008/117. Disponível em: http: //eprint . iacr .org/2008/117. Acesso em: abril de 2008.

GALINDO, D.; HASUO, I. Security Notions for Identity Based Encryption. 2005. Cryptology ePrint Archive, Report 2005/253. Disponível em: http: //eprint .iacr .org/2005/253. Acesso em: março de 2006.

GENTRY, C.; SILVERBERG, A. Hierarchical id-based cryptography. In: ASIACRYPT '02: Proceedings of the 8th International Conference on the Theory and Application of Cryptology and Information Security. London, UK: Springer-Verlag, 2002. p. 548-566. ISBN 3-540-00171-9.

GIBSON, T. Securing Wireless Communications with Identity-based Encryption. 2005. Gov’t Wireless \& Mobile Computing. Disponível em: http: //www.e-gov . com/events/2005/. Acesso em: maio de 2006.

GOLDWASSER, S.; MICALI, S. Probabilistic encryption. Journal of Computer and Systems Sciences, v. 28, n. 2, p. 270-299, 1984.

GORANTLA, M. C.; GANGISHETTI, R.; SAXENA, A. A Survey on ID-Based Cryptographic Primitives. 2005. Cryptology ePrint Archive, Report 2005/094. Disponível em: http: //eprint .iacr.org/2005/094. Acesso em: maio de 2006. 
GOYA, D. H. Proposta de esquemas de criptografia e de assinatura sob modelo de criptografia de chave pública sem certificado. Dissertação (Mestrado) - Instituto de Matemática e Estatística, Universidade de São Paulo, 2006.

GRANGER, R.; HESS, F.; OYONO, R.; THERIAULT, N.; VERCAUTEREN, F. Ate pairing on hyperelliptic curves. In: Advances in Cryptology - EUROCRYPT 2007. [S.1.]: Springer, LNCS 4515, 2007. p. 430-447.

GUPTA, V.; GUPTA, S.; CHANG, S.; STEBILA, D. Performance analysis of elliptic curve cryptography for ssl. In: WiSE '02: Proceedings of the 3rd ACM workshop on Wireless security. New York, NY, USA: ACM Press, 2002. p. 87-94. ISBN 1-58113-585-8.

HANKERSON, D.; MENEZES, A.; VANSTONE, S. Guide to Elliptic Curve Cryptography. 1st. ed. USA: Springer, 2004.

HESS, F. Efficient identity based signature schemes based on pairings. In: SAC '02: Revised Papers from the 9th Annual International Workshop on Selected Areas in Cryptography. London, UK: Springer-Verlag, 2003. p. 310-324. ISBN 3-540-00622-2.

HOLT, J. E. Key Privacy for Identity Based Encryption. 2006. Cryptology ePrint Archive, Report 2006/120. Disponível em: http: //eprint.iacr .org/2006/120. Acesso em: maio de 2006.

HÉIGEARTAIGH, C. Ó. Speeding Up Pairing Computation. 2005. Cryptology ePrint Archive, Report 2005/293. Disponível em: http: //eprint . iacr . org/2005/293. Acesso em: maio de 2006.

KANG, B. G.; PARK, J. H. Powered Tate Pairing Computation. 2005. Cryptology ePrint Archive, Report 2005/260. Disponível em: http: //eprint .iacr .org/2005/ 260. Acesso em: maio de 2006.

KHADER, D. Public key encryption with keyword search based on k-resilient ibe. In: GAVRILOVA, M. L.; GERVASI, O.; KUMAR, V.; TAN, C. J. K.; TANIAR, D.; LAGANÀ, A.; MUN, Y.; CHOO, H. (Ed.). ICCSA (3). [S.1.]: Springer, 2006. (Lecture Notes in Computer Science, v. 3982), p. 298-308. ISBN 3-540-34075-0.

KILTZ, E. Chosen-Ciphertext Secure Identity-Based Encryption in the Standard Model with short Ciphertexts. 2006. Cryptology ePrint Archive, Report 2006/122. Disponível em: http: //eprint .iacr .org/2006/122. Acesso em: abril de 2006.

KIM, K. H.; KIM, S. I. A New Method for Speeding Up Arithmetic on Elliptic Curves over Binary Fields. 2007. Cryptology ePrint Archive, Report 2007/181. Disponível em http: //eprint. iacr .org/2007/181. Acesso em: janeiro de 2008.

LIBERT, B. Provable Security of Pairing-Based Protocols: The Case of Public Key and Identity-Based Encryption. 2007. IV Workshop on Cryptographic Algorithms and Protocols - WCAP 2007 Lectures. Disponível em: http: 


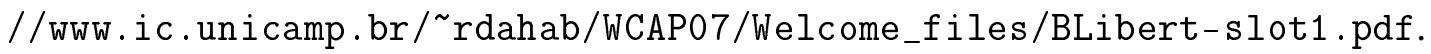
Acesso em: novembro de 2007.

LIM, H.; ROBSHAW, M. On identity-based cryptography and grid computing. In: AL., M. B. et (Ed.). M. Bubak et al. (Eds.): International Conference on Computational Science, ICCS 2004. [S.1.]: Springer-Verlag LNCS 3036, 2004. p. 474-477.

LIM, H. W. On the Application of Identity-Based Cryptography In Grid Security. Tese (Doutorado) — University of London, 2006.

LYNN, B. Authenticated Identity-Based Encryption. 2002. Cryptology ePrint Archive, Report 2002/072. Disponível em: http://eprint.iacr.org/2002/072. Acesso em: março de 2006.

LYNN, B. On the Implementation of Pairing-Based Cryptosystems. Tese (Doutorado) — Stanford University, 2007.

MALONE-LEE, J. Identity-Based Signcryption. 2002. Cryptology ePrint Archive, Report 2002/098. Disponível em: http://eprint.iacr.org/2002/098. Acesso em: novembro de 2006.

MCCULLAGH, N.; BARRETO, P. S. L. M. Efficient and Forward-Secure IdentityBased Signcryption. 2004. Cryptology ePrint Archive, Report 2004/117. Disponível em: http://eprint .iacr .org/2004/117. Acesso em: abril de 2006.

MCCUllAGH, N.; BARRETO, P. S. L. M. A New Two-Party Identity-Based Authenticated Key Agreement. 2004. Cryptology ePrint Archive, Report 2004/122. Disponível em: http: //eprint .iacr .org/2004/122.

MISAGHI, M.; SILVA, E. da; ZUFFO, M. K. Esquemas de acordo de chaves baseados em identidades e suas aplicações. Revista do IST, v. 7, n. 8, p. 24-31, 2007. ISSN 1678-3832.

MISAGHI, M.; ZUFFO, M. K. Criptografia baseada na identidade. In: SSI 2006 - 8th International Symposium on Systems and Information Security. São José dos Campos, Brasil: 3M do Brasil, 2006. p. 1-33. ISSN 1981-8882.

MISAGHI, M.; ZUFFO, M. K. Identity-based cryptography: From theory to practice. In: ICCyber 2007 - Proceeding of the Fourth International Conference on Cyber Crime Investigation. SP, Brasil: E-Forensic Press, 2007. p. 37. ISSN 1980-1106.

MISAGHI, M.; ZUFFO, M. K. Implementação de pesquisa de dados cifrados baseada em identidade do modelo waters. In: CONGED 2007 - V Congresso de Gestão de Dados e Metadados Conesul. Cascavel, Brasil: Unioeste, 2007. p. 90-99. ISSN 1981-8882.

MONT, M. C.; BRAMHALL, P. IBE Applied to Privacy and Identity Management. 2003. Hewlett-Packard Labs Technical Reports. Disponível em: http: //www . hpl . hp.co.uk/techreports/2003/HPL-2003-101.html. Acesso em: abril de 2006. 
NACCACHE, D. Secure and Practical Identity-Based Encryption. 2005. Cryptology ePrint Archive, Report 2005/369. Disponível em: http: //eprint .iacr .org/2005/ 369. Acesso em: abril de 2006.

NAOR, M.; YUNG, M. Public-key cryptosystems provably secure against chosen ciphertext attacks. In: STOC '90: Proceedings of the twenty-second annual ACM symposium on Theory of computing. New York, NY, USA: ACM Press, 1990. p. 427-437. ISBN 0-89791-361-2.

OHTAKI, Y. Constructing a searchable encrypted log using encrypted inverted indexes. In: International Conference on Cyberworlds. Washington: IEEE Computer Society, 2005. p. 130-138. ISBN 0-7695-2378-1.

PATERSON, K. G. ID-based Signatures from Pairings on Elliptic Curves. 2002. Cryptology ePrint Archive, Report 2002/004. Disponível em: http: //eprint.iacr.org/2002/004. Acesso em: março de 2006.

RACKOFF, C.; SIMON, D. R. Non-interactive zero-knowledge proof of knowledge and chosen ciphertext attack. In: CRYPTO '91: Proceedings of the 11th Annual International Cryptology Conference on Advances in Cryptology. London, UK: Springer-Verlag, 1992. p. 433-444. ISBN 3-540-55188-3.

SAKAI, R.; KASAHARA, M. ID based Cryptosystems with Pairing on Elliptic Curve. 2003. Cryptology ePrint Archive, Report 2003/054. Disponível em: http: //eprint. iacr .org/2003/054. Acesso em: março de 2006.

SCOTT, M. Authenticated ID-based Key Exchange and remote log-in with simple token and PIN number. 2002. Cryptology ePrint Archive, Report 2002/164. Disponível em: http: //eprint.iacr .org/2002/164. Acesso em: abril de 2006.

SCOTT, M. Faster pairings using an elliptic curve with an efficient endomorphism. In: MAITRA, S.; MADHAVAN, C. E. V.; VENKATESAN, R. (Ed.). INDOCRYPT. [S.1.]: Springer, 2005. (Lecture Notes in Computer Science, v. 3797), p. 258-269. ISBN 3-540-30805-9.

SCOTT, M.; COSTIGAN, N.; ABDULWAHAB, W. Implementing Cryptographic Pairings on Smartcards. 2006. Cryptology ePrint Archive, Report 2006/144. Disponível em: http: //eprint.iacr.org/2006/144. Acesso em: maio de 2006.

SHAHANDSHTI, S. F.; SAFAVI-NAINI, R. Construction of Universal Designated-Verifier Signatures and Identity-Based Signatures from Standard Signatures. 2007. Cryptology ePrint Archive, Report 2007/462. Disponível em http: //eprint . iacr .org/2007/462. Acesso em: dezembro 2007.

SHAMIR, A. Identity-based cryptosystems and signature schemes. In: CRYPTO. [S.1.: s.n.], 1984. p. 47-53.

SHIM, K. Efficient id-based authenticated key agreement protocol based on the weil pairing. Electronics Letters, v. 39, n. 8, p. 653-654, 2003. 
SMART, N. P. An identity based authenticated key agreement protocol based on the weil pairing. Electronics Letters, v. 38, n. 13, p. 630-632, June 2002. ISSN 00135194.

SONG, D. X.; WAGNER, D.; PERRIG, A. Practical techniques for searches on encrypted data. In: SP '00: Proceedings of the 2000 IEEE Symposium on Security and Privacy. Washington, DC, USA: IEEE Computer Society, 2000. p. 44 - 55. ISBN 0-7695-0665-8.

SRIVASTAVA, S. S. V. Performance analysis of elliptic curve cryptography in network systems. In: IWWST '05: Proceedings of the 3rd International Workshop in Wireless Security Technologies. London, UK: Westminster University, Cavendish School of Computing Science, Wireless Information Technology Research Centre (WITRC)., 2005. p. 144-151. ISSN 1746-9058.

TERADA, R. Segurança de Dados Criptografia em Redes de Computador. Primeira. São Paulo: Edgard Blücher Ltda, 2000.

VERCAUTEREN, F. Optimal Pairings. 2008. Cryptology ePrint Archive, Report 2008/096. Disponível em: http: //eprint.iacr.org/2008/096. Acesso em: abril de 2008.

WATERS, B. Efficient identity-based encryption without random oracles. In: Advances in Cryptology-EUROCRYPT 2005. [S.1.]: Springer-Verlag, 2005. (Lecture Notes in Computer Science, v. 3494), p. 114-127. ISBN 3-540-25910-4.

WATERS, B. R.; BALFANZ, D.; DURFEE, G.; SMETTERS, D. K. Building an Encrypted and Searchable Audit Log. 2004. Internet Society. Disponível em: http: //www . parc . xerox.com/research/publications/files/5059.pdf. Acesso em: fevereiro de 2006.

YAO, D.; FAZIO, N.; DODIS, Y.; LYSYANSKAYA, A. Id-based encryption for complex hierarchies with applications to forward security and broadcast encryption. In: CCS '04: Proceedings of the 11th ACM conference on Computer and communications security. New York, NY, USA: ACM Press, 2004. p. 354-363. ISBN 1-58113-961-6.

ZHAO, C.-A.; ZHANG, F.; HUANG, J. Speeding up the Bilinear Pairings Computation on Curves with Automorphisms. 2006. Cryptology ePrint Archive, Report 2006/474. Disponível em: http: //eprint.iacr.org/2006/474. Acesso em: janeiro de 2007.

ZHAO, C.-A.; ZHANG, F.; HUANG, J. A Note on the Ate Pairing. 2007. Cryptology ePrint Archive, Report 2007/247. Disponível em http: //eprint . iacr .org/2007/ 247. Acesso em: novembro de 2007.

ZHENG, Y. Digital signcryption or how to achieve cost(signature \& encryption) cost(signature) + cost(encryption). In: CRYPTO '97: Proceedings of the 17th Annual International Cryptology Conference on Advances in Cryptology. London, UK: Springer-Verlag, 1997. p. 165-179. ISBN 3-540-63384-7. 
ZHENG, Y.; IMAI, H. How to construct efficient signcryption schemes on elliptic curves. Inf. Process. Lett., Elsevier North-Holland, Inc., Amsterdam, The Netherlands, The Netherlands, v. 68, n. 5, p. 227-233, 1998. ISSN 0020-0190.

ZHU, R. W.; TIAN, X.; WONG, D. S. A Suite of Enhanced Security Models for Key Compromise Impersonation Resilience and ID-based Key Exchange. 2005. Cryptology ePrint Archive, Report 2005/455. Disponível em: http: //eprint.iacr .org/2005/455. Acesso em: dezembro de 2005. 


\section{APÊNDICE A - Aplicações e Produtos de IBE}

\section{A.1 Produtos IBE}

\section{A.1.1 Plataforma Voltage}

A plataforma de Voltage possui mecanismos para envio seguro de: emails, mensagens instantâneas, Voz sobre IP entre outros. Além disso, o kit de ferramentas Voltage permite aos desenvolvedores utilizarem uma grande variedade de algortimos criptográficos, inclusive IBE. A tabela A.1 apresenta algumas funcionalidades do produto SecureMail IBE Server:

Tabela A.1: Funcionalidade de SecureMail IBE Server

\begin{tabular}{|l|l|}
\hline Funcionalidade & Vantagens \\
\hline \hline $\begin{array}{l}\text { Integração com Sistemas de } \\
\text { Gerenciamento de Identidade }\end{array}$ & $\begin{array}{l}\text { Não necessita ter infra-estrutura } \\
\text { complexa e tem implementação } \\
\text { fácil e barata. }\end{array}$ \\
\hline Trilhas de Auditoria & $\begin{array}{l}\text { Gerencia de forma centralizada } \\
\text { a emissão de chaves. }\end{array}$ \\
\hline Segurança sem Certificado & $\begin{array}{l}\text { Não necessita gerenciar tempo } \\
\text { de vida de certificado }\end{array}$ \\
& Custo mais baixo para adminsitração. \\
\hline
\end{tabular}

A figura A.1 ilustra os processos contidos em um ambiente SecureMail do Voltage. 


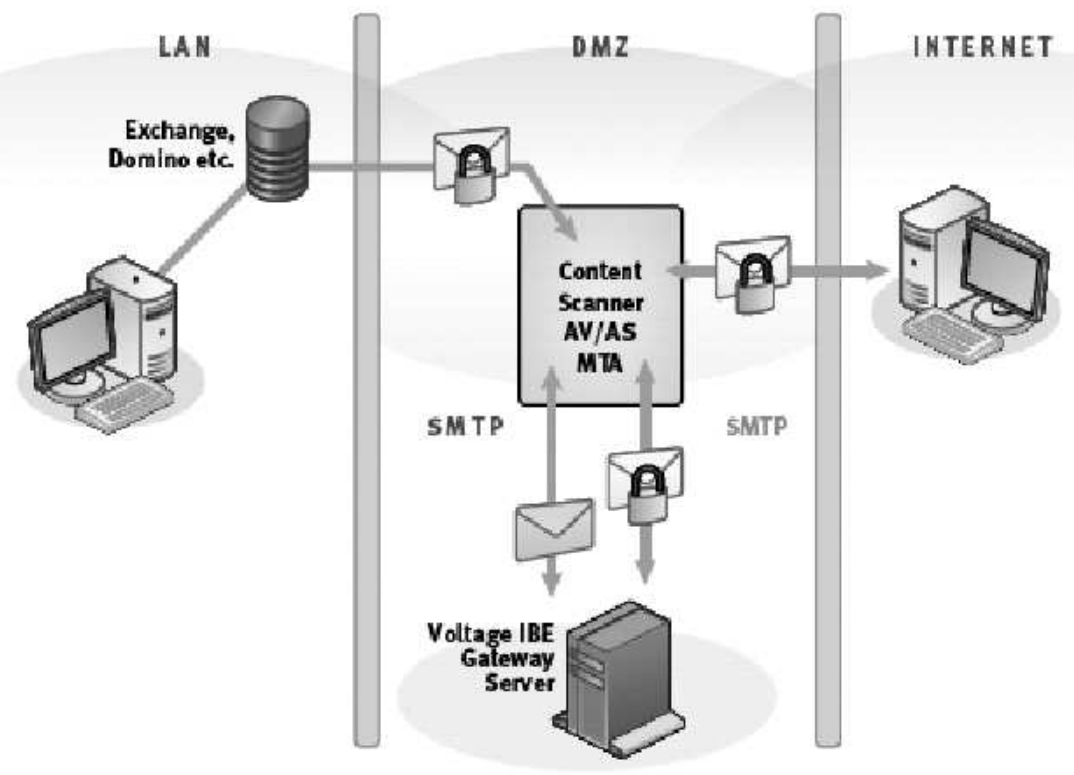

Figura A.1: Ambiente de SecureMail do Voltage. Esta figura ilustra os processos contidos neste ambiente.

\section{A.2 Aplicações IBE}

\section{A.2.1 Redes Sem Fio}

Praticamente as mesmas vulnerabilidades que ameaçam as redes corporativas, presentes na redes sem fio. Como normalmente os sinais de redes sem fio podem atravessar qualquer barreira física, as redes sem fio precisam ser protegidas contra tais ameaças. As ferramentas agregadas para cifragem de dados não são eficientes e na maioria das vezes há necessidade de utilizar um VPN para criar um ambiente seguro de tráfego de dados com a utilização do protocolo IPSEC. Desta forma para estabelecimento de comunicação segura utiliza-se certificados digitais que permite a cifragem e assinatura.

Desta forma, para utilização de certificados digitais, precisa-se de um dispositivo que possa armazenar tal certificado e isto encarece a solução adotada devido ao alto custo do token.

Uma outra solução interessante que fornece recursos de cifragem e assiantura é o emprego de algoritmos de IBE em ambientes wireless. A utilização de IBE em um ambiente wireless pode ocorrer quando temos (GIBSON, 2005):

1.necessidade de comunicação entre domínios; 
2.necessidade de comunicação segura e rápida;

3.requisito de cifragem fim-a-fim presente.

\section{A.2.2 Cartões Inteligentes}

Com o crescimento desenfreado de transações via web, aumentou também a quantidade e variedade de ataques em busca de alguma vulnerabilidade para invadir tais sistemas. Desta forma, há necessidade de utilização de diversos métodos de autenticação mútua.

Uma das formas de implementação de autenticação mútua poderá ser através da utilização de cartões inteligentes. Michael Scott, Neil Costigan, e Wesam Abdulwahab em (SCOTT; COSTIGAN; ABDULWAHAB, 2006) descrevem a implementação de vários emparelhamentos sobre um smartcard de 32 bits. Neste artigo eles demonstram que os emparelhamentos poderão ser calcuadas de forma eficiente com menos de 0,15 segundos, como as primitivas criptográficas clássicas.

\section{A.2.3 Computação em Grade}

A utilização de computação em grade se deve ao fato de um aumento expressivo de aplicações que requerem cada vez maior poder computacional e uma capacidade maior de armazenamento. A comunicação segura com infra-estrutura de computação em grade normalmente ocorre com a utilização de PKI. Uma forma de aliviar a carga de trabalho (LIM; ROBSHAW, 2004) e a largura de banda utilizada sem a necessidade de armazenar uma grande quantidade de certificados digitais e se preocupar com as questões de gerenciamento é o emprego de IBE como uma abordagem alternativa de segurança para tais ambientes.

Os detalhes do esquema proposto em (LIM; ROBSHAW, 2004) poderão ser encontrados em (LIM, 2006). Dentre os recursos deste sistema, podem ser destacados os seguintes:

1.Single Sign-On: Este esquema suporta Single Sign-On através da utilização de IBE, com chaves menores. 
2.Autenticação Mútua e Acordo de Chaves: Sem a necessidade de certificado, este protocolo permite a implementação de autenticação mútua.

3.Delegação: Permite implementar os recursos de delegação em diversos níveis.

\section{A.2.4 Protocolos de Cifração na Camada de Rede}

Em (APPENZELLER; LYNN, 2002), Guido Appenzeller e Ben Lynn propuseram um novo protocolo de segurança na camada de rede que permitia comunicação autenticada e cifrada entre os hosts. Para implementar IBE neste caso, podem ser utilizados os endereços de IP ou de MAC que garantem a cada host uma chave pública única na Internet.

Dentre as vantagens da utilização de IBE, podem ser citados o fato de não necessitar do processo de handshaking e também não há necessidade de troca de certificados para enviar uma mensagem cifrada. Neste caso, o remetente simplesmente envia um pacote cifrado com o endereço de IP do destinatário. 


\section{APÊNDICE B - Fundamentos Matemáticos de IBE}

O objetivo deste apêndice é esclarecer de uma forma simples alguns conceitos matemáticos fundamentais que são utilizados em sistemas criptográficos baseados na identidade, confome (BENITS, 2003; GORANTLA; GANGISHETTI; SAXENA, 2005; BENTAHAR et al., 2005; KANG; PARK, 2005; EISENTRAEGER; LAUTER; MONTGOMERY, 2003; HANKERSON; MENEZES; VANSTONE, 2004; GOYA, 2006).

\section{B.1 Grupo}

Um grupo pode ser considerado como um conjunto não vázio $\mathbb{G}$, contendo uma operação binária $*$, tal que $\mathbb{G} \times \mathbb{G} \rightarrow \mathbb{G}$, com as seguinte propriedades:

1.Associatividade: $a *(b * c)=(a * b) * c$ para $\forall a, b, c \in \mathbb{G}$.

2.Existência de uma identidade: Existe um elemento $e \in \mathbb{G}$, tal que $\forall a \in \mathbb{G}: a * e=$ $e * a=a$

3.Existência de inverso: Para $\forall a \in \mathbb{G}: \exists b \in \mathbb{G}$, chamado inverso de $a$, tal que $a * b=b * a=e$

4.Comutatividade: Característica especial dos grupos abelianos, onde $\forall a, b \in \mathbb{G}$ : $a * b=b * a$

\section{B.2 Corpo}

Um CORPO pode ser definido como uma estrutura algébrica que possui um conjunto $K$ e duas operações binárias de adição e multiplicação. Existe isomorfismo, entre 
dois corpos, quando haja uma função bijetora entre eles, mapeando os elementos identidade e os inversos de um corpo no outro.

\section{B.3 Curvas Elípticas}

Os sistemas de curvas elípticas são utilizados para resolução de diversos problemas e estão sendo estudados por matemáticos há bastante tempo. A utilização de curvas elípticas em criptografia é devido a possibilidade de ter chaves significativamente menores, quando comparado com outros modelos de criptografia. Considerando um corpo $k$, os elementos $a, b, c, d, e \in K$ e a seguinte equação:

$$
y^{2}+a x y+b y=x^{3}+c x 2+d x+e
$$

Dessa forma, define se uma curva elíptica sobre corpo $k$, sendo $E(K)$, satinsfazendo a equação acima citada.

\section{B.4 Emparelhamentos Bilineares}

Sejam $\mathbb{G}_{1}$ e $\mathbb{G}_{2}$ dois grupos de ordem $q$, para algum número primo $q$ que seja muito grande. Emparelhamento pode ser definido como um mapeamento ê entre esses grupos, tal que:

$$
\text { ê }: \mathbb{G}_{1} \times \mathbb{G}_{1} \longrightarrow \mathbb{G}_{2}
$$

Para que um mapeamento bilinear seja admissível deve possui as seguintes características (GORANTLA; GANGISHETTI; SAXENA, 2005):

-Bilinear: $e(a R, b S)=e(R, S)^{a b}$ para $\forall R, S \in \mathbb{G}_{1}$ e $a, b \in Z_{q}^{*}$. Isto pode ser escrito como $\forall R, S, T \in \mathbb{G}_{1}, e(R+S, T)=e(R, T) e(S, T)$ e $e(R, S+T)=e(R, S) e(R, T)$.

-Não Degenerativo: Neste caso existem $R, S \in \mathbb{G}_{1}$, tais que, $e(R, S) \neq I_{\mathbb{G}_{2}}$. Onde $I_{\mathbb{G}_{2}}$ representa o elemento identidade do grupo $\mathbb{G}_{2}$.

-Computável: Deve existir um algoritmo eficiente para computar $e(R, S) \forall R, S \in$ $\mathbb{G}_{1}$. 


\section{B.4.1 Emparelhamento Tate}

O emparelhamento Tate é considerado como um emparelhamento admissível e é definido entre os pontos linearmente independentes $P$ e $Q$ da curva $E\left(\mathbb{F}_{q^{k}}\right)$, sendo $k$, o grau de imersão da curva considerada. Dessa forma, o emparelhamento $e_{t}(P, Q)$ assume valores no corpo finito estendido $F_{q}^{k}$.

\section{B.4.2 Emparelhamento ate}

O emparelhamento ate ${ }^{1}$ utiliza uma varição otimizada de função de Miller e é mais rápido do que o emparelhamento Tate. $\mathrm{O}$ emparelhamento ate pode ser definido da seguinte forma: Seja $E$ uma curva sobre $\mathbb{F}_{q}$, contendo um subgrupo cíclico $G_{1}$ de ordem $r$ e grau de imersão $k$. Seja $G_{2}$ um grupo de pontos zero traço em $E^{\prime}\left(\mathbb{F}_{q}^{d}\right)$. Seja $t$, traço de Forbenius, que satifaça $\# E\left(\mathbb{F}_{q}\right)=q-t+1$. Seja $f_{n, P}$ uma função racional com divisor $n(P) /(n P)$ para qualquer inteiro $n$ e qualquer ponto $P$. Dessa forma os emparelhamentos Tate e ate podem ser definidos da seguinte forma (LYNN, 2007):

Emparelhamento Tate:

$$
f_{r, P}(Q)
$$

Emparelhamento ate:

$$
f_{t-1, Q}(P)
$$

\section{B.5 Problemas Computacionais utlizados em IBE}

O objetivo desta seção é apresentar de forma sucinta os conceito dos diversos problemas que são utilizados em criptossistemas baseados em identidade.

\section{B.5.1 Problema de Fatoração de Inteiros}

O Problema de Fatoração de Inteiros - IFP é definido da seguinte forma: dado um inteiro positivo $n$, achar as suas fatorações, isto é:

\footnotetext{
${ }^{1}$ segundo Granger et al. (2007), é ate e não Ate.

${ }^{2}$ do inglês trace zero points.
} 


$$
n=q_{1}^{e_{1}} q_{2}^{e_{2}} \ldots q_{k}^{e_{k}}
$$

onde $q_{i}$ são pares distintos primos e cada $e_{i} \geq 1$.

\section{B.5.2 Problema de Resíduos Quadráticos}

Cocks (2001) define da seguinte forma o resíduo quadrático:

Seja $a \in Z_{n}^{*}$ é considerado a ser um resíduo quadrático módulo $n$, ou uma raíz módulo $n$, se existir um $x \in Z_{n}^{*}$ tal como $x^{2} \equiv a(\bmod n)$. Se tal $x$ não existir, então $a$ é chamado de não-resuíduo quadrático módulo $n$. O conjunto de todos os resuíduos quadráticos módulo $n$ é denotado por $Q_{n}$ e o conjunto de todos os não-resíduos é denotado por $\bar{Q}_{n}$ (TERADA, 2000; GORANTLA; GANGISHETTI; SAXENA, 2005).

\section{B.5.3 Critério Euler}

Seja $q$ um primo maior do que dois e $\operatorname{gcd}(a, q)=1$, então $a$ é módulo quadrático $q$, se e somente se, $a^{(q-1) / 2}=1(\bmod q)$. Se $q=3(\bmod 4)$ e $a$ é um QR módulo $q$ onde $q$ é um primo, existe uma fórumla simples para computar raizes quadrados $r_{\{1,2\}}$ de QR $a$ módulo $q$ como $r_{\{1,2\}}= \pm a^{(p+1) / 4}(\bmod q)$.

\section{B.5.4 Problema de Logarítmo Discreto}

O Problema de Logarítmo Discreto, DLP $^{3}$ pode ser definido assim:

Dado um primo $q$, um gerador $g \in Z_{q}^{*}$ e um elemento $b \in Z_{q}^{*}$ achar um inteiro $x$, $0 \leq x \leq q-2$, tal que $g^{x} \equiv b(\bmod q)$.

O DLP pode ser generalizado para qualquer grupo cíclico de ordem finita é considerado como um problema computacionalmente dífcil.

\footnotetext{
${ }^{3}$ Discrete Logarithm Problem
} 


\section{B.5.5 Problema Diffie-Hellman}

O Problema Diffie-Hellman, $\mathrm{DHP}^{4}$ pode ser definido dado um primo $q$ e um gerador $g \in Z_{q}^{*}$ e elementos $g^{a} \bmod q$ e $g^{b} \bmod q$ achar $g^{a b} \bmod q$. O DHP pode ser generalizado para grupos cíclicos e também é considerado um problema computacionalmente difícil e reduz para DLP em tempo polinomial.

Entre diversos tipos de problemas Diffie-Hellman existentes, podem ser destacados alguns, que serão abordados na versão final deste documento, como por exemplo Problema Computacional Diffie-Hellman, Problema de Decisão Diffie-Hellman, Problema Diffie-Hellman Fraco, Problema Diffie-Hellman Bilinear, Problema de Decisão Bilinear Diffie-Hellman, Problema de Diffie-Hellman Lacunar.

\footnotetext{
${ }^{4}$ Diffie-Hellman Problem
} 